\title{
Cracking and Fracture Analysis of HVOF Coatings under Vickers Indentation
}

\author{
by \\ Azidah Puteri Buang \\ B.Eng \\ A thesis submitted to the Faculty of Graduate Studies and Research in partial fulfillment \\ of the requirements for the degree of
}

\section{Master of Applied Science}

\author{
Department of Mechanical and Aerospace Engineering \\ Ottawa-Carleton Institute for \\ Mechanical and Aerospace Engineering
}

\author{
Carleton University \\ Ottawa, Ontario \\ Canada \\ January, 2008 \\ (C) Copyright
}

2008, Azidah Puteri Buang 


$\begin{array}{ll}\begin{array}{l}\text { Library and } \\ \text { Archives Canada }\end{array} & \begin{array}{l}\text { Bibliothèque et } \\ \text { Archives Canada }\end{array} \\ \begin{array}{l}\text { Published Heritage } \\ \text { Branch }\end{array} & \begin{array}{l}\text { Direction du } \\ \text { Patrimoine de l'édition }\end{array} \\ \begin{array}{l}\text { 395 Wellington Street } \\ \text { Ottawa ON K1A 0N4 } \\ \text { Canada }\end{array} & \begin{array}{l}\text { 395, rue Wellington } \\ \text { Ottawa ON K1A 0N4 } \\ \text { Canada }\end{array}\end{array}$

Your file Votre référence ISBN: 978-0-494-40633-5

Our file Notre référence

ISBN: 978-0-494-40633-5

NOTICE:

The author has granted a nonexclusive license allowing Library and Archives Canada to reproduce, publish, archive, preserve, conserve, communicate to the public by telecommunication or on the Internet, loan, distribute and sell theses worldwide, for commercial or noncommercial purposes, in microform, paper, electronic and/or any other formats.

The author retains copyright ownership and moral rights in this thesis. Neither the thesis nor substantial extracts from it may be printed or otherwise reproduced without the author's permission.
AVIS:

L'auteur a accordé une licence non exclusive permettant à la Bibliothèque et Archives Canada de reproduire, publier, archiver, sauvegarder, conserver, transmettre au public par télécommunication ou par l'Internet, prêter, distribuer et vendre des thèses partout dans le monde, à des fins commerciales ou autres, sur support microforme, papier, électronique et/ou autres formats.

L'auteur conserve la propriété du droit d'auteur et des droits moraux qui protège cette thèse. $\mathrm{Ni}$ la thèse ni des extraits substantiels de celle-ci ne doivent être imprimés ou autrement reproduits sans son autorisation.
In compliance with the Canadian Privacy Act some supporting forms may have been removed from this thesis.

While these forms may be included in the document page count, their removal does not represent any loss of content from the thesis.
Conformément à la loi canadienne sur la protection de la vie privée, quelques formulaires secondaires ont été enlevés de cette thèse.

Bien que ces formulaires aient inclus dans la pagination, il n'y aura aucun contenu manquant.

\section{Canada}




\begin{abstract}
The fracture strength of seven HVOF coatings, which are made of hard metals, Tribaloy alloy and superalloys, respectively, coated on 1018 low carbon steel substrate, are studied under Vickers indentation, associated with FEA stress computation in this research. The cross sections of the coating specimens are examined on a Hitachi Model S-570 Scanning Electron Microscope (SEM), which investigates the quality and measures the geometry of the coatings. The mechanical properties of the coatings and the substrate are determined in the cross sections using the nano-indentation technique. The cracking and fracture behavior of the coatings under different indentation loads is investigated using a Vickers hardness tester. It is demonstrated that the hard metal coatings have the lowest fracture strength with significant cracking under low indentation loads while the Tribaloy alloy coating has the highest resistance to cracking. The superalloy coatings possess good ductility so that they are not seriously cracked even under high indentation loads. Three-dimensional FEA simulation of the Vickers indentation test is conducted to determine the stress fields in the coating/substrate systems in order to understand the fracture mechanisms of the coatings under the indentation loads using the ABAQUS software package. The stress results are in good agreement with the experimental observation. In terms of the maximum principal stress, the highest tensile stress occurs in the central area of the indentation edge, which induces the edge crack in the coating surfaces first. Increase in the indentation load results in the corner crack. The edge crack grows along the indentation edge and the corner crack propagates radially along the outward diagonal of the indentation due to the tensile stresses in the areas of the indentation edge and the indentation corner.
\end{abstract}




\section{Acknowledgements}

First and foremost, I would like to express how deeply indebted I am to my supervisor

Prof. Dr. Rong Liu. Without her kind boundless help and support, this thesis would not be possible.

My utmost gratitude to National Research Council Canada (NRC) and NRC personnel;

Dr. X. J. Wu, Dr. Zong Zhang, David Morphy, Olga Lupandina, Dave Chow, Robert McKellar, and Pascale Lafleur, for providing me the instruments and the technical assistances during my working days at NRC.

I also would like to express my appreciation to Deloro Stellite Inc. for providing the coating samples and technical information.

I would like to thank Dr. Jun Zhao for his helpful techniques, advice and help in FEA.

To my husband, thank you for always being there and being my loyal supporter.

To my mother, thank you for the endless prayers. 


\section{Table of Contents}

\section{Page}

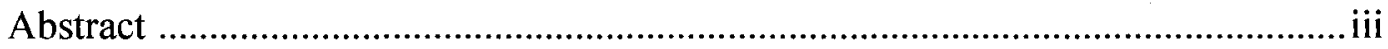

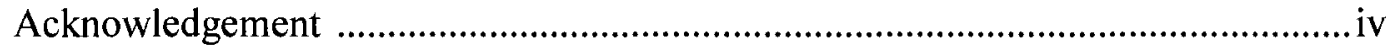

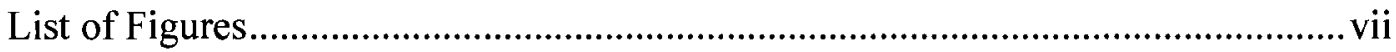

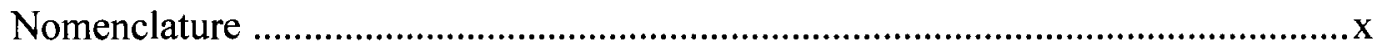

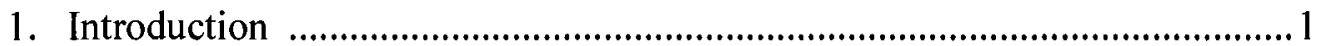

1.1 Background and Significance .................................................. 1

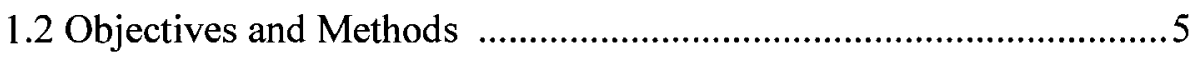

1.3 Construction of the Thesis .......................................................... 7

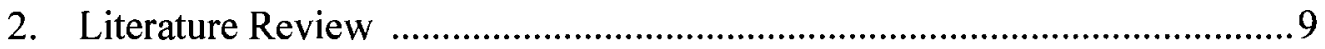

2.1 Introduction to Coatings .............................................................

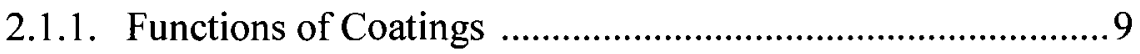

2.1.2. Applications of Coatings ................................................. 10

2.2 Coating Techniques .................................................................. 12

2.2.1. Various Processes ................................................................ 12

2.2.2. Chemical Vapor Deposition (CVD) ................................... 15

2.2.3. Physical Vapor Deposition (PVD)....................................... 18

2.2.4. Thermal Spray ...........................................................222

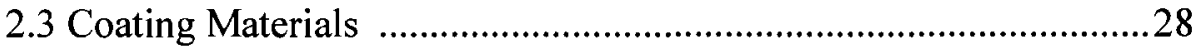

2.3.1. Introduction to Coating Materials......................................28

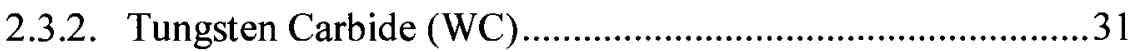

2.3.3. Nistelle $\mathrm{C}$ and Nistelle Super C ....................................... 34

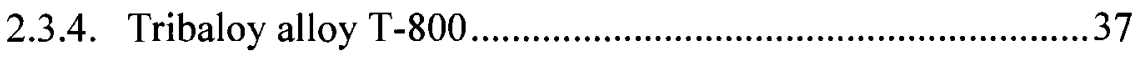

2.4 Coating Strength Evaluation............................................................38

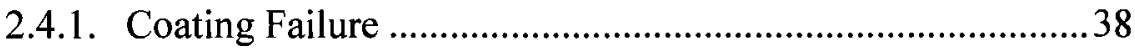

2.4.2. Various Evaluation Methods ............................................39

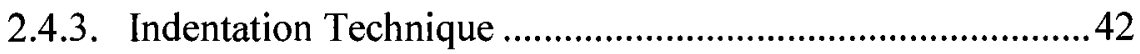




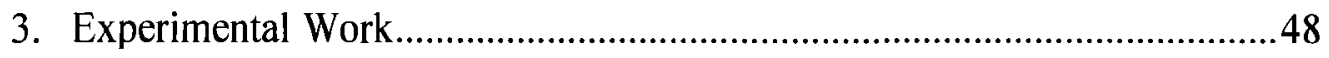

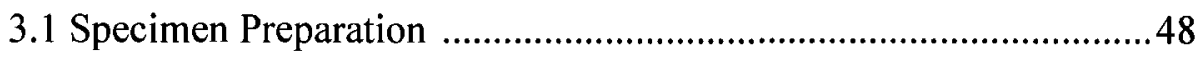

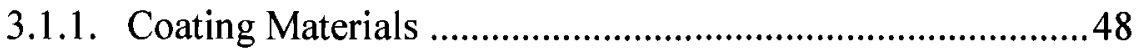

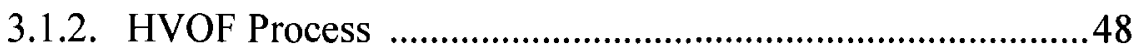

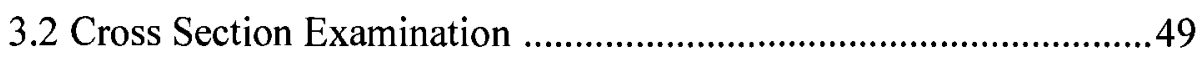

3.2.1. Section Surface Preparation...................................................49

3.2.2. Cross Section Profiles ............................................................50

3.3 Vickers Indentation Test ................................................................53

3.3.1. Coating Surface Preparation ...................................................53

3.3.2. Testing Procedure ..................................................................53

3.3.3. SEM Images of Indented Surfaces .......................................5

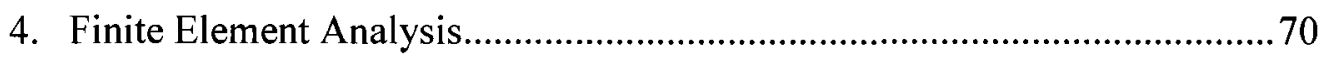

4.1 Simulation of Vickers Indentation Test ........................................... 70

4.1.1. Problem Description ........................................................... 70

4.1.2. Indenter-tip Geometry .....................................................

4.2 Construction of FEA Models..............................................................

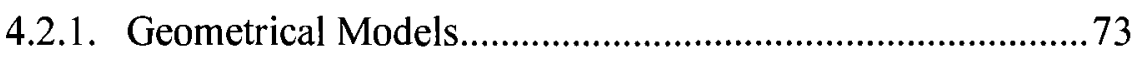

4.2.2. Constraint Treatment .........................................................

4.2.3. Material Properties.................................................................. 76

4.2.4. Indentation Load ..................................................................

4.3 Stress Results ............................................................................

4.3.1. Maximum Principal Stress.....................................................77

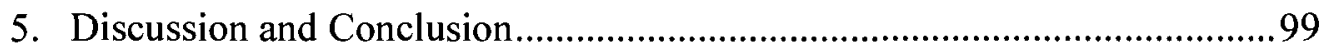

5.1 Discussion on the Results ................................................................99

5.1.1. Coating Material versus Fracture Strength ...........................99

5.1.2. Indentation Test versus FEA Stress Results ......................... 101

5.1.3. Indentation Load versus Coating Fracture........................... 103

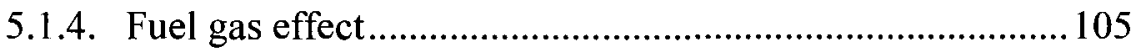

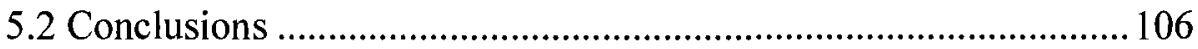

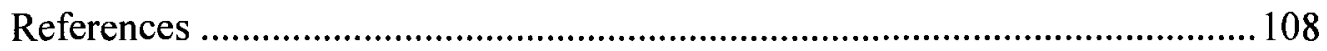




\section{List of Figures}

Figure 2.1 A CVD reactor assembly system [53]

Figure 2.2 An ion beam-assisted PVD unit [57]

Figure 2.3 Schematic drawing of a HVOF thermal spray torch [69]

Figure 2.4 Microstructure of: (a) WC-Co and WC-Co-Cr

Figure 2.5 Microstructure of: (a) Nistelle C and Nistelle Super C

Figure 2.6 Microstructure of T-800

Figure 2.7 The FEM model developed to describe the indentation procedure [113]

Figure 2.8 Three-dimensional finite element mesh of scratch testing.

Figure 3.1 SEM images of cross section of the specimens: (a) WC-Co; (b) WC-CoCr; (c) T-800; (d) Nistelle C-propylene; (e) Nistelle Super C-propylene; (f) Nistelle C-hydrogen and (g) Nistelle Super C-hydrogen

Figure 3.2 SEM images of indented surface of WC-Co under $10 \mathrm{~N}$ : (a) indentation edge with cracks and (b) indentation corner without cracks

Figure 3.3 SEM images of indented surface of WC-Co under $35 \mathrm{~N}$ : (a) edge cracks and (b) corner crack

Figure 3.4 SEM images of indented surface of WC-Co under $100 \mathrm{~N}$ : (a) extended corner crack and (b) edge cracks and corner cracks

Figure 3.5 eSEM image of fractured surface of WC-Co under $500 \mathrm{~N}$ due to edge cracks and corner cracks

Figure 3.6 SEM images of indented surface of WC-Co-Cr: (a) under $10 \mathrm{~N}$; (b) under $35 \mathrm{~N}$; (c) under $100 \mathrm{~N}$ and (d) under $300 \mathrm{~N}$

Figure 3.7 SEM images of indented surface of T-800 under $10 \mathrm{~N}$ : (a) no cracks at indentation edges and (b) no cracks at indentation corner

Figure 3.8 SEM images of indented surface of T-800 under $35 \mathrm{~N}$ : (a) no cracks at indentation edges and (b) no cracks at indentation corner

Figure 3.9 SEM images of indented surface of T-800 under $100 \mathrm{~N}$ : (a) no cracks at indentation edges and (b) no cracks at indentation corner 
Figure 3.10 SEM images of indented surface of T-800 under $500 \mathrm{~N}$ : (a) no obvious cracking at indentation edges and (b) microcracks at indentation edge

Figure 3.11 SEM images of indented surface of T-800 under $700 \mathrm{~N}$ : (a) no obvious cracking at indentation edges and (b) microcracks at indentation edge

Figure 3.12 SEM images of indented surface of Nistelle C-propylene under $100 \mathrm{~N}$ :

(a) overall indentation area and (b) indentation edge and corner areas

Figure 3.13 SEM images of indented surface of Nistelle C-propylene under $700 \mathrm{~N}$ :

(a) overall indentation area; (b) indentation edge area and (c) indentation corner area

Figure 3.14 SEM images of indented surface of Nistelle Super C-propylene under 100

$\mathrm{N}$ : (a) overall indentation area and (b) indentation edge and corner areas

Figure 3.15 SEM images of indented surface of Nistelle Super C-propylene under 700

$\mathrm{N}$ : (a) overall indentation area; (b) indentation edge area and (c)

indentation corner area

Figure 3.16 SEM images of indented surface of Nistelle C-hydrogen under $100 \mathrm{~N}$ :

(a) overall indentation area and (b) indentation edge and corner areas

Figure 3.17 SEM images of indented surface of Nistelle C-hydrogen under $700 \mathrm{~N}$ :

(a) overall indentation area; (b) indentation edge area and (c) indentation corner area

Figure 3.18 SEM images of indented surface of Nistelle Super C-hydrogen under 100

$\mathrm{N}$ : (a) overall indentation area and (b) indentation edge and corner areas

Figure 3.19 SEM images of indented surface of Nistelle Super C-hydrogen under 700

$\mathrm{N}$ : (a) overall indentation area; (b) indentation edge area and (c) indentation corner area

Figure 4.1 Indenter-tip geometry under an optical microscope: (a) side view and (b) top view

Figure 4.2 FEA model of a coating/substrate system under Vickers indentation test

Figure 4.3 Maximum principal stress under $10 \mathrm{~N}$ : (a) WC-Co and (b) WC-Co-Cr

Figure 4.4 Maximum principal stress under $100 \mathrm{~N}$ : (a) T-800; (b) Nistelle C and (c)

Nistelle Super C 
Figure 4.5 Maximum principal stress vector: (a) WC-Co and (b) WC-Co-Cr

Figure 4.6 Maximum principal stress vector: (a) T-800; (b) Nistelle $\mathrm{C}$ and

(c) Nistelle Super C

Figure 4.7 Schematic drawing of the indentation components

Figure 4.8 Variations of the maximum principal stress along the indentation edge:

(a) low-load group under $10 \mathrm{~N}$ and (b) high-load group under $100 \mathrm{~N}$

Figure 4.9 Variations of the maximum principal stress along the diagonal of the indentation edge: (a) low-load group under $10 \mathrm{~N}$ and (b) high-load group under $100 \mathrm{~N}$

Figure 4.10 Variations of the maximum principal stress from the indented area to the indentation-free area across the center of the indentation edge: (a) lowload group under $10 \mathrm{~N}$ and (b) high-load group under $100 \mathrm{~N}$

Figure 4.11 Variations of the maximum principal stress from the indentation corner along the normal of the indentation diagonal: (a) low-load group under 10 $\mathrm{N}$ and (b) high-load group under $100 \mathrm{~N}$

Figure 4.12 Variations of the maximum principal stress along the indentation edge for low-load group: (a) under $35 \mathrm{~N}$ and (b) under $100 \mathrm{~N}$

Figure 4.13 Variations of the maximum principal stress along the diagonal of the indentation for low-load group: (a) under $35 \mathrm{~N}$ and (b) under $100 \mathrm{~N}$

Figure 4.14 Variations of the maximum principal stress along the indentation edge for high-load group: (a) under $300 \mathrm{~N}$ and (b) under $500 \mathrm{~N}$

Figure 4.15 Variations of the maximum principal stress along the diagonal of the indentation for high-load group: (a) under $300 \mathrm{~N}$ and (b) under $500 \mathrm{~N}$ 


\section{Nomenclature}

AISI

APCVD

ASTM

BEM

CAE

$\mathrm{CBE}$

CVD

CVI

DLC

EBPVD

fcc

FEA

$\mathrm{H}$

hcp

HRC

HV

HVOF

IBAD

IBED

LCVD

LPCVD

MOCVD

NASA

PACVD

PCC

PCVD

PECVD

PVD

SEM

American Iron and Steel Institute

Atmospheric Pressure Chemical Vapor Deposition

American Society for Testing and Materials

Boundary element method (BEM)

Computer-aided engineering

Chemical Beam Epitaxy

Chemical Vapor Deposition

Chemical Vapor Infiltration

Diamond-Like-Carbon

Electron beam physical vapor deposition

Face centered cubic

Finite element analysis

Hardness

Hexagonal close packed

Hardness Rockwell type ' $C$ '

Vickers hardness

High velocity oxygen fuel

Ion beam assisted deposition

Ion beam enhanced deposition

Laser Chemical Vapor Deposition

Low Pressure Chemical Vapor Deposition

Metal-Organic Chemical Vapor Deposition

National Aeronautics and Space Administration

Plasma Assisted Chemical Vapor Deposition

Protective Ceramic Coating

Photochemical Vapor Deposition

Plasma Enhanced Chemical Vapor Deposition

Physical Vapor Deposition

Scanning electron microscope 


$\begin{array}{ll}\text { WC } & \text { Tungsten Carbide } \\ E & \text { Young's modulus } \\ v & \text { Poisson's ratio } \\ \mathrm{U} & \text { Displacement } \\ \mathrm{UR} & \text { Rotational Displacement } \\ \mathrm{TF} & \text { Total Force } \\ \eta_{e} & \text { Ratio of the elastic deformation energy to the total } \\ & \text { deformation energy } \\ \eta_{p} & \text { Ratio of the plastic deformation energy to the total }\end{array}$




\section{CHAPTER 1 INTRODUCTION}

\subsection{Background and Significance}

Coatings comprise one of the most up-to-date technologies used to enhance the superficial properties of machine elements and components of tools. As such, thermal spray coatings can be a cost-effective way to enhance the performance of manufactured components. Advanced thermal spray coatings find wide applications in industry because of their superior surface properties, in which case the surfaces with resistance to corrosion, wear, and high temperature can result. High velocity oxygen fuel (HVOF) thermal spray technique is emerging as one of the most cost effective ways to produce coatings combating wear and corrosion. HVOF spraying is essentially a variation of powder flame spraying in which a modified torch is used to constrict the gas flow. This produces an extremely high velocity flame that is similar to that of a jet engine. The process is involved with an internal combustion to rapidly heated and accelerated powder consumable to high velocities. HVOF coatings provide very dense (low porosity), high bond strength to substrate and very smooth as-sprayed textures, superior to the coatings produced by other processes. It is reported to be a versatile technology and has been adopted by many industries due to its flexibility, cost effectiveness and high quality of coatings produced. HVOF products show low residual tensile stress, or in some cases, compressive stress, which enables much thicker coatings to be applied than previously possible with other processes [1].

A HVOF system consists of a combustion chamber and a nozzle with connecting orifices and a tube that allows injection of the powder into the nozzle. Oxygen and fuel gas 
are introduced into the combustion chamber; continuous combustion of the oxygen and fuel results in hot, high pressure gas which is allowed to expand and accelerate through orifices into the nozzle. The fuel gas is usually propane, propylene, liquid fuels or hydrogen. A flow of powder is introduced axially into the nozzle, allowing sufficient heating and acceleration of the powder particles. The powder is heated and accelerated by the product of the combustion, usually to temperatures above its melting point and to velocities approaching or exceeding $550 \mathrm{~m} / \mathrm{sec}$. The properties of HVOF coatings are highly dependent on a number of parameters including the preparation of the part surface, composition, morphology, size distribution and feed rate of the powder, the precise control of the gas flow, relative torch/part motions, stand-off angle of deposition, and part temperature, etc [2].

Considerable research studies were carried out to investigate the HVOF coating performance of corrosion and wear resistance [3-10]. These studies include the comparison of HVOF coatings with the coatings produced by other techniques, for example, electroplated coatings, microstructure evolution and oxidation behavior of coatings. However, because of the weakness of the interface and the brittleness of the coating materials, coatings often fail before exhaustion of the useful life of the substrate material in service, and in some cases, the coating/substrate interaction may result in earlier crack nucleation in the substrate material when cracking or spallation of the coating occurs prematurely. Therefore, coating fracture toughness and interfacial bonding strength of a coating/substrate system are key factors influencing the coating service life and have been primary concerns to engineers ever since thermal spray processes were introduced to various industries. As a result, investigation on the bonding mechanisms of coating-substrate, which is an important element in the theory of 
thermal spray technology, has attracted a great deal of attention in the past decades. Generally, there are three different mechanisms of the coating-substrate adhesion during a thermal spraying process: (1) mechanical interlocking effect, (2) physical bond, and (3) chemical-metallurgical bond [11]. For a conventional spray process with spray particles at a relatively low velocity, the adhesion between the coating and the substrate primarily depends on mechanical interlocking, which is mainly related to the substrate surface roughness and the solidification of the impacting droplets. However, the diffusion process may occur due to the high temperature of the substrate when vacuum plasma spray or low pressure plasma spray technology is used to deposit a coating $[12,13]$. Finally, chemical-metallurgical bond of the coating with the substrate may also develop when the coating of the material that has a higher melting point, is deposited on a substrate having a lower melting point [14].

There have been a number of methods developed to evaluate interfacial bonding strength of coatings. A simple test to assess the adhesive strength is the direct pull test, as described in the ASTM Standards $[15,16]$. Non-standard test methods have also been developed, such as laser spallation [17] and ultracentrifugal tests [18]. There are also quality control test methods, such as the peel test [19], the hammering test [20] and so on. Instead of measuring the adhesive strength, many testing methods have also been devised to measure the fracture energy of the coating/substrate interface - a fundamental measure of the adhesion. These include the pull test of chevron-notched sandwich specimens [21, 22], the bending test of notched delamination specimens [23], and the pull test of radial-notched cylindrical specimens [24]. 
In recent years, indentation/scratch technique has been widely used to study the fracture behavior of coatings. Indentation technique, historically employed as a testing method of hardness, has been employed in the study of the mechanical properties of brittle materials [25-27]. For example, indentation is used to evaluate fracture toughness through crack length measurement. The particular attraction of this technique lies in its unique simplicity as a nondestructive means for producing regions of high stress intensity in a specimen. Previous research investigated the mechanics of point-indentation microfracture in brittle solids, describing both initiation and propagation stages of crack growth. It provided a descriptive basis for the more general features of point-indentation microfracture patterns in brittle solids. It is presumed that coatings may have similar cracking behavior to brittle solids under point indentation because most coating materials are brittle, thus the mechanics of point-indentation microfracture in brittle solids may also be suitable for coatings. However, due to the variation of coating geometry (thickness) and the influence of the interface, the cracking pattern and fracture behavior of coatings would be more complex.

Attempts have been made to determine the fracture toughness of coatings and the coating-substrate interface strength via indentation [28-35]. For example, coating fracture toughness, as an important parameter in cavitation erosion resistance of a thermally sprayed coating, was determined through Vickers indentation [29]; the use of indentation pressure as a measure of the actual resistance of the coating to deformation in determination of the coating fracture toughness was made [30]. A lateral force-sensing microindentation technique was developed for determination of the interface bonding strength of coatings [34]. 
These studies have demonstrated that indentation technique, in addition to its basic function of hardness test, can be an effective approach to coating strength analysis.

\subsection{Objectives and Methods}

The present research is a joint project between Carleton University and Deloro Stellite Inc., sponsored by NSERC Collaborative Research and Development Grant (CRD) program, co-funded by Deloro Stellite Inc. In this research, seven coating specimens, produced by HVOF process, were studied. These coatings were made of different materials but with the same parameters (flow velocity and temperature) of the HVOF process except for two different gas fuels. The coating strengths of the specimens were studied through investigating the response of cracking and fracture of the coatings to the load under Vickers indentation. The indented surfaces of the specimens were examined using SEM to obtain the cracking patterns. Three-dimensional finite element analysis (FEA) was employed to simulate the indentation test and thus to determine the stress distributions in the coating/substrate systems under the indentation loads. The fracture mechanisms of the coatings under Vickers indentation were discussed in terms of the stress results. The goal of this research is to provide the coating industry with an effective method evaluating coating strength by determining the failure Ioad of a coating under the Vickers indentation load and calibrating the corresponding stress using FEA. The effect of the gas fuel used in the HVOF process on the coating properties and strength was also investigated.

The detailed tasks involved in this research are outlined below: 
1. Seven coating specimens, with the coating materials of WC/17Co (hard metal), $\mathrm{WC} / 10 \mathrm{Co} / 4 \mathrm{Cr}$ (hard metal), $\mathrm{Co} / 17 \mathrm{Cr} / 28 \mathrm{Mo} / 3 \mathrm{Si}$ (Tribaloy $\mathrm{T}-800$ ), $\mathrm{Ni} / 16 \mathrm{Cr} / 16 \mathrm{Mo} / 4 \mathrm{Fe} / 4 \mathrm{~W}$ (Nistelle C), and $\mathrm{Ni} / 23 \mathrm{Cr} / 18 \mathrm{Mo}$ (Nistelle Super C), respectively, and the substrate material of AISI 1018 low carbon steel, were produced by HVOF process at Deloro Stellite Inc. Two types of fuel gas were used for Nistelle C and Nistelle Super C specimens - hydrogen and propylene. Hydrogen was used for the hard metal and $\mathrm{T}-800$ specimens.

2. The cross section of each specimen was examined under SEM and the geometrical profiles of the coatings, such as coating thickness and interface configuration, were obtained with backscatter electron imaging. The defects, flaws and porosity in the coatings and the interface features were investigated.

3. Conventional Vickers indentation test with diamond tip of $136^{\circ}$ was performed on each coating surface at different load levels, ranging from $10 \mathrm{~N}$ to $700 \mathrm{~N}$, to investigate the cracking/fracture behavior of the coatings under different indentation loads and thereby to obtain the cracking profiles.

4. SEM was employed to obtain the morphology image of the indentation mark on the coating surface of each specimen after the indentation test. The cracks induced in the coatings by the indentation loads would be observed. 
5. Three-dimensional FEA models were developed simulating the Vickers indentation test on the coating specimens with different load levels, using ABAQUS CAE v.6.5.1. The interface between the indenter and the coating surface was modeled as a "contact" problem; the geometry of the indenter tip was measured under an optical microscope. The displacement of the indenter was applied as the external load and the reaction force obtained after the computation represents the force applied on the coating through the indenter. Under this condition the stress fields in the indentation areas were determined.

6. Incorporating with the cracking profiles obtained from the Vickers indentation test, the stress concentrations at the crack initiations were identified based on the FEA results. The cracking behavior and fracture mechanisms of the coatings under Vickers indentation were discussed.

\subsection{Construction of the Thesis}

This thesis is composed of five chapters, as described below:

Chapter 1 is a preliminary view of this research, which covers the background and significance of the research, and lays out the objectives and methodologies that were used to achieve the goals.

Chapter 2 is the literature review of the previous research related to this research with respects to coating applications, coating techniques, coating materials and coating strength evaluation. 
Chapter 3 describes the experimental details, including specimen preparation, Vickers indentation test and SEM examination of the cross sections and indented surfaces of the coating specimens. The experimental results are also presented in this chapter.

Chapter 4 presents the FEA modeling details, including the creation of the geometrical models, mesh of the models, applying boundary conditions and loads, nonlinear treatment of "contact" problems and the review of the results.

Chapter 5 discusses the experimental and FEA results correlating the stress fields with the cracking profiles to analyze the coating fracture strengths. The fracture mechanisms of the coatings under Vickers indentation are discussed. The conclusions derived from this research are presented. 


\section{CHAPTER 2 LITERATURE REVIEW}

\subsection{Introduction to Coatings}

\subsubsection{Functions of Coatings}

When coating was found to be a very useful type of application that could protect tools or machine parts in order to last longer and perform better, a series of research studies which cover every inch of coating aspects, have been conducted during the past decades. From these studies, be it analytical, experimental or computational, various complex material mixtures and coating processes have been developed to produce many options of coatings that can be fully utilized by industries.

Coatings, depending on which industry they will be used in, can be tailored accordingly through specific process and material selection. As early as the 1970s, the development of hard coatings could be a single layer or superlattice of different substrates. Hard coatings are also known as metallurgical coatings, which are used to increase the cutting efficiency and operational life of cutting tools and to maintain the dimensional tolerance of components used in applications where wear can occur, for example, in injection moulds. In addition, hard coatings can act as a diffusion barrier where high temperatures are generated by motion between surfaces or corrosion protection in aggressive environments.

There are various classes of hard coating materials, including ionically bonded metal oxides $\left(\mathrm{Al}_{2} \mathrm{O}_{3}, \mathrm{ZrO}_{2}\right.$, and $\left.\mathrm{TiO}_{2}\right)$, covalently bonded materials $(\mathrm{SiC}$, boron carbon nitride, 
diamond, amorphous hard carbon such as diamond-like-carbon, TiC, AIN, CrC, mixed carbides, nitride and carbonitride compound alloys, and cubic boron nitride), and alloys (cobalt-based and nickel-based superalloys, NiAl, NiCrBSi, Stellite alloys, Tribaloy alloys).

Hard coatings are also used to minimize fatigue-wear, for example, they are found in ball bearings. In the polymer industry some components such as aircraft accessories or wear-glass lenses, where light loads and scratch wear are the common problems, hard coatings such as $\mathrm{SnO}_{2}$ are used [35]. Hard coatings deposited on plastics can improve scratch resistance; the applications are on molded plastic lenses and plastic airplane canopies. In some cases, wear-resistant coatings, such as $\mathrm{SiO}_{2}$ or $\mathrm{Al}_{2} \mathrm{O}_{3}$, may be applied to already hard surfaces, such as glass, to increase the scratch resistance. In addition, coatings, as described by Freller [36], have gained a new environmental respect for reducing hazardous chemicals. Coatings in tribological applications reduce the friction and hence the need for harmful chemical lubricants, which are of significant concern to the government and non-government bodies.

\subsubsection{Applications of Coatings}

Coating applications can be found in automotive, aerospace, machinery cutting tools and in domestic uses. The ability of coating to prolong the service lives of components with its wear-resistivity in harsh working conditions, such as extreme heat and low friction and low chemical interaction $[37,38]$, has encouraged the involved industries to develop the best coatings for their particular product needs. Tungsten carbide thermal spray coatings, for instance, are important to the aerospace industry due to the superior properties of tungsten 
carbide such as high hardness, excellent wear resistance, and high modulus of elasticity. They are ideal coatings for high performance parts and reduce the damper wear on jet engine fan and compressor blades [37, 39]. For better chemical resistivity and good lubrication, chromium is electroplated on tungsten carbide [40]. Besides the physical advantages that hard coatings can provide, the attractive color and the glossy features, which can be found in titanium-based coatings, are the main factors in decorative applications such as door knobs, jewelry or watch cases, and other exquisite writing instruments [41, 42]. The diamond-like-carbon coatings are commonly found in various applications, for instance, in the automotive industry, magnetic recording media [43-45], optics, medical devices [38], bearing and forming tools [46]. This is due to their excellent tribological properties such as surface smoothness, high hardness and chemical inertness, in combination with a low friction coefficient against most metals $[46,47]$. Nevertheless, the diamond-like-carbon application has an adhesive problem, especially in the steel production industry [46]. Another example of coating application is the large use of nickel-based superalloy coatings in gas turbine engine components such as seals, containment rings, duct segments, casings, fasteners, racket nozzles and pumps, owing to their high strength, corrosion and wear resistance at high temperatures [48].

More often, the coating research and application conducted in major-scale industries such as aerospace and automotive have developed into small-scale industries such as building construction and home use. For instance, a protective ceramic coating (PCC) of the space shuttle's launch pad and heat shields made from flexible ceramic composites leads a coating modification to shield ceramics, wood, plasterboard, steel, plastics, fiberglass, and other 
building materials' applications [49, 50]. Further modification is made to tailor the needs of commercial ductwork insulation and fire- resist window blinds [50]. Apart from the thermal insulation purpose, the coatings in NASA space facilities are studied to overcome the premature natural corrosive problems of their reinforced steel structures. The high cost of unexpected repairing and reconstruction has promoted the galvanic liquid-applied coating system, designed by NASA engineers [51]. This system uses inorganic coating materials, which can delay or hold the corrosion process of the reinforced steel. The success of this coating application leads to a better protective coating system in steel bridges and oil-refinery tools.

\subsection{Coating Techniques}

\subsubsection{Various Processes}

The deposition of hard coatings has evolved over the years. From electro-plating, material scientists discovered new ways such as thermal spray, chemical vapor and physical vapor deposition. These new techniques of coating deposition, indeed, have improved the bonding strength and the mechanical properties of coatings such as hardness, thermal resistance and so on. Some of the techniques can deposit a very thin film up to nano-meter scale without sacrificing the material strength and mechanical properties. The recent studies have been focused on the multilayered different intermetallic and metallic substances which provide the coating matrices with higher strength and higher fracture toughness. Coatings can vary from a few to several hundred microns and be deposited by different means. 
There are both practical and impractical ways to produce coatings. From an industry point of view, deposition that allows productions of mass manufacturing and the ability to coat large parts is one of the required characteristics. For this reason, most of the scientists have been working closely with respective industries such as aerospace, chemical manufacturing plants, oil and gas parts manufacturers to develop with processes that allow them to produce such coatings. Various coating techniques [52] in application are listed below:

\section{Chemical vapor deposition techniques}

- Metalorganic vapor phase epitaxy

\section{Physical vapor deposition techniques}

- Arc-PVD

- $\quad$ Cathodic arc deposition

- $\quad$ Electron beam physical vapor deposition or EBPVD

- Pulsed laser deposition

- $\quad$ Sputter deposition

\section{Thermal spray techniques}

- $\quad$ Flame spraying

- $\quad$ Plasma spraying

- High velocity oxygen fuel or HVOF

- Wire arc spraying 


\section{Other techniques}

- $\quad$ Anodising

- $\quad$ Bead

- Curtain

- EB-ion implantation

- Electroplating

- $\quad$ Enamel

- Evaporative deposition

- Extrusion

- Hydrothermal treatment

- Ion implantation

- $\quad$ Ion plating

- Ion beam assisted deposition or IBAD

- Ion beam enhanced deposition or IBED

- $\quad$ Laser alloying

- $\quad$ Mist deposition

- Magnetron sputtering

- $\quad$ Molecular beam epitaxy

- $\quad$ Pack cementation

- Plasma electrolytic oxidation

- $\quad$ Slurry technique

- $\quad$ Slide bead

- Sol-gel 
- $\quad$ Sputter ion plating

Among these techniques, chemical vapor deposition, physical vapor deposition and thermal spray are the most popular and have been largely employed in various fields of engineering.

\subsubsection{Chemical Vapor Deposition (CVD)}

Among conventional coating deposition techniques, vapor phase deposition is the most popular and is widely used because it is well established in the coating deposition industry, while other new coating techniques are still under development [36]. There are two common vapor phase deposition techniques; CVD - chemical vapor deposition and PVD physical vapor deposition, which have been developed over the last two decades and the advantages of these techniques have been optimized. CVD is a generic name for a group of processes that involve depositing a solid material from a gaseous phase and is similar in some respects to PVD. PVD differs in that the precursors are solid, with the material to be deposited being vaporized from a solid target and deposited onto the substrate.

CVD covers processes such as [52]:

- Atmospheric pressure chemical vapor deposition or APCVD

- Low pressure chemical vapor deposition or LPCVD

- Metal-organic chemical vapor deposition or MOCVD

- $\quad$ Plasma assisted chemical vapor deposition or PACVD

- $\quad$ Plasma enhanced chemical vapor deposition or PECVD

- $\quad$ Laser chemical vapor deposition or LCVD

- $\quad$ Photochemical vapor deposition or PCVD 
- Chemical vapor infiltration or CVI

- Chemical beam epitaxy or CBE

In the CVD process, as shown in Figure 2.1, precursor gases (often diluted in carrier gases) are delivered into the reaction chamber at approximately ambient temperatures. As they pass over or come into contact with a heated substrate, they react or decompose forming a solid phase and are deposited onto the substrate. The substrate temperature is critical and can influence what reactions will take place. CVD coatings are usually only a few microns thick and are generally deposited at fairly slow rates, usually of the order of a few hundred microns per hour.

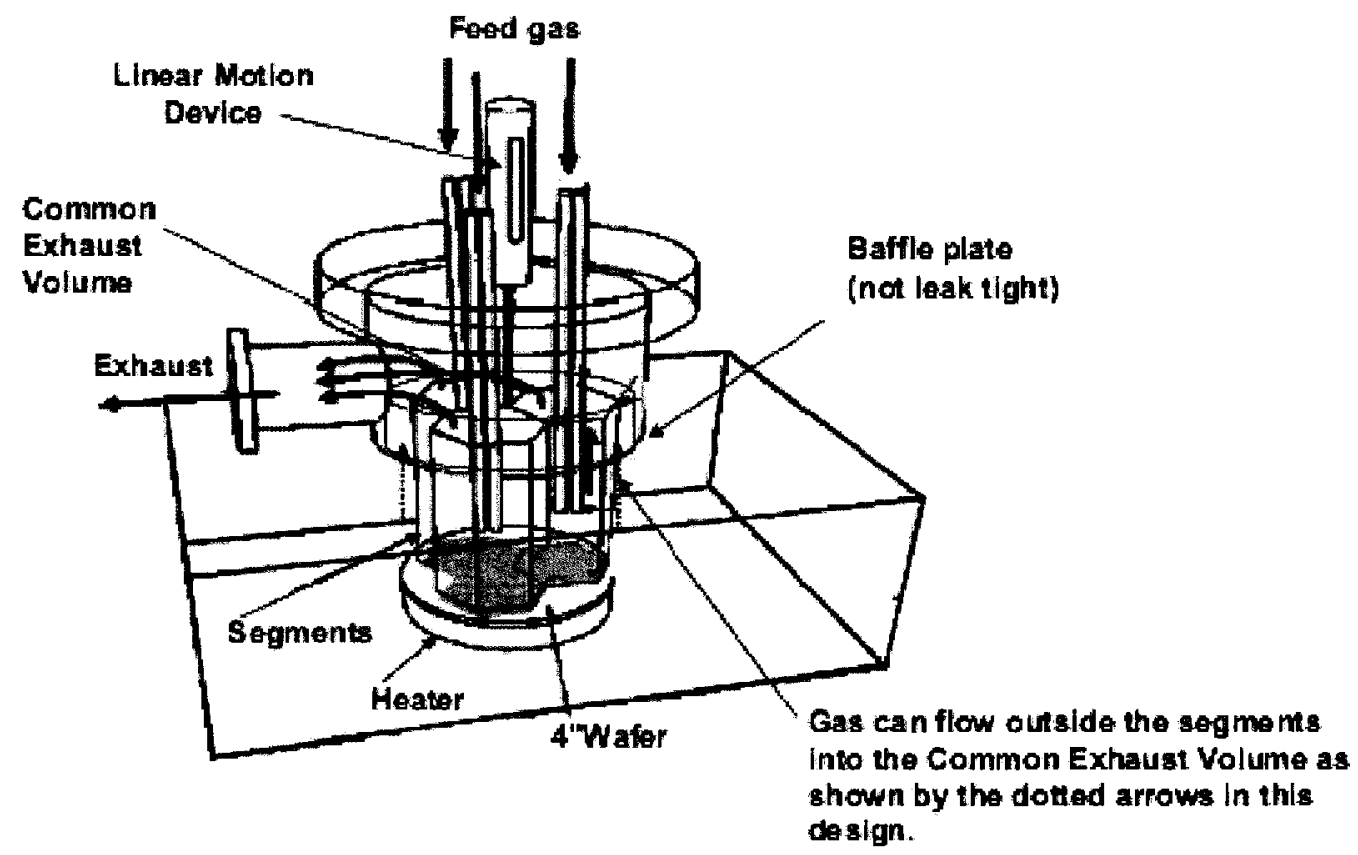

Figure 2.1 A CVD reactor assembly system [53] 
The characteristics of CVD coatings are typically [52]:

- $\quad$ Fine grained

- Impervious

- $\quad$ High purity

- Harder than similar materials produced using conventional ceramic fabrication processes

CVD is an extremely versatile process that can be used to process almost any metallic or ceramic compound. Some of these include: elements, metals and alloys, carbides, nitrides, borides, oxides and intermetallic compounds.

CVD has applications across a wide range of industries such as:

- Coatings - Coatings for a variety of applications such as wear resistance, corrosion resistance, high temperature protection, erosion protection and combinations thereof.

- $\quad$ Semiconductors and related devices - Integrated circuits, sensors and optoelectronic devices

- Dense structural parts - CVD can be used to produce components that are difficult or uneconomical to produce using conventional fabrication techniques. Dense parts produced via CVD are generally thin walled and maybe deposited onto a mandrel or former.

- Optical fibres - For telecommunications.

- $\quad$ Composites - Preforms can be infiltrated using CVD techniques to produce ceramic matrix composites such as carbon-carbon, carbon-silicon carbide and silicon 
carbide-silicon carbide composites. This process is sometimes called chemical vapor infiltration or CVI.

- $\quad$ Powder production - Production of novel powders and fibres

- Catalysts

- $\quad$ Nano-machines

CVD coatings are deposited at higher temperatures $\left(700\right.$ to $\left.1500^{\circ} \mathrm{C}\right)$ and are not suitable especially for cemented carbide, as the high temperatures will change the fracture properties [54] of the coating materials. To resolve this problem, it is suggested to use plasma activated chemical vapor deposition (PACVD) $[36,55]$ to deposit superhard coating materials. However, for industry scale to produce environment-safe wear resistant coatings with moderately low cost budget of medium size substrates, microwave plasma can be used.

\subsubsection{Physical Vapor Deposition (PVD)}

Since CVD high temperatures give disadvantages to the coating process especially for a metal substrate, PVD, which operates under vacuum pressure of $10^{-2} \mathrm{Mbar}$ at half lower temperatures than CVD is introduced to compensate the CVD inability to deposit hard coatings $[36,56]$. It is a term used to describe a family of thin-film coating processes, which are applied under vacuum conditions. This technique is used to deposit thin layers of material to reduce friction and wear, or to act as a diffusion barrier.

PVD process, as shown in Figure 2.2, involves the generation of positively charged ions of various metals. These metal ions react with gas ions that are introduced into the 
chamber in order to create various compositions. The parts to be coated are given a negative bias in order to attract the positively charged ions. The result is a very strong mechanical bond between the coating and the tool. This process has been successful in a wider range of substrates and applications, which is largely due to its lower process temperatures $\left(200^{\circ} \mathrm{F}\right.$ $750^{\circ} \mathrm{F}$ ) and average coating thicknesses of $2-5$ microns. These characteristics, among others, make PVD coatings ideal for high speed steels and carbide cutting tools as well as parts with tight tolerances such as plastic injection molding components and fine blanking tools. In addition, the lower process temperatures mean zero distortion will be caused on most materials, as long as proper draw temperatures are maintained.

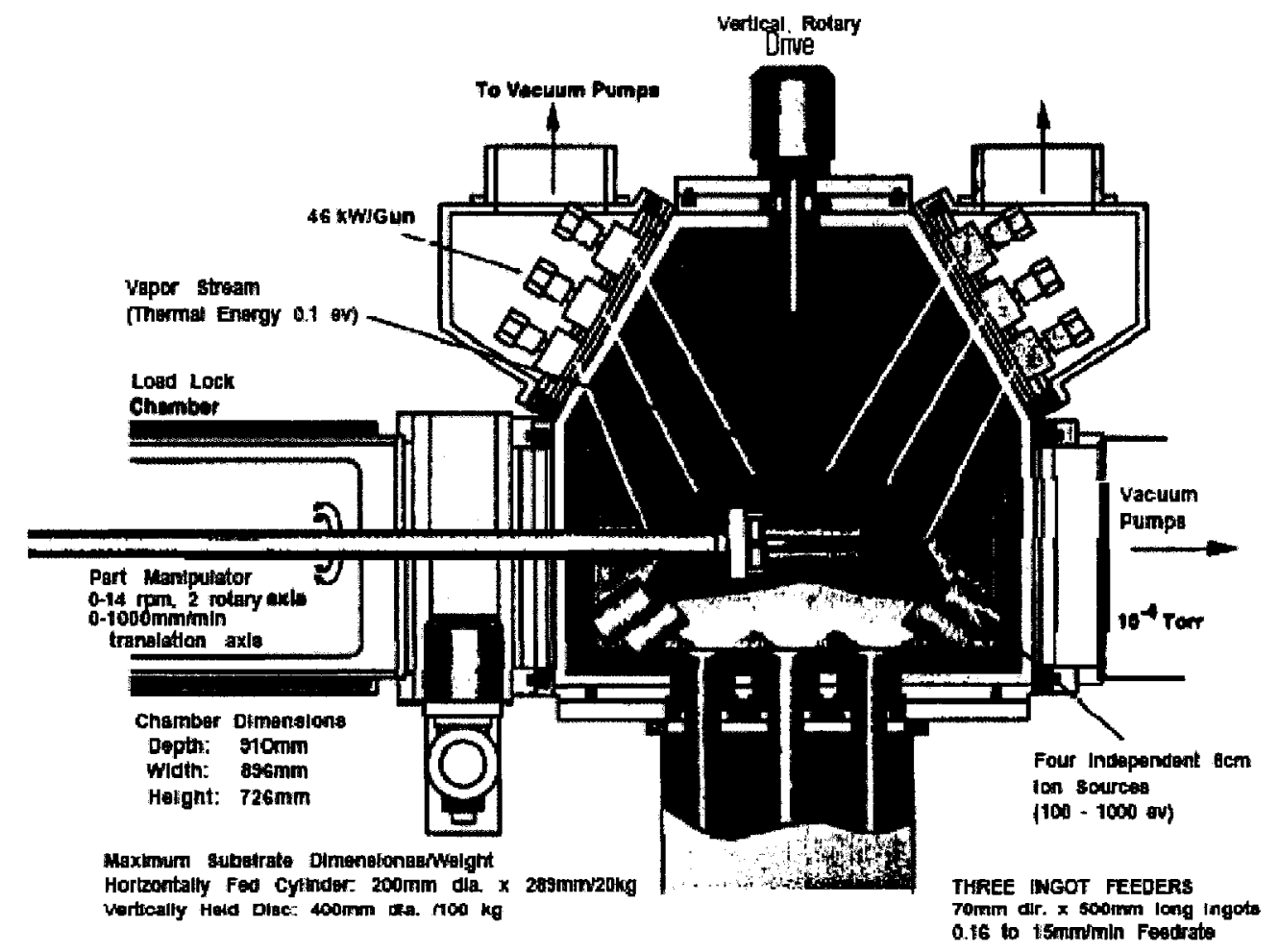

Figure 2.2 An ion beam-assisted PVD unit [57] 
PVD can be divided into three main types of technique processes:

- Evaporation

- $\quad$ Sputtering

- $\quad$ Ion-plating

Among these three, sputtering and ion plating models have been developed by many research studies [58-62] due to their capability to deposit multilayer superlattice of transition metals (such as $\mathrm{Ni}, \mathrm{Mn}, \mathrm{Cu}, \mathrm{Zn}$ ) with up to a nanometer-scale thickness [62-65]. In sputtering process, the substrate is coated with electrical discharge ions at a high kinetic energy speed in a vacuum chamber. The sputter cleaning of the substrate allows additional coating process; hence, it improves the quality and the bonding of the coating and the substrate. Ion-plating, on the other hand, uses energy particles from the glow discharge to deposit the coatings. This type of deposition produces better coating adhesion and quality. When researchers and industries noticed the advantages of ion plating, many research activities were conducted on this model and many different versions of ion-plating have been developed with the combination of two other PVD processes such as hollow cathode evaporators, low voltage anodic-arc evaporators, magnetic driven arc sport, unbalanced magnetron, etc.

The most common ceramic coatings available are TiN, CrN, TiCN, and TiAIN. The properties of these ceramic coatings have been improved by the addition of other elements such as vanadium, yttrium, chromium, etc. and the development of multilayers and nano-composite coatings.

The typical physical properties of PVD coatings are [66]: 
- Wear resistance

- $\quad$ Fretting/Galling/Sticking

- Environment/Corrosion

- $\quad$ Cryogenic to high temperature applications

- Wear resistance on precision components

- $\quad$ Adhesive wear

- Smooth operation of moving components

- $\quad$ Sliding wear

- Low friction

- Hold sharp edges and corners

- Non-stick, easy release

- Cavitation erosion prevention

- Inert, biocompatible surfaces

- $\quad$ Conductive - does not oxidize

- Non-reactive surface

- Erosion resistance

The applications of PVD coatings include [66]:

- Galling, fretting, seizing, and microwelding

- $\quad$ Adhesive wear

- $\quad$ Abrasive wear

- Friction

- $\quad$ Temperature resistance 
- Corrosion

- Inert surfaces

- Improved performance of moving parts

- Improved life of blades

- Reduce sticking, improved release

- Maintain sharp edges and corners

- Prevent erosion

- Hard chrome replacement/Alternative

- Thermal barrier

\subsubsection{Thermal Spray}

Thermal spray coating is a coating produced by a process in which molten or softened particles are applied by impact onto a substrate. A common feature of all thermal spray coatings is their lenticular or lamellar grain structure resulting from the rapid solidification of small globules, flattened from striking a cold surface at high velocities. The processes include:

- Flame spraying

- $\quad$ Plasma spraying

- HVOF, etc.

which work on the same fundamental principle. The thermal spray system consists of a heat source, a means of introducing powder particles into the heat source and a way of accelerating the semi solid particles toward the target. Upon hitting the target the particles 
deform and "key-into" mechanically to defects in the substrate. Other particles follow and a layer is then built up.

Flame spraying is the most basic form of thermal spraying and often involves an oxy-acetylene burner as the heat source. Advantages of such a system are that it is cheap, moderate deposition rates can be achieved $(0.5-0.6 \mathrm{~kg} / \mathrm{hour})$ and manual operation of the spraying unit can be employed. Disadvantages of the system include low particle velocities $(40-200 \mathrm{~m} / \mathrm{s})$ leading to low bond strength, high porosity $(10-15 \%)$ and a high impurity level [67].

Plasma spraying uses an electric arc as the heat source, which is much hotter than the temperature produced by an oxy-acetylene flame. This means that higher melting point materials can be deposited at higher velocities $(200-400 \mathrm{~m} / \mathrm{s})$ leading to moderate bond strength in air plasma spraying condition and high bonded strength in vacuum plasma spraying condition. In addition, porosity contents are lower at 2 to $5 \%$ as are impurity levels, especially in the case of vacuum plasma spraying. The disadvantages of this means are that the process requires more expensive equipment and it is not suitable for manual operation, that is, some form of manipulation or robotic system is required [68].

HVOF is a refined oxy-fuel burner, which uses advanced nozzle design technology to accelerate the gas/particle stream to achieve particle velocities in excess of $600 \mathrm{~m} / \mathrm{s}$. The coatings with very high densities and bond strengths can be achieved by HVOF. Unfortunately, the noise levels are very high $(>130 \mathrm{db})$ and only some systems are suitable 
for depositing ceramics. In addition, deposition rates are moderate - on a par with air plasma spraying $[67,68]$. A torch geometry is illustrated in Figure 2.3.

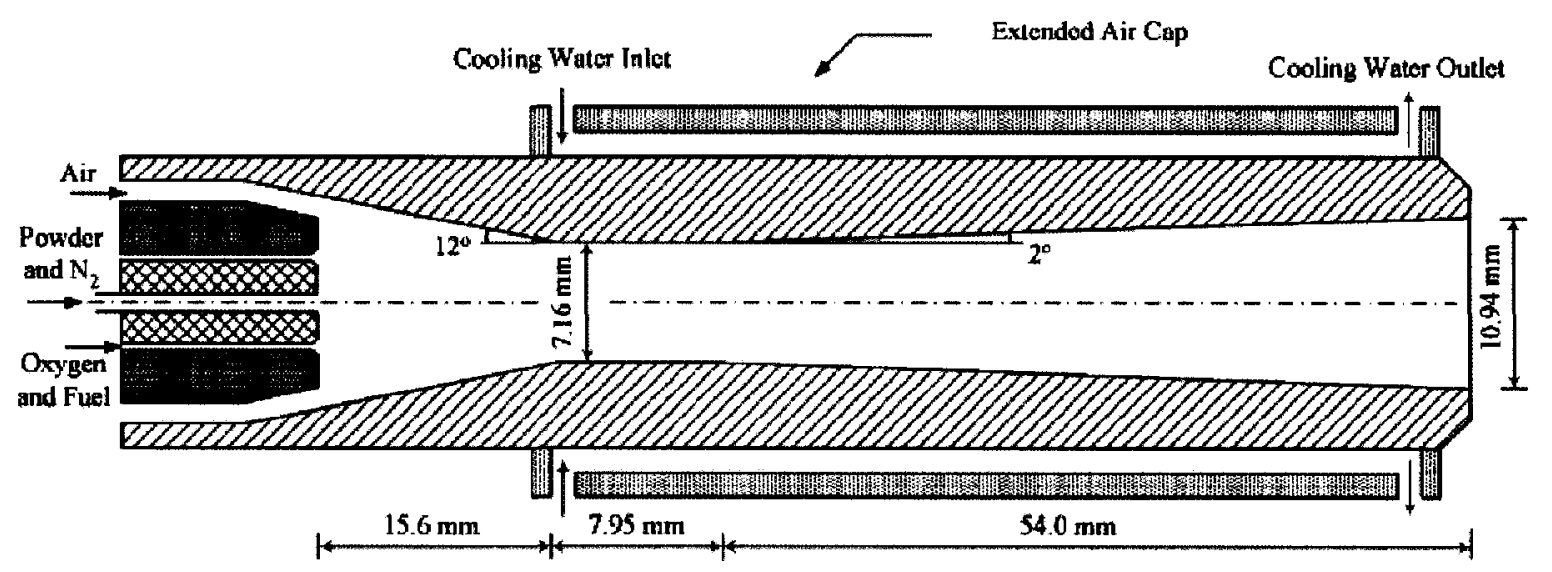

Figure 2.3 Schematic drawing of a HVOF thermal spray torch [69]

Thermal sprayed metal coatings are depositions of metals, which have been melted immediately prior to projection onto the substrate. The metals used and the systems used vary, but most applications result in thin coatings applied to surfaces requiring improvement to their corrosion or abrasion resistance properties. The materials used for thermal spray coatings cover a wide range as below [70]:

- $\quad$ Tungsten carbide

- $\quad$ Chrome carbide

- Metal alloys

- $\quad \mathrm{MCrAIY}$ coatings for hot corrosion and high-temperature wear resistance

- Tribological coatings of Stellite alloys, Triballoy alloys, $\mathrm{NiCr}$, Mo, etc. for surface properties

- $\quad \mathrm{NiAl}$ to build-up and machine to dimension

- $\quad$ Oxidation resistant turbine blade coatings 
- Abradable coatings for clearance control

- Ceramic coatings

- Dielectric

- $\quad$ Pure metal coatings such as Ti, Al, Mo

- Bone adhesion coatings for medical implants

The bonding mechanism at the thermal spray coating/substrate interface and between the particles making up the thermal spray coating is an area, which in many cases, is still subject to speculation. It generally suffices to state that both mechanical interlocking and diffusion bonding occur. The possible bonding mechanisms involved include [71]:

- Mechanical keying or interlocking

- Diffusion bonding or metallurgical bonding

- $\quad$ Other adhesive, chemical and physical bonding mechanisms - oxide films, Van der Waals forces etc.

The factors effecting bonding and subsequent build up of the coating are:

- Cleanliness

- $\quad$ Surface area

- Surface topography or profile

- $\quad$ Temperature (thermal energy)

- $\quad$ Time (reaction rates $\&$ cooling rates etc.)

- $\quad$ Velocity (kinetic energy)

- $\quad$ Physical and chemical properties 
- $\quad$ Physical and chemical reactions

All conventionally thermally sprayed coatings contain some porosity $(0.025 \%$ to $50 \%)$. Porosity is caused by [67]:

- Low impact energy (unmelted particles/low velocity)

- Shadowing effects ( unmelted particles/spray angle)

- $\quad$ Shrinkage and stress relieve effects

Porosity can be important with respect to:

- $\quad$ Lubrication - porosity acts as reservoir for lubricants.

- Increasing thermal barrier properties.

- $\quad$ Reducing stress levels and increasing thickness limitations.

- $\quad$ Increasing shock resisting properties.

- Abradability in clearance control coatings.

- Applications in prosthetic devices and nucleate boiling etc.

Generally, the as-sprayed surface is rough and textured. The rough and high bond strength coatings are ideal for bond coats for less strongly bonding coatings. Many coatings have high friction surfaces as-sprayed and this property is used in many applications (rolling road drum surfaces for motorcycle brake testing). Some plasma sprayed ceramic coatings produce smooth but textured coatings important in the textile industry. Other applications make use of the abrasive nature of some coating surfaces. Thermally sprayed coatings do not provide bright high finish coatings without finishing like that of electroplated deposits. 
Coatings generally have poor strength, ductility and impact properties. These properties tend to be dictated by the "weakest link in the chain," which in coatings tends to be the particle or grain boundaries and coating/substrate interface. Coatings are limited to the load they can carry, and thus require a substrate for support; even then, coatings are poor when point loaded. Internal tensile coating stresses generally effect properties adversely. Effective bond strength is reduced and can be destroyed by increasing levels of internal stress. This in turn affects coating thickness limits. Coatings on external diameters can be built up to greater thickness than that on internal diameters.

Surface properties, such as wear resistance, are usually good, but the properties are more specific to the material or materials used in the coating. The properties of a substrate need only to be strength, ease of fabrication and economical (like mild steel). The coating supplies the specific surface properties desired. For example, materials used for applications of thermal barrier and abradable clearance control by nature, have poor strength and thus benefit from being applied as a coating onto a substrate, the source of the strength. Thermally sprayed coatings can provide the following properties [71]:

- $\quad$ Tribological (wear resistance)

- $\quad$ Corrosion resistance

- Heat resistance

- Thermal barrier

- Electrical conductivity or resistivity

- Abradable or abrasive

- $\quad$ Textured surfaces 
- $\quad$ Catalyst and prosthetic properties

- Restoration of dimension

- Copying of intricate surfaces,

which can be found in the following applications [67]:

- Wear resistance

- $\quad$ Fretting and galling prevention

- Harsh environments/Corrosion

- Abrasion and erosion resistance

- Cryogenic to high temperature applications

- Low friction

- Conductivity or dielectric surface properties

- Temperature resistance

- Dimensional restoration

- Special properties: abradables, bone adhesion, etc.

- Larger parts

\subsection{Coating Materials}

\subsubsection{Introduction to Coating Materials}

The materials used for coatings can be various types, such as metals, alloys, composites, ceramics, polymers, and so on, depending on the coating application and the coating process employed. For industrial applications, coating materials require high hardness, good wear and thermal resistance with low coefficient of friction in order to be able 
to protect the tools from severe wear. In some cases, corrosion resistance is also required for coating materials.

For years, research on hard metals has been conducted as a cheaper placement for other expensive hard materials, such as diamond. Nowadays, plenty of hard metals have been developed. Hard metal is the term used to signify a group of sintered, hard, wear-resisting materials. They are based on the carbides of one or more of the elements such as tungsten, tantalum, titanium, molybdenum, niobium and vanadium, bonded with a metal of lower melting point usually cobalt, which are widely used for cutting tools where for many applications they have replaced conventional high speed steels. Tungsten carbide is the most widely used.

Superalloys are also popular materials for coatings when the components serve at elevated temperatures. These alloys are usually based on group VIIA elements of the periodic table, and are generally used for elevated temperature applications where the resistance to deformation and stability are prime requirements $[72,73]$. The common superalloys are based on nickel, cobalt or iron. This group of materials exhibit excellent mechanical strength and creep resistance at high temperatures, good surface stability, and corrosion and oxidation resistance. Superalloys typically have an austenitic face-centered cubic crystal structure and develop high temperature strength through solid solution strengthening. Oxidation and corrosion resistance is provided by the formation of a protective oxide layer, which is formed when the metal is exposed to oxygen and encapsulates the material protecting the rest of the component. Superalloy development has relied heavily on both chemical and process 
innovations and has been driven primarily by the aerospace and power industries. Typical applications of superalloys are in the aerospace industry, for example, for turbine blades of jet engines. Such materials allow the turbine to operate more efficiently by withstanding higher temperatures. In recent years, these alloys have found application for coatings to resist high-temperature deformation and rupture.

Tribaloy alloys are another group of materials that are widely used for coatings where high-temperature corrosion and wear resistance is the major consideration. These alloys are cobalt-based or nickel-based alloys, which are primarily strengthened by intermetallic Laves phase dispersed in a softer eutectic matrix. It is the presence of this large volume fraction of Laves phase that enables these materials to achieve their good wear resistance, which differ from carbide-strengthened alloys that gain their wear resistance from a dispersion of various carbides $[74,75]$. These alloys are usually hypereutectic with a volume fraction of $30-70 \%$ primary Laves phase $[76,77]$. The eutectic solid solution in Tribaloy alloys provides high mechanical strength, fracture toughness, and ductility, while the Laves phase gives excellent wear resistance under poor or unlubricated conditions. Their corrosion resistance comes from a high level of chromium content. The advantage of Tribaloy alloys over carbide-strengthened alloys (for example, Stellite alloys) is that Laves phase is softer than carbides (hardness about half) so that it would not act as a cutting tool to wear away a mating surface. The carbon content in Tribaloy alloys is kept low to prevent carbides forming in preference to the Laves phase. 
In the present research, the coatings being studied were made of hard metal, superalloy and Tribaloy alloy, respectively. These materials will be introduced in the following sections.

\subsubsection{Tungsten Carbide (WC)}

In the cutting tool industry, hard metals like tungsten carbide (WC) are commonly used as coatings, since they have exceptional hardness and toughness. WC has low wear rate, especially when it has metallic binder in its cemented matrix. The common metallic substance used in WC is cobalt (Co) and is normally written as WC-Co. WC-Co coatings can be deposited on the substrate in various ways, however, previous studies have found the HVOF process to produce the best WC-Co coatings, so far [78-81]. According to Li et al., the speed and the melting temperature of the particles are the main factors in forming the microstructure of the coating [82]. Nevertheless, the content of cobalt in WC compounds greatly influences their material properties. Cobalt acts as a binder in the cemented carbide. Although the Co element in WC adamantly increased the hardness and strength, as a binder, the Co causes the low corrosion resistance $[83,84]$. Based on the experiment result of Chivavibul et al. [85], by increasing the Co content in WC, the fracture toughness increases but the hardness decreases. The decrement of the coating's hardness is due to the fact that the binder content is increased and suppressed the $\mathrm{WC}$ and $\mathrm{W}_{2} \mathrm{C}$ phase region [86].

Another way to obtain higher hardness in WC-Co coating is by adding additional metallic substances into the matrix. Hence, the additional advantage is added to the matrix mechanical properties. For instance, by adding chromium to WC-Co matrix, the coating has good lubricant and better erosive and corrosive resistance in corrosive environments, such as 
pipe valves in offshore industry $[40,87]$. However, adding a metallic substance like $\mathrm{Cr}$ is not cheap and environmentally safe. The waste from its inexpensive technique, electroplating, is hazardous and becomes an inevitable threat to humans, water and soil if disposed without a proper waste treatment [88].

For years, studies were conducted to improve the conventional electroplating. Nascimento et al. suggested that HVOF can be used as an alternate process to add the metallic substances into the matrix without harming the environment [40]. In their experiments, HVOF process produced better results than electroplating of $\mathrm{Cr}$ substance, and reduced the heavy metal waste enormously $[40,88]$. The waste was reduced by converting the residual sludge into inert vitrified slag [88]. Similar to Co, by increasing the $\mathrm{Cr}$ content in the matrix would enhance the erosive-corrosive resistance in weak erosive conditions. However, overheating the matrix would produce a poor quality of coatings as the substrate would get affected and cause a change in coating mechanical bonding [35].

Figure 2.4 shows the microstructures of two $\mathrm{WC}$ hard metals: WC/17Co and $\mathrm{WC} / 10 \mathrm{Co} / 4 \mathrm{Cr}$. It can be seen that a large volume fraction of $\mathrm{WC}$ particles uniformly cemented in the Co or Co-Cr solution matrix. It is reported that $\mathrm{WC} / 17 \mathrm{Co}$ and $\mathrm{WC} / 10 \mathrm{Co} / 4 \mathrm{Cr}$ have a Young's modulus of $300 \mathrm{GPa}$ and $310 \mathrm{GPa}$, respectively [89] and a similar tensile strength of about $200 \mathrm{MPa}$ [90]. 


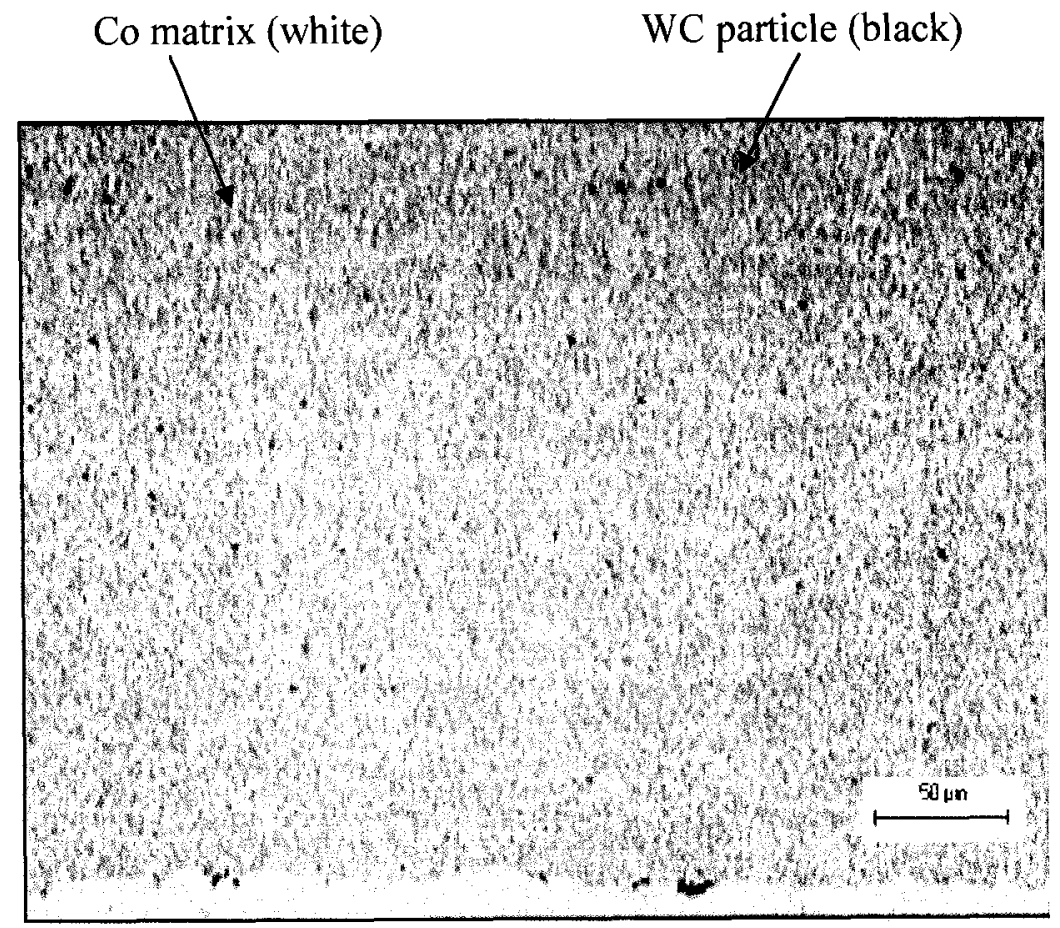

(a)

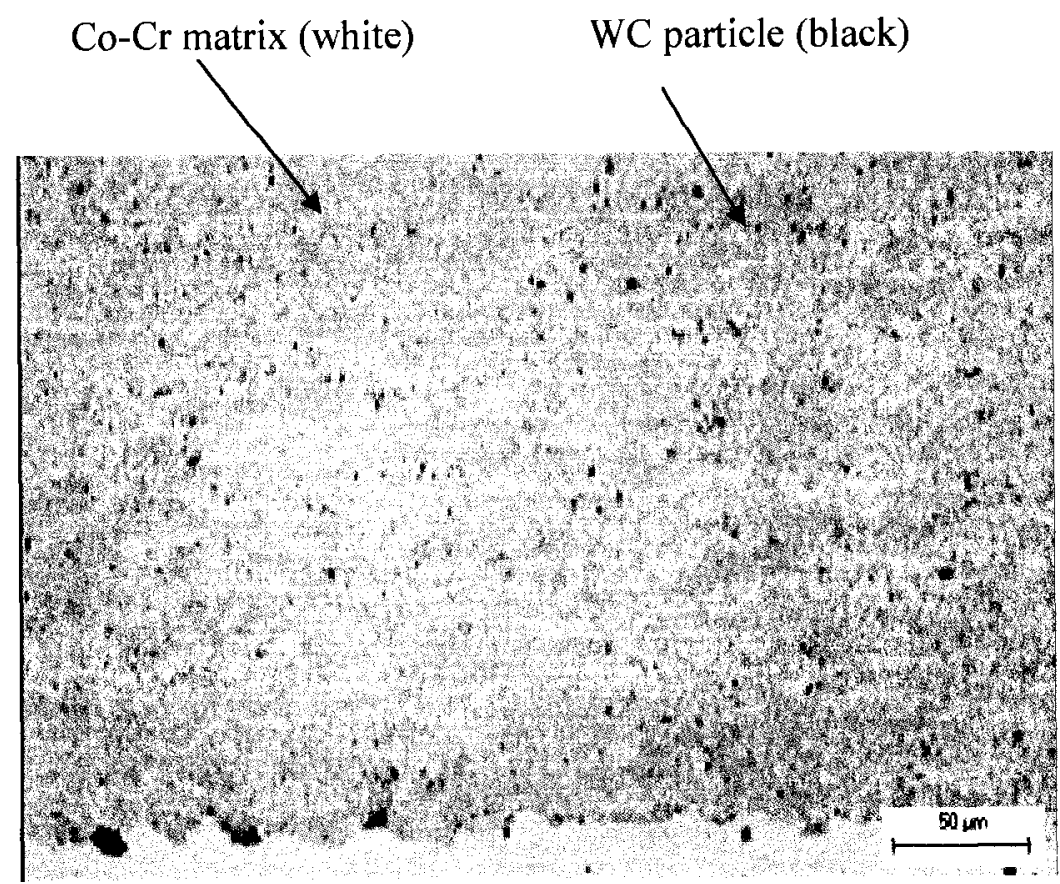

(b)

Figure 2.4 Microstructure of: (a) WC-Co and WC-Co-Cr 


\subsubsection{Nistelle C and Nistelle Super C}

Nickel-based superalloys are a very important group of engineering materials for high strength and high corrosion/wear resistance applications at high temperatures. For example, they have been selected for a variety of gas turbine engine components, such as seals, containment rings, duct segments, casings, fasteners, racket nozzles and pumps. Alloys based on the Ni-Cr-Mo ternary system constitute a class of superalloys utilizing long range ordered phases as a primary mechanism for providing high strength at both room temperature and elevated temperatures [91, 92]. Nickel, as the base metal, possesses high hardness, which contributes to superior wear resistance. It is also a good base metal for corrosion-resistant materials because it readily alloys with other corrosion-resistant metals. Chromium is included because it is an element known to promote the formation of passive films in oxidizing acids. Molybdenum is an element known to enhance the resistance of nickel to reducing acids, such as hydrochloric. Another important contribution of molybdenum to these alloys is its solid-solution strengthening effect, owing to its large atomic volume in the matrix to pin dislocations [85]. When alloyed with both $\mathrm{Cr}$ and Mo, Ni-based alloys display resistance to complex corrosive media [93].

One of the popular Ni-Cr-Mo alloys is known as Nistelle C, which has a nominal composition (wt.\%) of $\mathrm{Ni} / 16 \mathrm{Cr} / 16 \mathrm{Mo} / 4 \mathrm{Fe} / 4 \mathrm{~W}$, where tungsten has the same solid solutioning effect as molybdenum, and iron is present as a less expensive raw material [93, 94]. However, for some specific applications, structural or thermal stability requires minimization or removal of tungsten and iron from the alloy, because both of the elements have a negative effect on thermal stability [93]. Iron is also vulnerable to corrosive attacks. 
Furthermore, because most industrial environments contain oxidizing impurities, such as ferric ions and dissolved oxygen, the chromium content in the alloy must be increased.

To this end, a novel Ni-Cr-Mo alloy, designated as Nistelle Super C, with a nominal composition (wt.\%) of $\mathrm{Ni} / 23 \mathrm{Cr} / 18 \mathrm{Mo}$, was developed for enhanced corrosion resistance at Deloro Stellite Inc. Material characterization of this new alloy was carried out as well as analyses of phase transformation and microstructure; the mechanical properties and corrosion resistance in oxidizing and reducing acids of this alloy were investigated [48]. The microstructures show that Nistelle $\mathrm{C}$ and Nistelle Super $\mathrm{C}$ all consist of a Ni solid solution matrix with a eutectic of intermetallic compounds embedded that are well known to enhance the hardness, strength and mechanical properties. It is reported that Nistelle Super C, exhibits much higher corrosion resistance to both oxidizing acid and reducing acid than Nistelle C, due to the increased $\mathrm{Cr}$ and Mo contents and minimized Fe content. Both of the alloys are ductile materials, with high elongation. It is measured that the elongations of Nistelle $\mathrm{C}$ and Nistelle Super C are $12.5 \%$ and $14 \%$, respectively. This new alloy also exhibits better mechanical properties, in particular, an increase in ductility, compared with Nistelle C. This is attributed to the lower volume fractions of the brittle intermetallic compounds $\mathrm{Ni}_{3}(\mathrm{Mo}, \mathrm{Cr})$ and $\mathrm{Ni}_{4}(\mathrm{Mo}, \mathrm{Cr})$ in Nistelle Super C. Nistelle Super $\mathrm{C}$ contains more Mo and $\mathrm{Cr}$ compared to Nistelle $\mathrm{C}$ which contains $\mathrm{W}$ and $\mathrm{Fe}$. Indeed, the large contents of Mo and $\mathrm{Cr}$ make Nistelle Super $\mathrm{C}$ an excellent coating in highly corrosive and acidic, high temperature working environments. However, Nistelle $\mathrm{C}$ has the advantage of having a larger volume fraction of eutectic intermetallic phase, which contributes to tremendous reduction in deformation [48]. Figure 2.5 shows the microstructures of Nistelle C and Nistelle Super C. The Young's 
modulus of Nistelle C and Nistelle Super C are $180 \mathrm{GPa}$ and $200 \mathrm{GPa}$, respectively, and the tensile strengths of the two alloys are very close, about $530 \mathrm{MPa}$ [48].

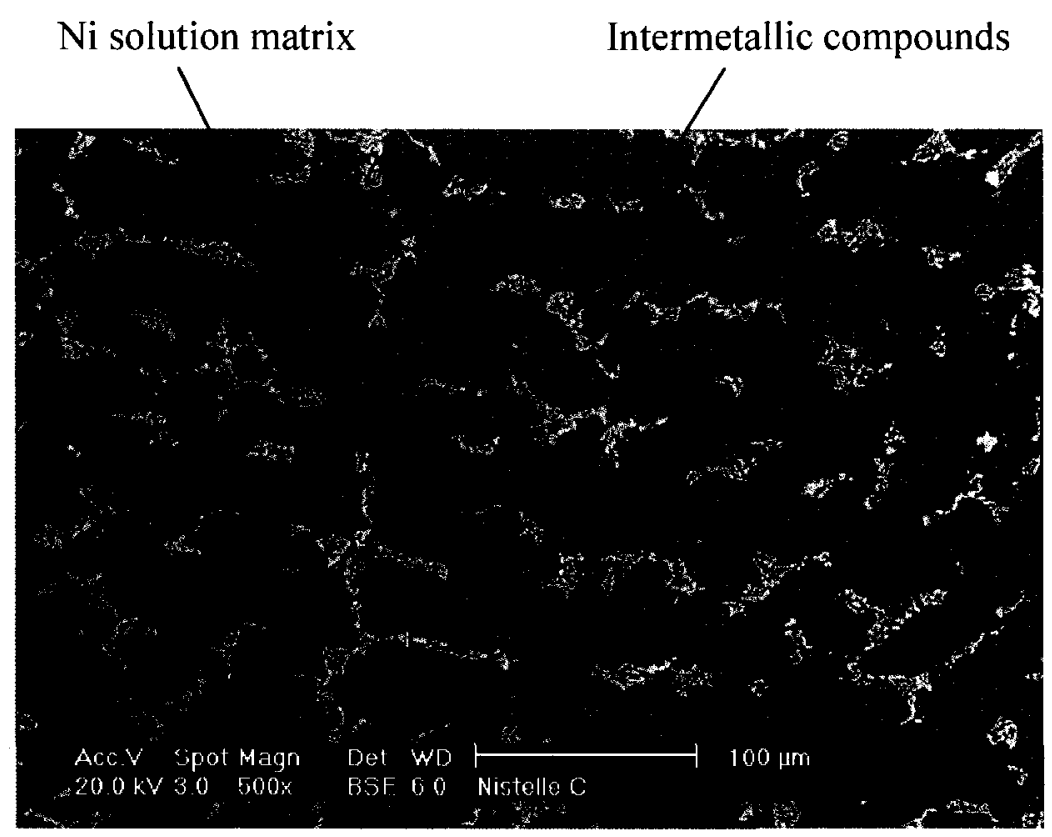

(a)

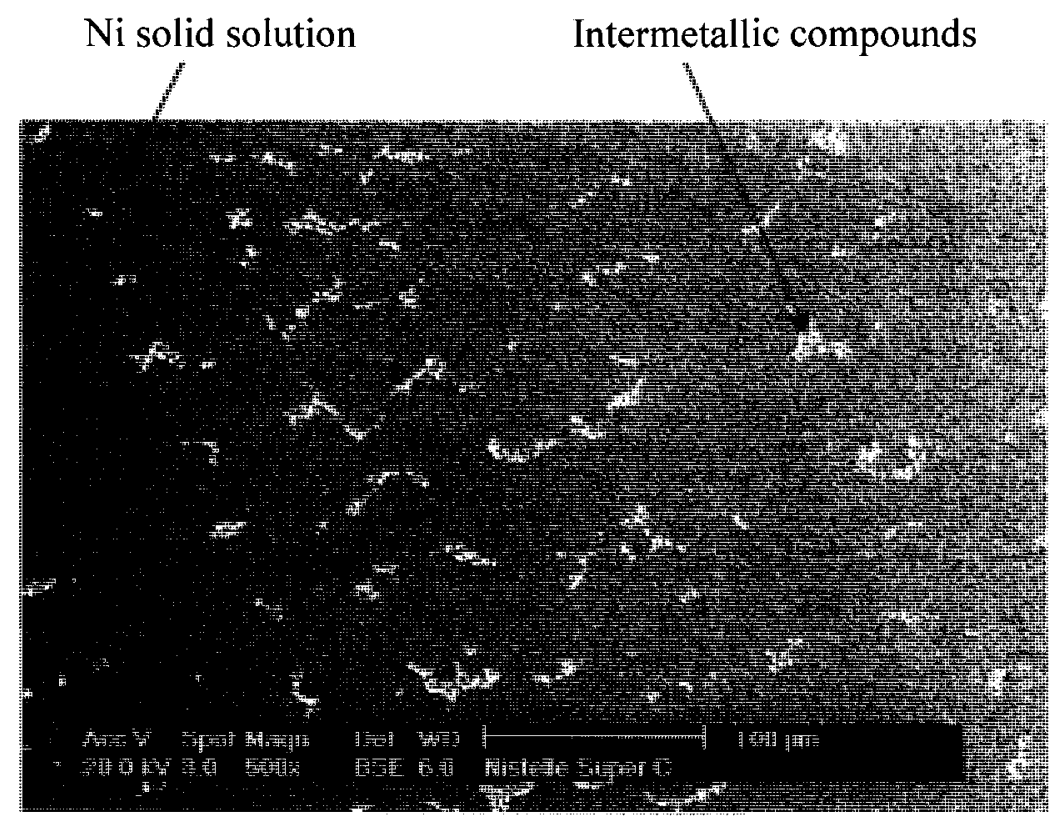

(b)

Figure 2.5 Microstructure of: (a) Nistelle C and Nistelle Super C 


\subsubsection{Tribaloy alloy $\mathrm{T}-800$}

Tribaloy alloy $\mathrm{T}-800$ has a chemical composition of $\mathrm{Co} / 18 \mathrm{Cr} / 28 \mathrm{Mo} / 3 \mathrm{Si}$, in which chromium is added to enhance corrosion resistance, whereas molybdenum and silicon are used to impart wear resistance by forming the Laves phase. T-800 has exceptional oxidation/corrosion and wear-resistance due to the high $\mathrm{Cr}$ and $\mathrm{Si}$ contents. It is harder and has better abrasive wear-resistance than either Tribaloy alloys T-400 or T-700 [74]. Depending on the thermal treatment, the allotropic nature of cobalt can cause either the face centered cubic (fcc) or hexagonal close packed (hcp) crystal structures or both to be present in Triboloy alloys. The hard primary phase is a ternary Laves phase of the C-14 $\left(\mathrm{MgZn}_{2}\right)$ type having a melting point of about $1560^{\circ} \mathrm{C}$, and its compositions are approximately $\mathrm{Co}_{3} \mathrm{Mo}_{2} \mathrm{Si}$ or $\mathrm{CoMoSi}$ for the Co-Mo-Cr-Si Tribaloy family. The primary dendrites of the hard intermetallic phase are in a eutectic matrix of smaller intermetallic particles embedded in a Co solid solution; there are also regions of Co solid solution which are free from the secondary Laves phase $[77,95,96]$.

T-800 is a typical Tribaloy alloy for corrosion and wear applications, with the overall hardness of Laves phase and cobalt solid solution of $54-60 \mathrm{HRC}$; the Laves phase content is 55\% [77]. However, the Laves phase limits ductility and impact strength [93]. Figure 2.6 shows the microstructure of T-800, in which a large volume fraction of Laves phase can been seen embedded in the cobalt solution matrix. The Young's modulus and the tensile strength of this alloy are reported to be $240 \mathrm{GPa}$ and $700 \mathrm{MPa}$, respectively [77]. 


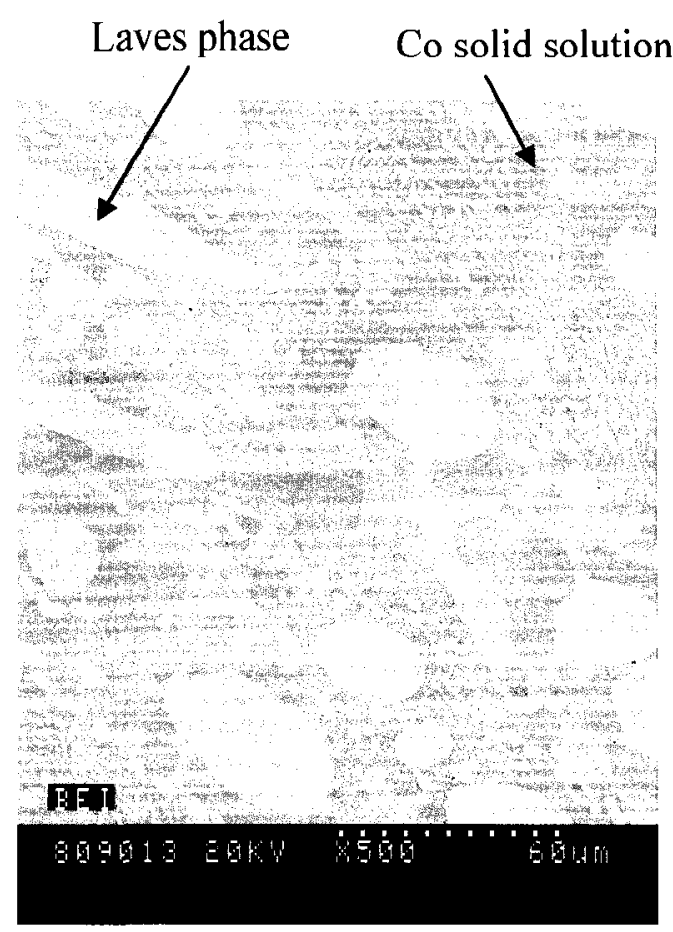

Figure 2.6 Microstructure of T-800

\subsection{Coating Strength Evaluation}

\subsubsection{Coating Failure}

It has been demonstrated that in application, coatings often fail before the substrate material reaches its intended expectancy life, because of the weakness of the interface and the brittleness of the coating materials, thus causing substantial degradation and even catastrophic failure of many mechanical components. Wear-resistant coatings often do not fail in the conventional wear mode but usually fail due to coating fracture or spallation (interfacial adhesive failure) [97, 98]. Performance of corrosion resistant coatings also depends on their interfacial adhesive strength [99, 100]. In coating systems, failure often occurs via fracture mechanisms, either through thickness cracking or interfacial delamination leading to failure of the device or layer. In some cases, the coating/substrate interaction may 
result in earlier crack nucleation in the substrate material when cracking or spallation of the coating occurs prematurely.

With the growing interest in the development of wear/corrosion-resistant surfaces by means of surface coating, various techniques and methods have been developed for coating evaluation. They can be generalized into several groups: conventional testing methods, such as the pull-off test, the bending test, the peel test, the laser spallation test, the ultracentrifugal test, etc.; newly developed indentation test and scratch test methods including macro, micro and nano-indentation tests, which are also combined with fracture toughness determination and FEA modeling; theoretical analyses based on fracture mechanics theory, strain energy, hertz equation, etc.; FEA simulation.

There are many studies on the coating behaviors during loading, especially when the coating starts to lose its strength and hence, fails. The indication of the coating failure is when it starts to crack. However, understanding when, where or how it cracks, has left a void for many researchers to investigate, especially when there are many types of coating processes and applications in various industries.

\subsubsection{Various Evaluation Methods}

Performance of wear resistance coatings, in many cases, depends on the adhesive strength of the coating $[99,100]$. As such, quantification of the adhesive strength of the coating is of importance. Measurements of the adhesive strength are normally conducted using the direct pull test as defined in the ASTM D4541 and ASTM C633-79. In the direct 
pull test a coating is applied to the end of a cylindrical rod (i.e. a substrate) and another rod of the same material as the substrate is bonded to the top surface of the coating using a polymeric adhesive. When the adhesive strength of the coating/substrate interface is stronger than the strength of the polymeric adhesive, failure often occurs at the location of the adhesive and, as a result, the adhesion of the coating cannot be quantified. Even when failure does occur at the coating/substrate interface, the direct pull test provides ill-defined properties since the measured failure strength is strongly affected by the strength-controlling defects present at the interface before the test.

In addition to the direct pull test, many other tests for measuring the adhesive strength under engineering environments have been devised. Some examples of these tests are the laser spallation tests [101], the ultracentrifugal tests [101], the peel tests [19], the hammering tests [20] and the scratch tests [102, 103]. In laser spallation tests [104] a high-energy pulsed laser beam is directed towards the reverse side of the substrate. The generated compressive shock wave propagates through the substrate to the coating/substrate interface, causing detachment if its intensity is sufficient. The main limitation of this technique is that the coating has to be patterned into dots smaller in diameter than the incident laser beam. In the ultracentrifugal test [101], a coated specimen is levitated magnetically and rotated in a vacuum at continuously increasing speed until the coating is detached. The main limitation of this technique is that special equipment is required and the specimen has to be small. The peel tests [19], the hammering tests [20] and the indentation/scratch tests [102] are more suitable for quality control than for fundamental property measurements because the coating's response to these tests is affected by many factors. For example, the peeling force 
is sensitive to angle of peel, rate of peel, moduli of the coating and substrate, as well as the coating thickness [104].

Instead of measuring the adhesive strength, many tests have also been devised to measure the fracture energy of the coating/substrate interface - a fundamental measure of the adhesion. These include the pull test of chevron-notched sandwich specimens [21, 22], the bend test of notched delamination specimens [23], the microindentation test [32, 33], and the bending test of chevron-notched sandwich specimens [24, 105].

In addition, many numerical studies [105-107] and some approximate theoretical analyses $[108,109]$ for the spherical indentation on the surface of coating materials can also be found in the literature. For example, Wiklund et al. [107]studied the stress concentrations generated at the interface of coated systems using FEA. Such stresses induced at pores, edges or scratches were analyzed for a number of representative coating/substrate systems. The effect of the interface topography, coating thickness and elastic mismatch on the interfacial stresses were investigated. Xu and Muton [109] have deducted the two-dimensional analytical solution for interface stresses due to concentrated surface forces. Such an analytical solution can be used as a Green's function to deal with many complicated problems such as the indentation, scratching and contact problems in coating material structure. It can also be used as the fundamental solution in the boundary element method (BEM) analysis to improve the numerical accuracy. 


\subsubsection{Indentation Technique}

Indentation method is widely used to characterize layer (coating)/substrate composites [110]. In particular, the hardness, adhesion and Young's modulus are parameters, which are determinable by indentation with different shapes of indenter. The apparatus popularly used are Vickers, Knoop, Brinell, Rockwell, etc. The diamond tips or the spherical tips of these apparatus can produce a shapely indentation mark and cracks (macro or micro) at certain loads, which can be measured by using other means, such as SEM and optical microscopy. The indentation test method is sometimes combined with the scratch test or with analytical approach or FEA to study the bonding strength or determine the fracture toughness of a coating.

For the brittle material type of coating, the common tests that researchers have done to investigate the cracks that a brittle coating material can generate are Vickers test, Knoop test, micro indentation test, nano-indentation test etc. To investigate which part of the coating would fail during the indenter loading is not as direct as it seems. The crack, which is due to the contact load, can be generated on the surface, between the layers or at the interface. However, there are also findings of crack failure combination during the contact loading [26, 111, 112]. Cook and Pharr [26] have specified five types of cracks on the coating surface according to the indenter elastic stress field based on the Hertz equation. The cracks are (1) cone crack, (2) radial crack, (3) median crack, (4) half-penny, and (5) lateral crack. The microfracture theory of brittle solids under contact loading describes both initiation and propagation stages of the crack growth. It provides a descriptive basis for the more general features of point-indentation microfracture patterns in brittle coatings. It was observed that 
generally there were two main types of 'vent' cracks initiated in the deformation zone and propagating: median vents formed during indenter loading and spread downward below the point of contact on planes of symmetry, and lateral vents formed during unloading and spread sideways toward the specimen surface. Of these, the median vent was relatively well behaved, and was amenable to standard fracture-mechanics analysis. From such an analysis the means for predetermining the depth of fracture damage under given point loading conditions were derived. An expression for the stress intensity factor, which gives a measure of the intensity of the stress field in the near vicinity of the crack tip, was obtained, in terms of the indenter load and characteristic crack dimension. Given both loading situation and crack depth, one has the basis of a simple method for estimating the fracture surface energy. The stress intensity factors for the cracks can be determined through crack length and geometry measurements.

Bouzakis and Vidakis [113] introduced a novel method for determining the superficial relation between stresses and elastoplastic strains for hard and commonly brittle isotropic materials. An experimental-computational procedure was developed based on a FEM simulation of successive ball indentations with increasing loads. The FEM model is shown in Figure 2.7. The imprint profiles, measured by means of profilometry, are used as input data to an FEM-supported optimization algorithm. The goal of the optimization procedure is to determine the constitutive stress - strain curve, expressed as the multilinear hardening law. This method is useful for determining the stress - strain curves of brittle coatings which cannot be obtained by tensile tests. 


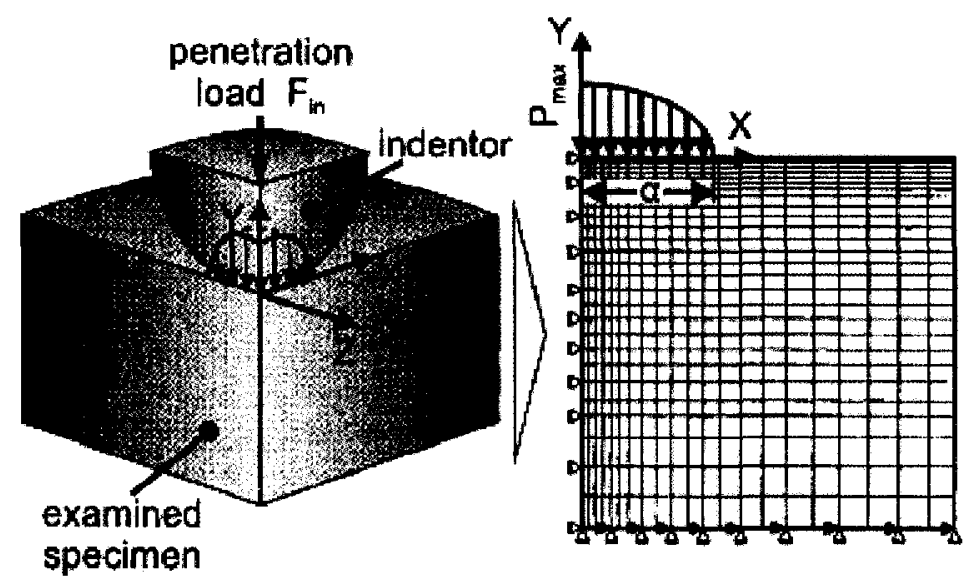

Figure 2.7 The FEM model developed to describe the indentation procedure [113]

A novel micro-indentation technique for interfacial bonding characterization of a coating/substrate system was developed by Zhang et al. [34, 114]. By conducting micro indentation in the cross section of a coating specimen near the interface, the indentation load versus time and the lateral force versus time were recorded simultaneously. Since the lateral force was very sensitive to the interfacial bonding, the critical indentation load at the interfacial debonding could be determined. In corporation with FEA, the interfacial bonding strength was evaluated quantitatively. Linss et al. [114] developed a new technique for the mechanical characterization of surfaces and coatings in combination with normal and lateral force-displacement measurements under nano-indentation test. This technique closes the gap between indentation and scratch, which allows more material parameters to be determined, such as the yield strength of a thin coating on a soft substrate and the critical stress for crack formation. Arai et al. [20] tested various types of surface coatings, such as ion plating and sputtering PVD coatings, CVD at ordinary temperature, medium temperature and low temperature, plasma-assisted CVD at low temperature and salt bath immersion carbide 
coatings. Additionally, conventional chromium electroplating, use an indentation technique with a Rockwell hardness tester and a diamond indenter of the $\mathrm{C}$ scale. The resulting damage of the coating around the indentation was examined by SEM, electron beam scanning (EBS) and optical microscopy.

Rossington et al. [33] have presented a fracture analysis of a model indentation crack system induced at the interface between a thin film and a substrate. The results provide an analytical basis for an indentation test to measure interface fracture toughness. One of the features of this analysis, which differs from other indentation analyses, is that the film above the interface crack is allowed to buckle under the influence of in-plane compressive stresses. In the absence of buckling, interface cracks are not affected by residual deposition stresses. However, once buckling occurs in the film, stress intensification develops at the buckle perimeter, such that the residual stresses provide a driving force for delamination and eventual spalling of the film. Consequently, a transition in the indentation-load/crack-length response is expected at the buckling condition.

Another approach to coating-substrate interface strength evaluation by differential load feed analysis of load-indentation measurements was reported by Rother et al. [28]. It implies an energy-related consideration of solid-state deformation processes under the action of a penetrating indenter. The required data was gained from load-indentation measurements. The interface strength is quantified in terms of a specific interface deformation energy accumulated into the interface deformation in the course of the indenter's penetration. 
The indentation/scratch combined test has been modeled by FEA to investigate the failure modes of coated materials based on the stress distribution, because the stress distribution of the coating/substrate system under scratch is one of the important factors that control the cracking behavior and failure modes of a coating. Bucaille et al. [115] performed a simulation of the scratch test using three-dimensional FEA. The indenter was a cone shape with the volume equivalent to that of Berkovich indenter; and the contact was assumed frictionless. The coating material was assumed to be elastic perfectly-plastic. The elastic/plastic deformation behaviors of the coating system during the scratch test were investigated. Jiang et al. [116, 117] analyzed the frictional contact between the slipping diamond indenter and the thin coating/substrate system in a scratch test using two-dimensional and three-dimensional FEA. The indenter was also a cone shape and the same as the Rockwell $\mathrm{C}$ geometry. The materials of the indenter and the coating were considered elastic while the substrate was elastic-plastic following the bilinear material law. Coulomb friction between the indenter and the coating surface was assumed. They explained the experimental failure mode of a coating under scratch in terms of the stress field generated in the coating/substrate system. Kral et al. [118-120] conducted three-dimensional FEA modeling of a rigid sphere sliding on an elastic-plastic layered half-space. Elastic perfectly-plastic material properties following Von Mises yield criteria were applied on the coating/substrate system. The authors analyzed both stress and strain fields in the coating/substrate system, associated with the material properties. Their results provide an insight into the effect of the coating and substrate material properties, contact friction, normal load and sliding cycle on the plastic strain and stress as well as residual tensile stress. Li and Beres [121] made a similar FEA model to Kral et al., but in the former model both normal 
and lateral loads were applied on the coating surface simultaneously, which was more representative of a real scratch test. Holmberg et al. [122] developed a computer model for describing the elastic and plastic behaviors, determining the stress strain distributions, calculating the fracture toughness of a TiN-coated steel surface subjected to a scratch contact load. The cracking mechanism of the coating in the contact region was investigated and the computation provided the best estimation of the stress intensity factor for the condition when the cracks had not grown through the whole scratch groove. He developed an FEM model, as shown in Figure 2.8, to examine the brittle fracture behavior of TiN-coated steel under a scratch test [123]. The computational results such as the maximum principal stress, were used to characterize the local stress field especially where the first crack was observed.

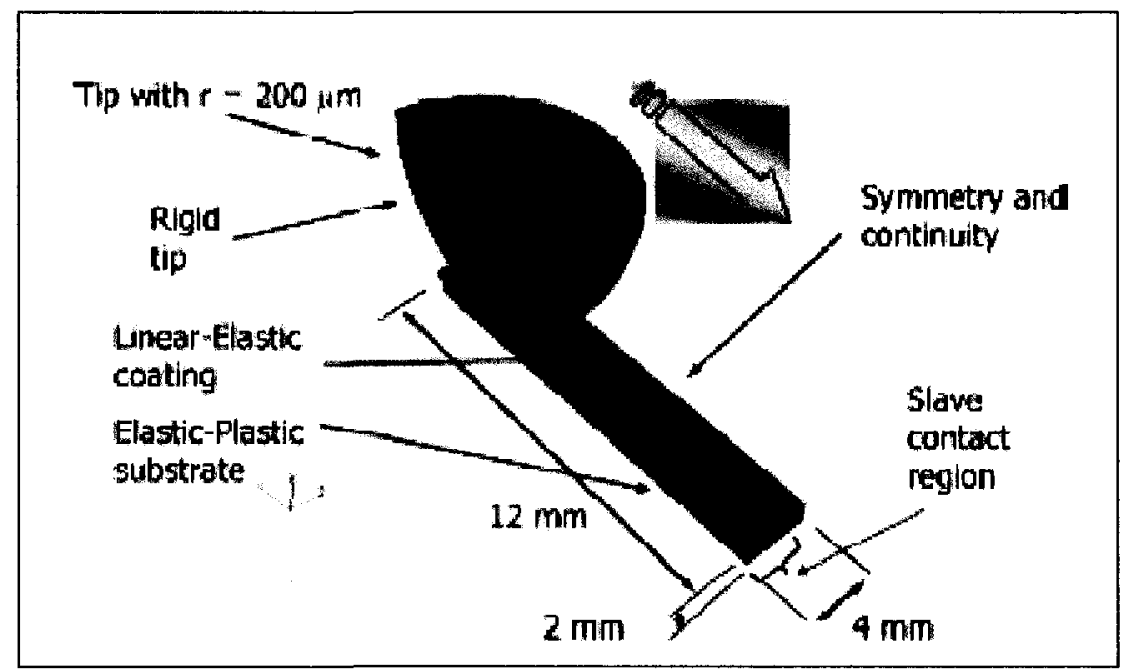

Figure 2.8 Three-dimensional finite element mesh of scratch testing. 


\section{CHAPTER 3 EXPERIMENTAL WORK}

\subsection{Specimen Preparation}

\subsubsection{Coating Materials}

Seven plate coating specimens $(\sim 100 \times 50 \mathrm{~mm})$ were fabricated with the Jet Kote HVOF process at Deloro Stellite Inc., designated as

- WC-Co hard metal (WC/17Co)

- WC-Co-Cr hard metal (WC/10Co/4Cr)

- $\quad$ Tribaloy $\mathrm{T}-800(\mathrm{Co} / 18 \mathrm{Cr} / 28 \mathrm{Mo} / 3 \mathrm{Si})$

- $\quad$ Nistelle C-propylene (Ni/16Cr/16Mo/4Fe/4W)

- $\quad$ Nistelle Super C-propylene (Ni/23Cr/18Mo)

- $\quad$ Nistelle C-hydrogen $(\mathrm{Ni} / 16 \mathrm{Cr} / 16 \mathrm{Mo} / 4 \mathrm{Fe} / 4 \mathrm{~W})$

- Nistelle Super C-hydrogen (Ni/23Cr/18Mo)

The substrate for all the specimens is 1018 low carbon steel. $\mathrm{WC} / 17 \mathrm{Co}$ and $\mathrm{WC} / 10 \mathrm{Co} / 4 \mathrm{Cr}$ are hard metals; T-800 is a Tribaloy alloy; Nistelle C and Nistelle Super C are superalloys. $\mathrm{WC} / 17 \mathrm{Co}, \mathrm{WC} / 10 \mathrm{Co} / 4 \mathrm{Cr}$ and $\mathrm{T}-800$ specimens were made with hydrogen fuel gas. Nistelle C-propylene and Nistelle Super C-propylene specimens were made with propylene fuel gas and Nistelle C-hydrogen and Nistelle Super C-hydrogen specimens were made with hydrogen fuel gas.

\subsubsection{HVOF Process}

During the HVOF process, the Jet Kote system developed high particle velocities through combustion of a fuel gas and oxygen. The high velocity combustion gases heated 
and propelled surfacing powders onto the workpiece. All powder materials were mixed thoroughly prior to use and applied directly to the substrate with no bond coat required. The powder feed featured a superior powder delivery unit to ensure repeatable powder flow. The gas stream produced by internal combustion of oxygen and fuel gas, had an initial velocity of $1350 \mathrm{~m} / \mathrm{s}$ at a temperature of $3000^{\circ} \mathrm{C}$. The pressure and flow of gases were monitored by a central console. The powder particle size was about $40 \sim 100$ microns. The coating thickness of the specimens was between $0.3 \sim 0.4 \mathrm{~mm}$.

\subsection{Cross Section Examination}

\subsubsection{Section Surface Preparation}

The coating specimens were sectioned into small pieces $3 / 4$ inch by $3 / 4$-inch for indentation tests using the Diamond Cut Saw machine with the cutting speed of $1000 \mathrm{rpm}$. Before the tests, the cross section of each specimen was examined on a Hitachi Model S-570 SEM machine. The purposes of doing this were two: one was to investigate the quality of the coatings, for example, porosity, cracking and defects or flaws present in the coatings; the other was to measure the geometry of the coatings such as coating thickness and interface profile.

The cross section surface of each specimen was prepared by grinding with grit papers from \#180 to \#600, and then polishing with an abrasive cloth plus $1 \mu \mathrm{m}$ alumina powders. After being cleaned with an ultrasonic cleaner, the surfaces were then etched with the solution of the mixture of $15 \mathrm{ml} \mathrm{HNO}_{3}, 15 \mathrm{ml}$ acetic acid, $60 \mathrm{ml} \mathrm{HCl}$ and $15 \mathrm{ml} \mathrm{H}_{2} \mathrm{O}$, in order 
to well develop the features of the coating, the interface and the substrate under SEM for cross section examination.

\subsubsection{Cross Section Profiles}

The polished and etched specimens were then carbonized and examined with SEM. The SEM images of cross section of the specimens, with sharp contrast between the substrate and the coating, are presented in Figure 3.1.
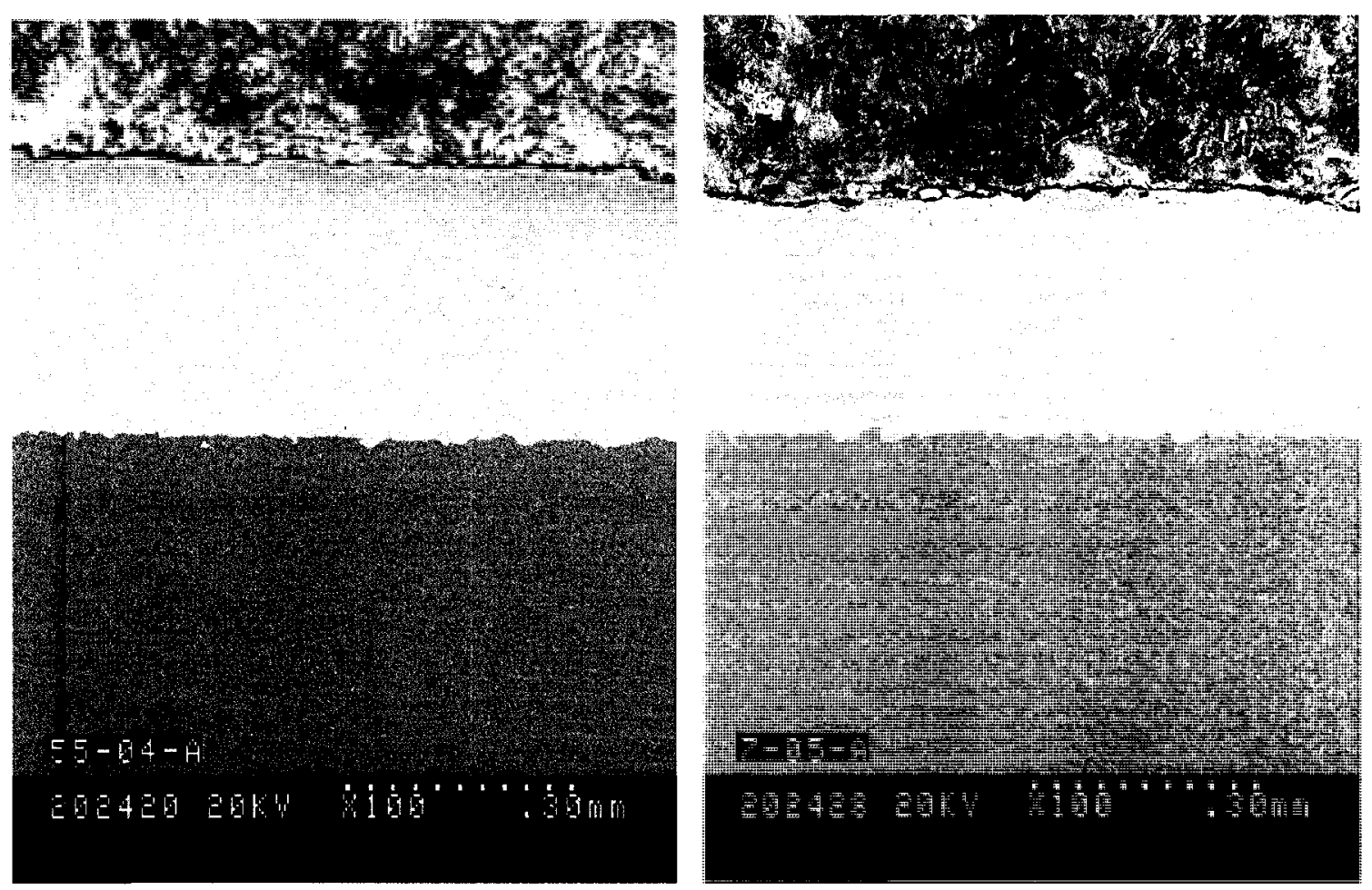

(a)

(b) 


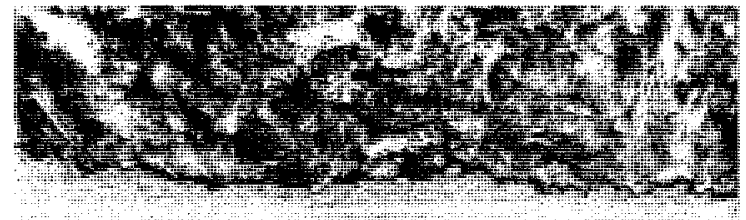

$[\mathrm{F}-\mathrm{B}] \mathrm{A}-\mathrm{B}$

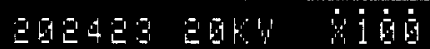
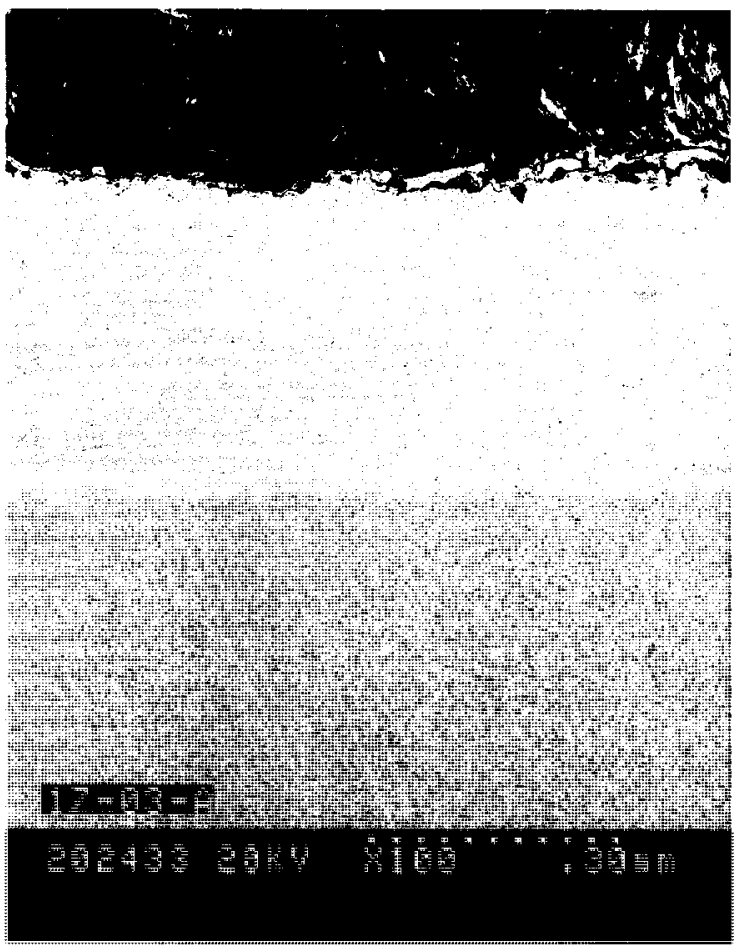

(d)

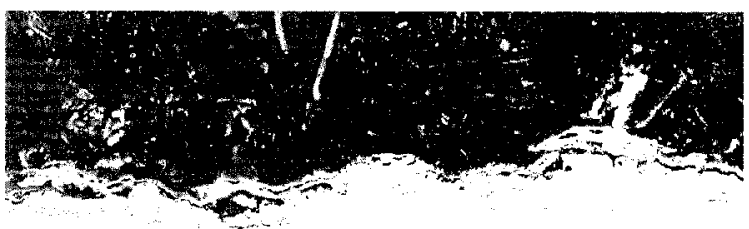

$19-19-3$

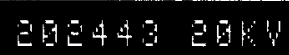
泊面

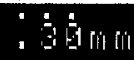

(e) 


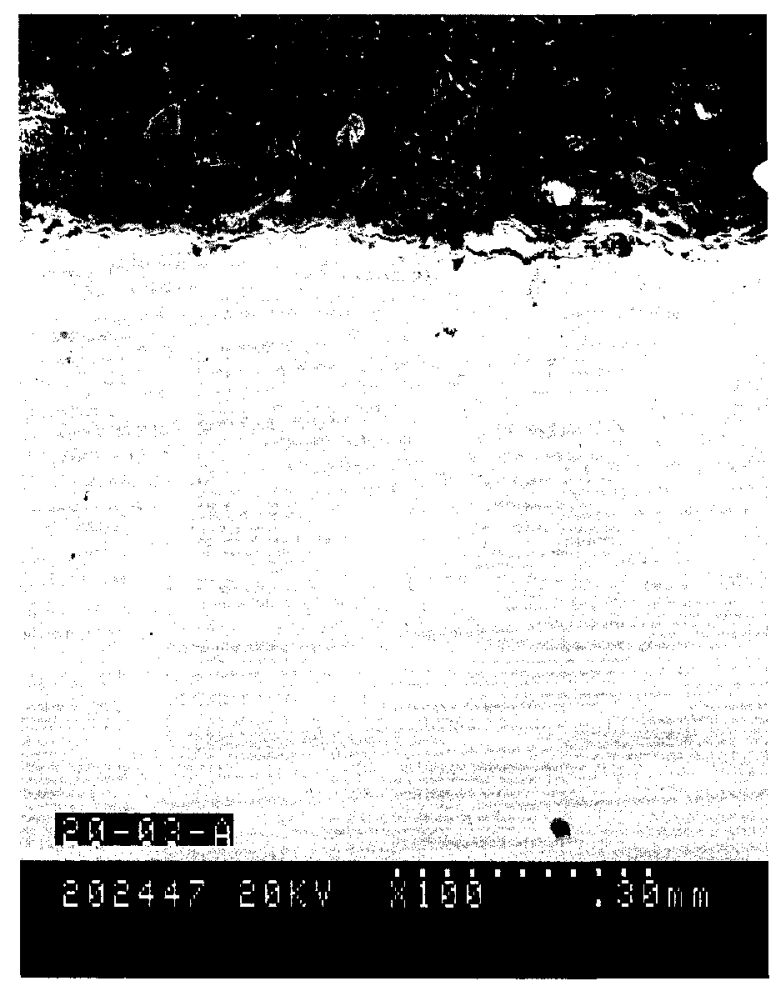

(g)

Figure 3.1 SEM images of cross section of the specimens: (a) WC-Co; (b) WC-Co-Cr;

(c) T-800; (d) Nistelle C-propylene; (e) Nistelle Super C-propylene;

(f) Nistelle C-hydrogen and (g) Nistelle Super C-hydrogen

It is observed that the coatings have a high-density structure and no obvious cracking and porosity are found. It is also noticed that the coatings do not have obvious diffusion zone at the interfaces and the interfaces are not very smooth but rugged. This may be due to the high temperature $\left(3000^{\circ} \mathrm{C}\right)$ in the HVOF process which melted the substrate surfaces, resulting in rugged interfaces. But since the velocity of the spray is very high, there is almost no time for diffusion; as a result no obvious diffusion zone formed at the interfaces. 
It is shown in the above images that the coating thickness is not uniform over the specimen surface. It is found that the average thickness of coating of specimens WC-Co, WC-Co-Cr and T-800 is about $0.3 \mathrm{~mm}$; that of the other specimens is about $0.4 \mathrm{~mm}$.

\subsection{Vickers Indentation Test}

\subsubsection{Coating Surface Preparation}

To evaluate the bonding strengths, the coating specimens were tested under Vickers indentation. The fracture behaviors of the coatings were investigated through the response of coating cracking to the indentation load. In order to remove the loose or porous structure in the top layer of the coating specimens, the coating surfaces were polished before the Vickers indentation test.

At first, the coating surfaces were ground with grit papers from \#180 to \#1200. After ultrasonic cleaning for 10 minutes to remove debris, the specimens were polished using Texmet 1500 cloth with 3 micron abrasive fluid and Buehler Metadi fluid. A Flourspoc cloth containing a $30 \mathrm{ml}$ Buehler Mastermet Colloidal Silica polishing suspension was used in the final polish process.

\subsubsection{Testing Procedure}

The indentation test was performed on the polished surface of each specimen using a standard Vickers machine with a diamond tip of $136^{\circ}$ angle. The full load was normally applied for 10 to 15 seconds. The test was started with a low indentation load of $10 \mathrm{~N}$ for each specimen and the load was then gradually increased up to a high level of $700 \mathrm{~N}$ to 
investigate the dynamic cracking/fracture response of the coatings to the increased load. When total fracture was observed in a coating under a load level, the indentation test was stopped on this specimen; otherwise the load was continuously increased up to the machine capability of $700 \mathrm{~N}$. Five indentations were taken on each specimen under each load level.

\subsubsection{SEM Images of Indented Surfaces}

The indented surfaces were examined under SEM after the indentation test. The morphologies of indentation marks left on the coating surfaces could be observed with SEM. For the hard metal WC-Co coating, cracks were observed at the indentation edges under the low load of $10 \mathrm{~N}$, but no cracks were found at the vertices or corners of the indentation, as shown in Figure 3.2.

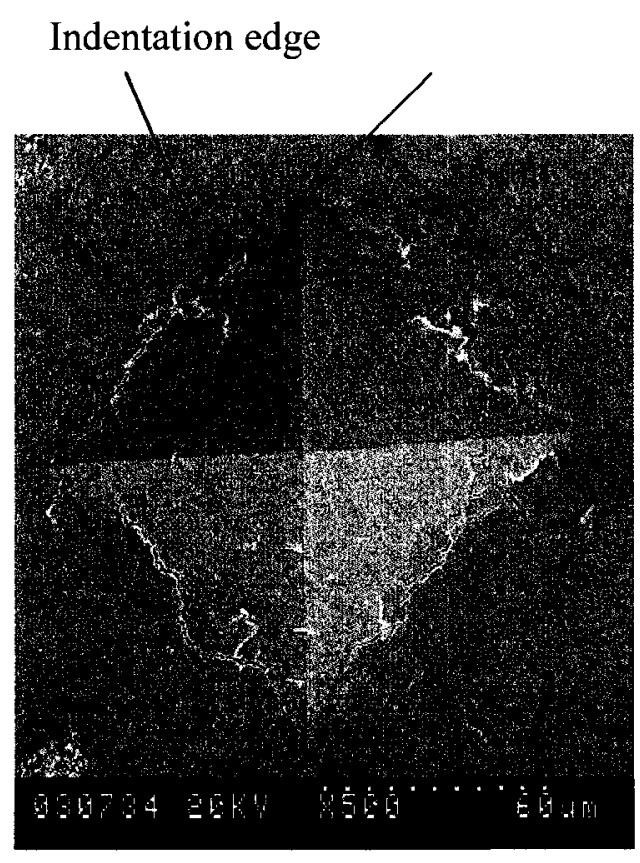

(a)

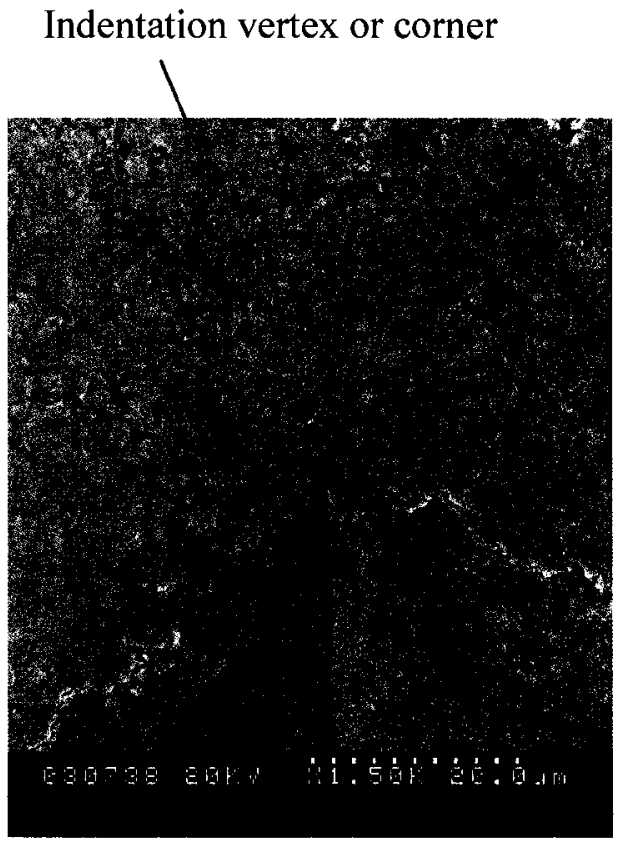

(b)

Figure 3.2 SEM images of indented surface of WC-Co under $10 \mathrm{~N}$ : (a) indentation edge with cracks and (b) indentation corner without cracks 
Under the higher load of $35 \mathrm{~N}$, the edge cracks grew deeper and longer; in the meanwhile, shallow and short cracks were found at some corners of the indentation, as shown in Figure 3.3. With the increase in the indentation load to $100 \mathrm{~N}$, the corner cracks propagated radially and at the same time cracks were initiated at all the corners of the indentation, as seen in Figure 3.4. Under the higher load of $500 \mathrm{~N}$, the cracks were further extended and connected with each other, leading to total fracture of the coating surface, as shown in Figure 3.5.

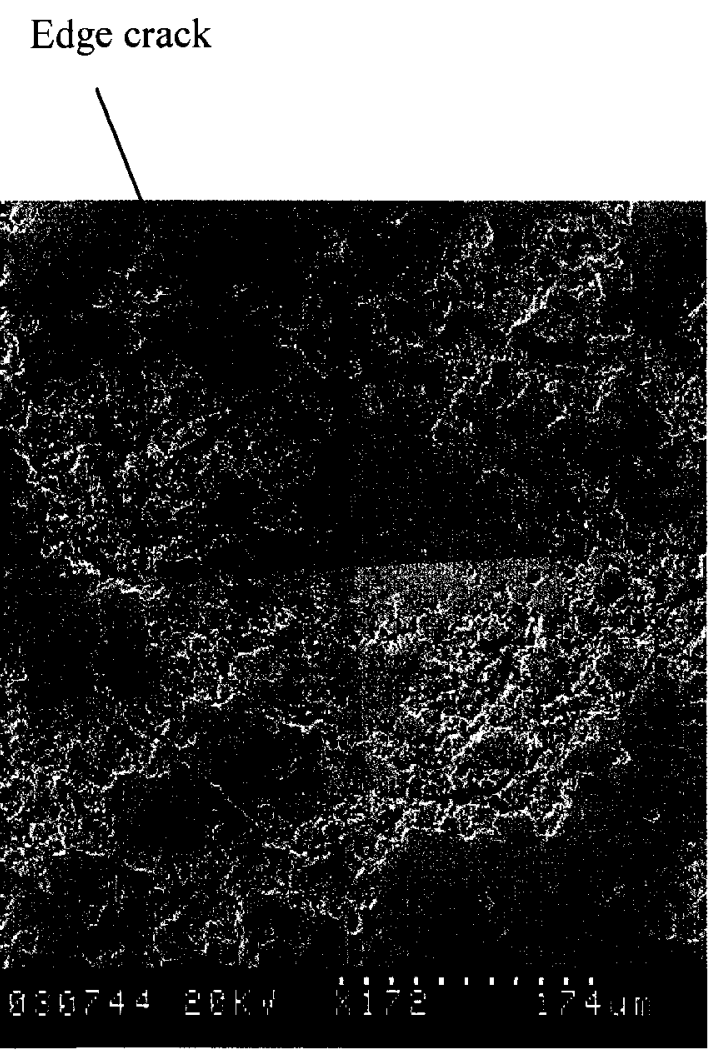

(a)

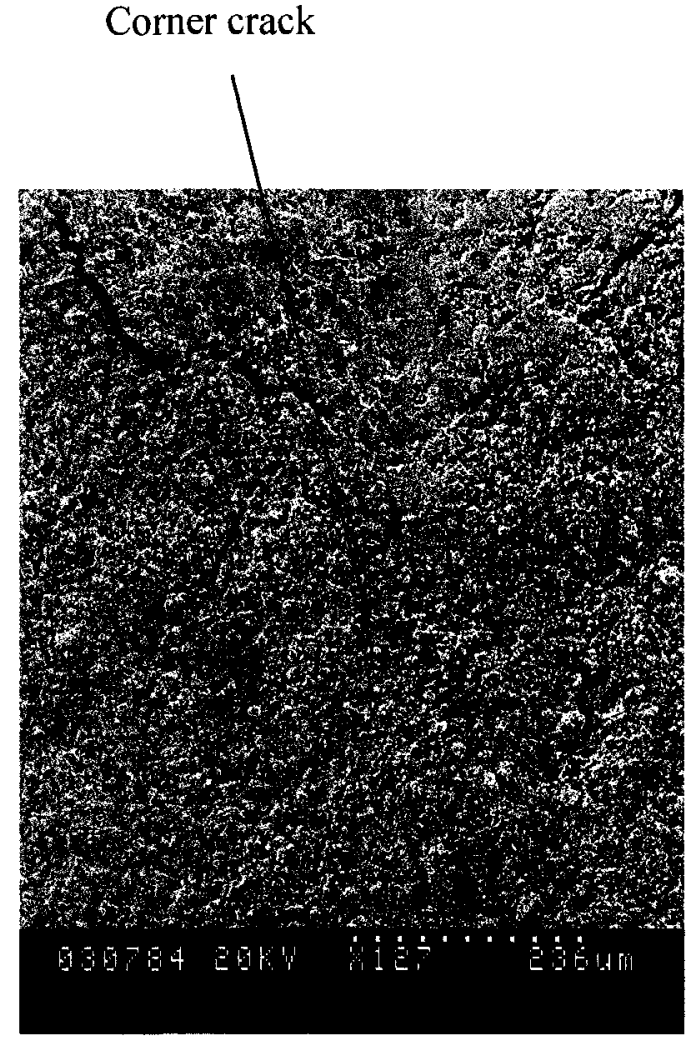

(b)

Figure 3.3 SEM images of indented surface of WC-Co under $35 \mathrm{~N}$ :

(a) edge cracks and (b) corner crack 


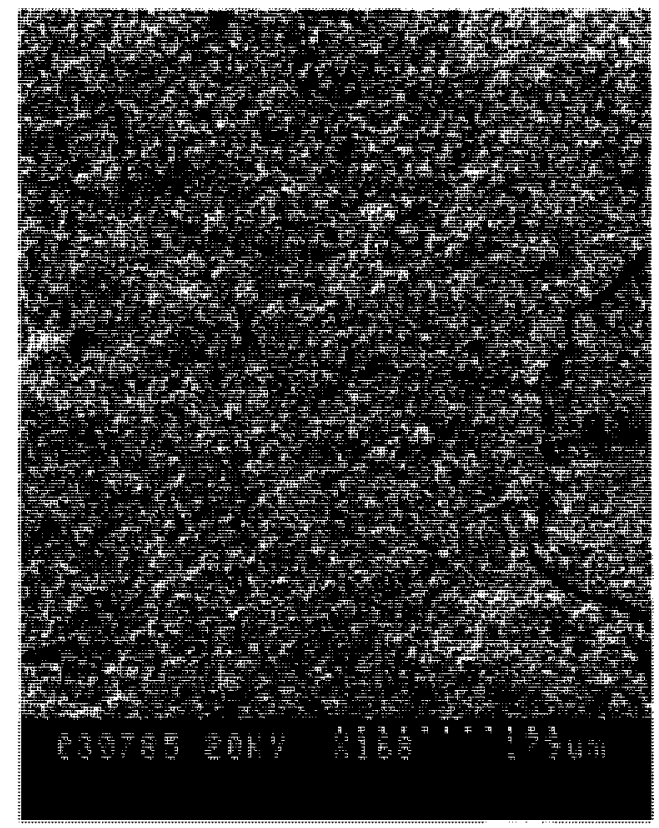

(a)

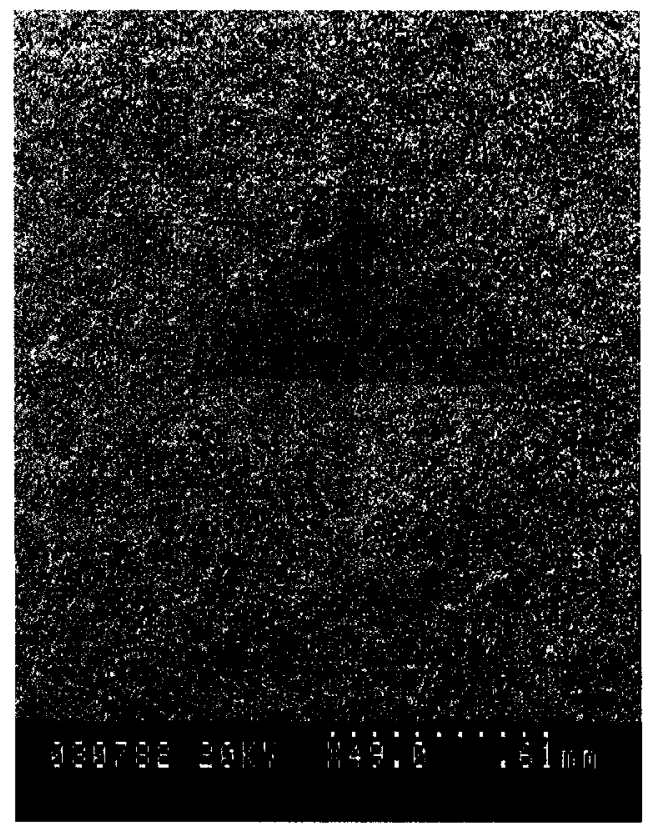

(b)

Figure 3.4 SEM images of indented surface of WC-Co under $100 \mathrm{~N}$ : (a) extended corner crack and (b) edge cracks and corner cracks

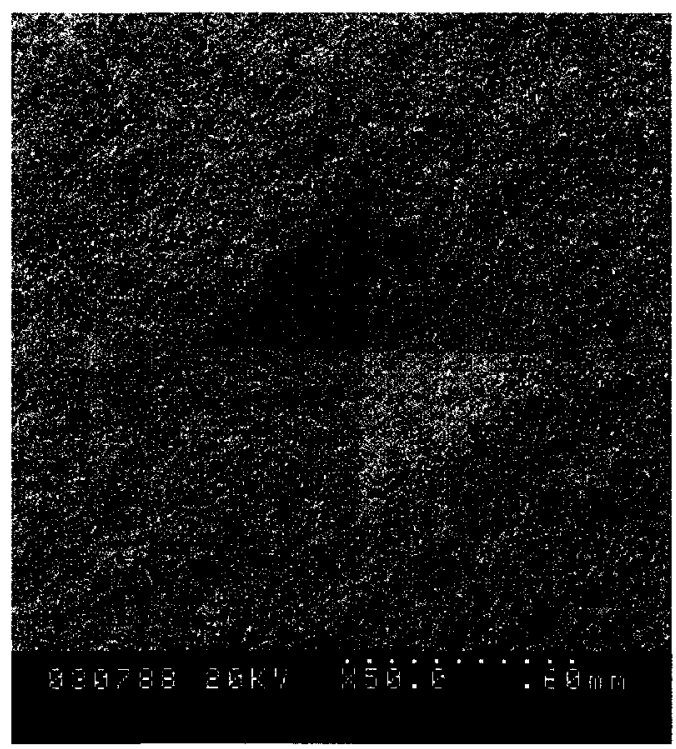

Figure 3.5 SEM image of fractured surface of WC-Co under $500 \mathrm{~N}$ due to edge cracks and corner cracks 
Similar to specimen WC-Co, cracks were also found in specimen WC-Co-Cr at the edges of the indentation under the load of $10 \mathrm{~N}$, but these were not found at every edge of the indentation, only in some of them, as shown in Figure 3.6(a). With the higher load of $35 \mathrm{~N}$, cracks were initiated at every edge of the indentation and they grew along the indentation edges, but no cracks were found at the corners of the indentation, see Figure 3.6(b). By further increasing the indentation load to $100 \mathrm{~N}$, one may see in Figure 3.6(c) that the edge cracks grew to longer and deeper cracks. In the meanwhile, small cracks were found at the corners of the indentation. The corner cracks were extended in both radial direction and depth direction under a high load of $300 \mathrm{~N}$, as seen in Figure 3.6(d).

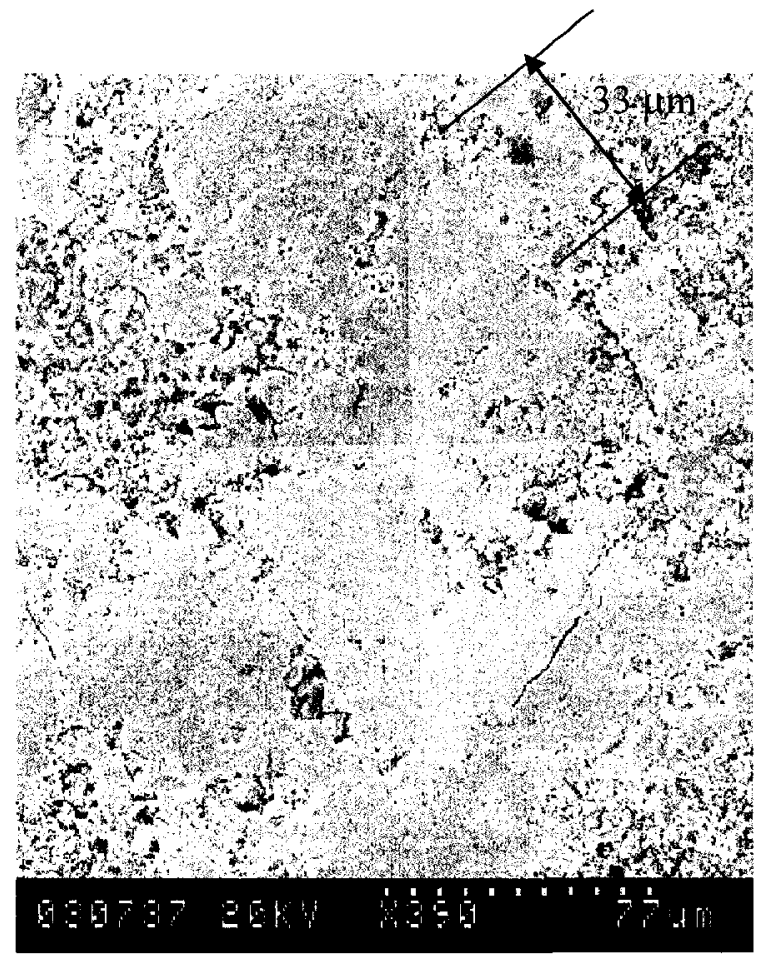

(a)

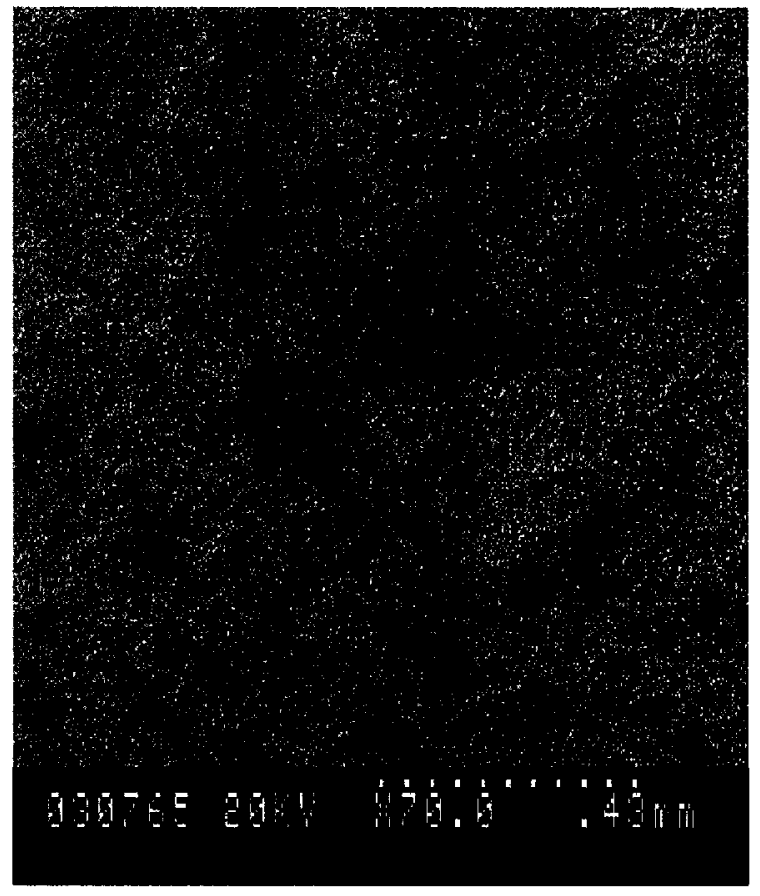

(b) 


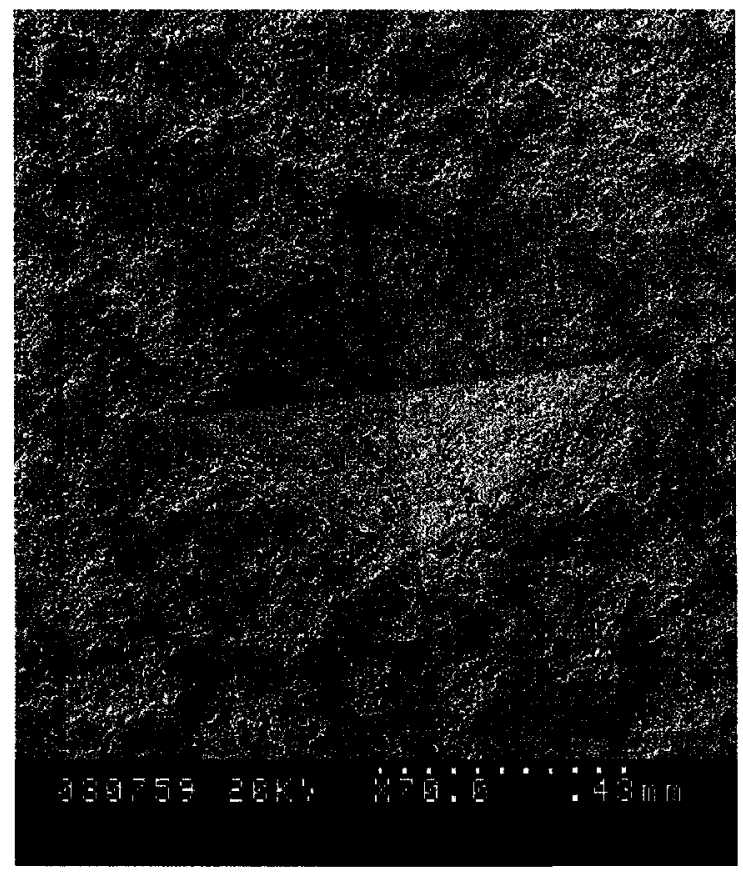

(c)

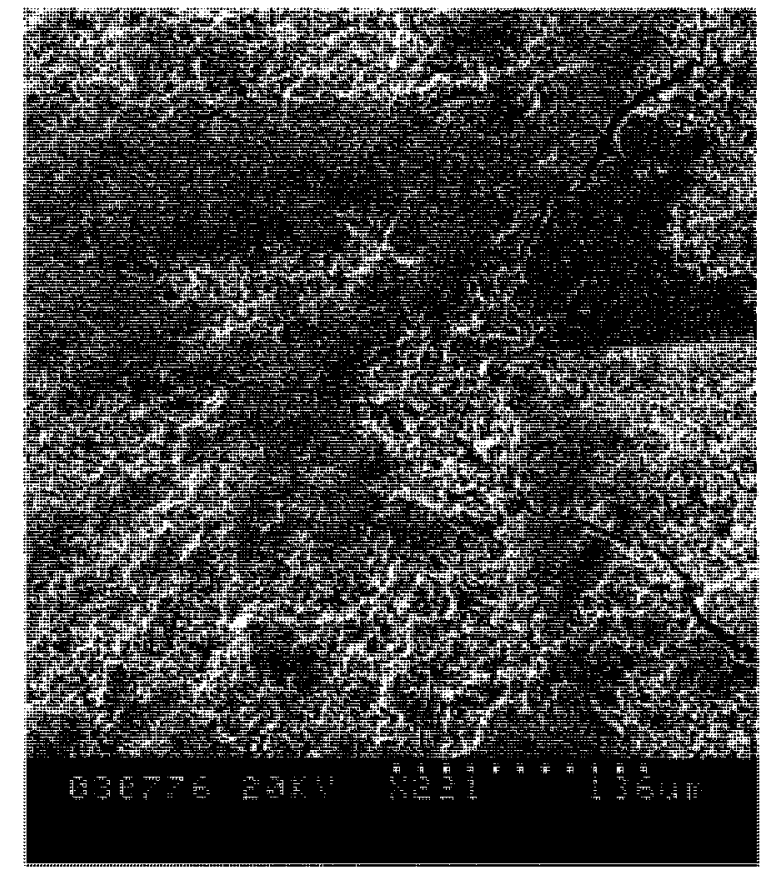

(d)

Figure 3.6 SEM images of indented surface of WC-Co-Cr: (a) under $10 \mathrm{~N}$;

(b) under $35 \mathrm{~N}$; (c) under $100 \mathrm{~N}$ and (d) under $300 \mathrm{~N}$

According to the cracking profiles of specimens WC-Co and WC-Co-Cr under different load levels, one may summarize the steps of the crack development process as:

Step 1: Cracks were initiated in the area around the indentation edges.

Step 2: The edge cracks grew along the indentation edges and also developed deeper.

Step 3: Cracks were initiated at the vertices (corners) of the indentation.

Step 4: The corner cracks grew in both radial direction and the depth direction.

It should be noticed that Step 2 and Step 3 may occur simultaneously, depending on the load level and the coating material. Since hard metals, WC-Co and WC-Co-Cr, are typical brittle materials, their fractured surfaces exhibited obvious brittle failure features. 
However, for the Tribaloy alloy coating, T-800, no obvious edge cracks and corner cracks were found in the coating surface, whether the load was low or high. No cracks were observed in the indented surface under the load below $500 \mathrm{~N}$, see Figures 3.7 - 3.9. Under high loads only micro or small cracks were observed in the areas of the indentation edge and indentation corner. Even under the highest load of $700 \mathrm{~N}$, no obvious cracking was observed in this specimen, see Figures 3.10 and 3.11. Therefore, compared with the WC hard metals, the Tribaloy alloy T-800 exhibited higher resistance to cracking/fracture.

Indentation edge

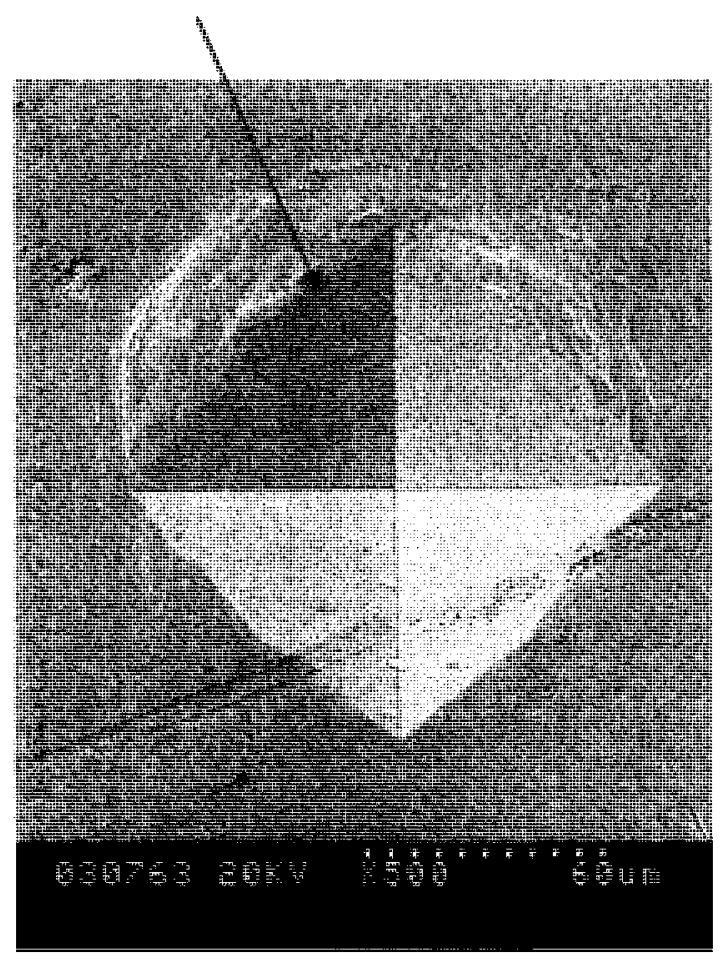

(a)
Indentation corner

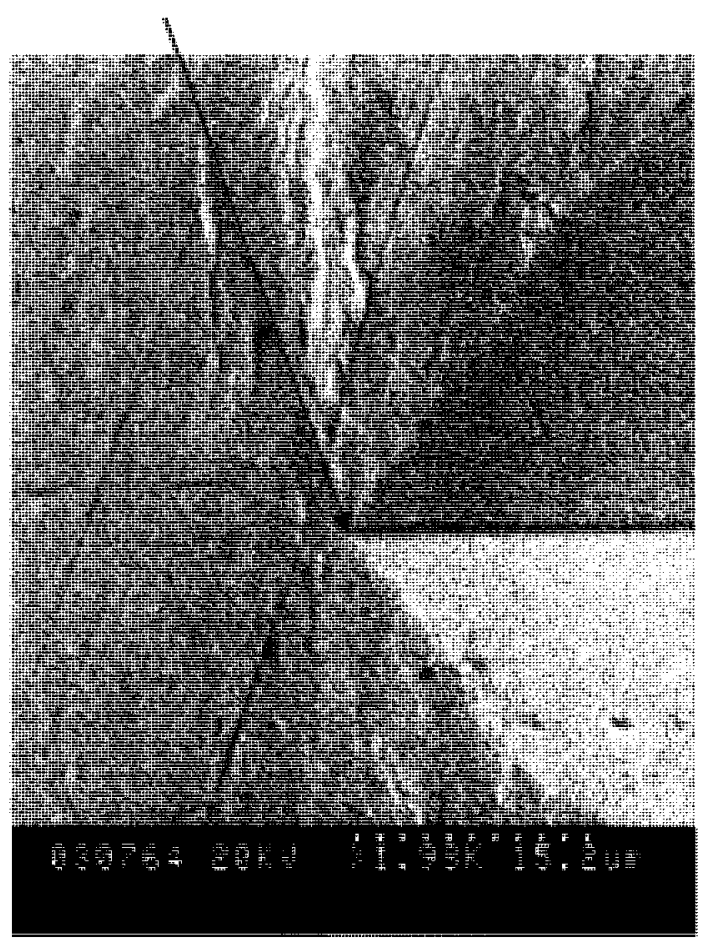

(b)

Figure 3.7 SEM images of indented surface of T-800 under $10 \mathrm{~N}$ : (a) no cracks at indentation edges and (b) no cracks at indentation corner 


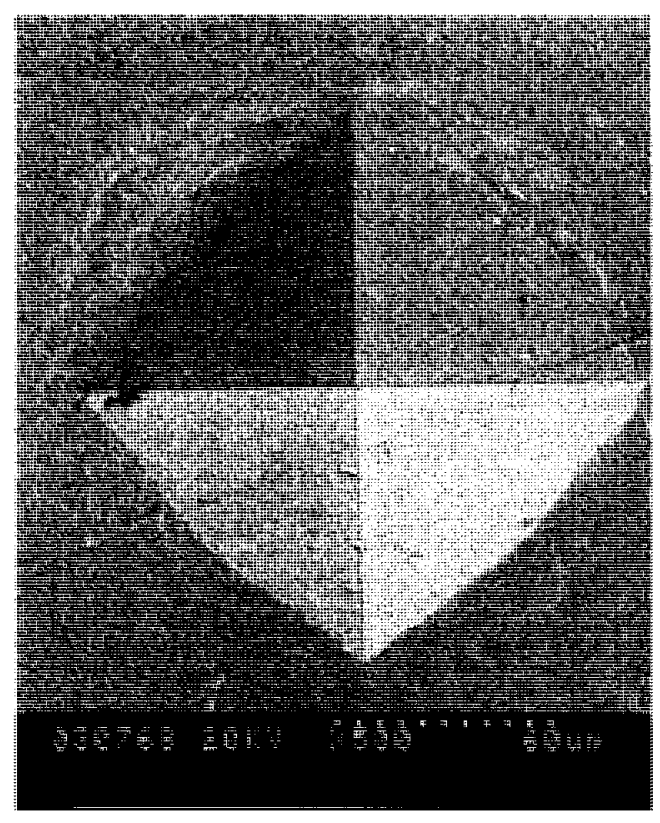

(a)

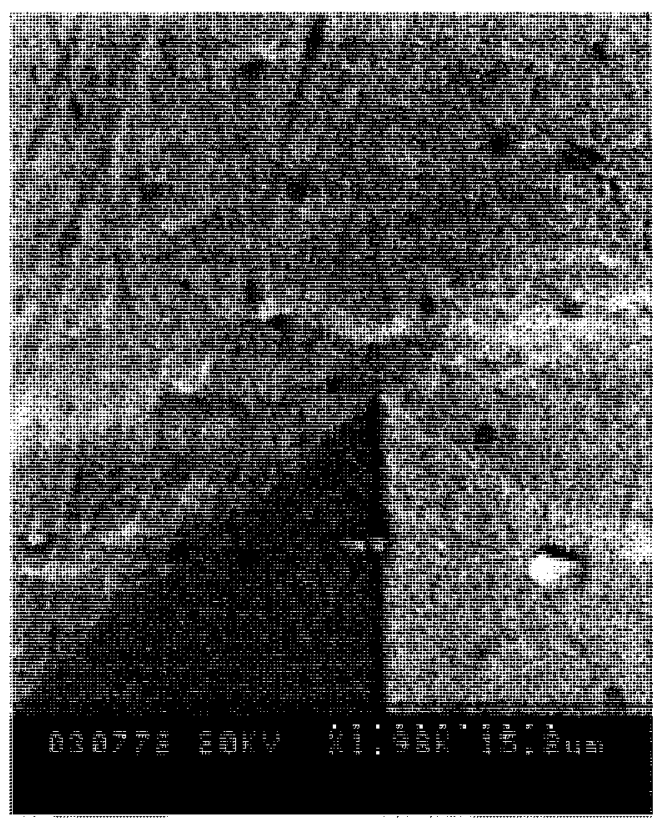

(b)

Figure 3.8 SEM images of indented surface of T-800 under $35 \mathrm{~N}$ : (a) no cracks at indentation edges and (b) no cracks at indentation corner

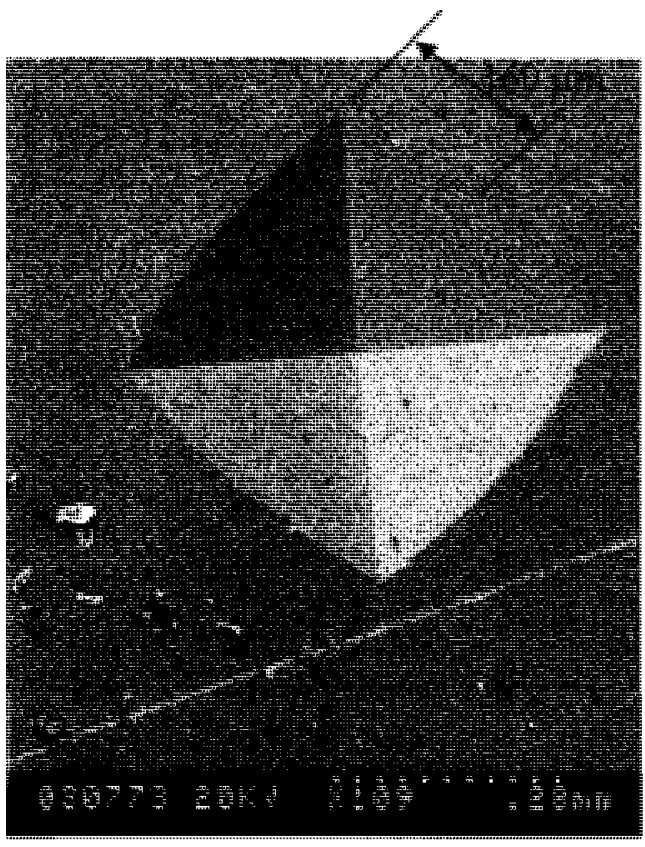

(a)

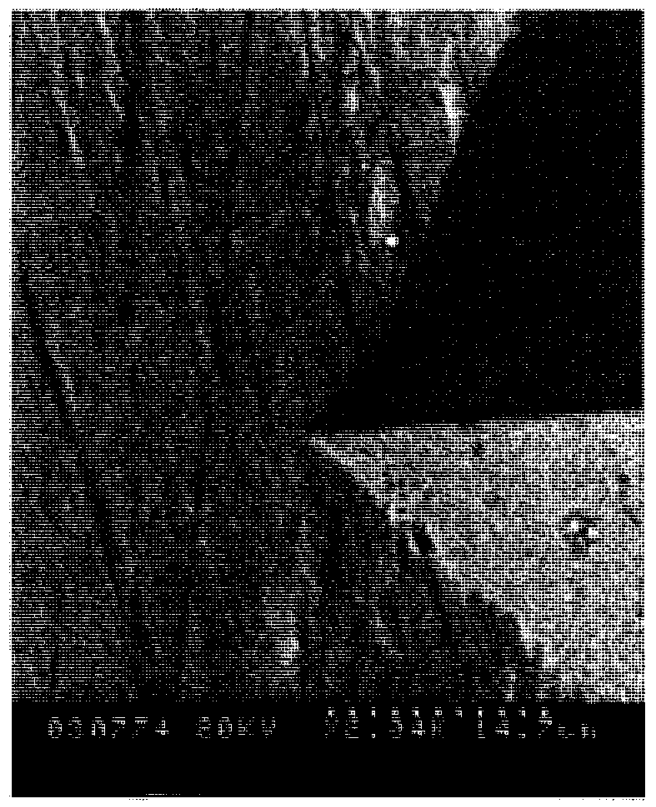

(b)

Figure 3.9 SEM images of indented surface of T-800 under $100 \mathrm{~N}$ : (a) no cracks at indentation edges and (b) no cracks at indentation corner 


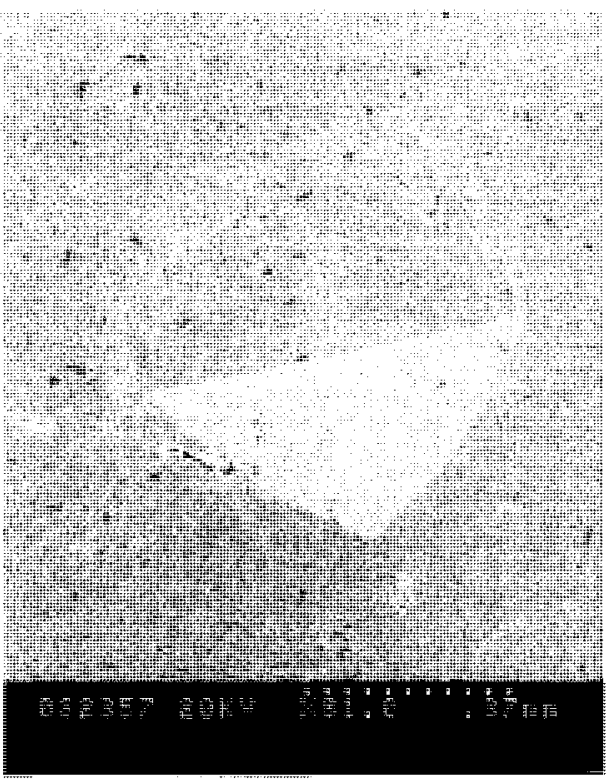

(a)

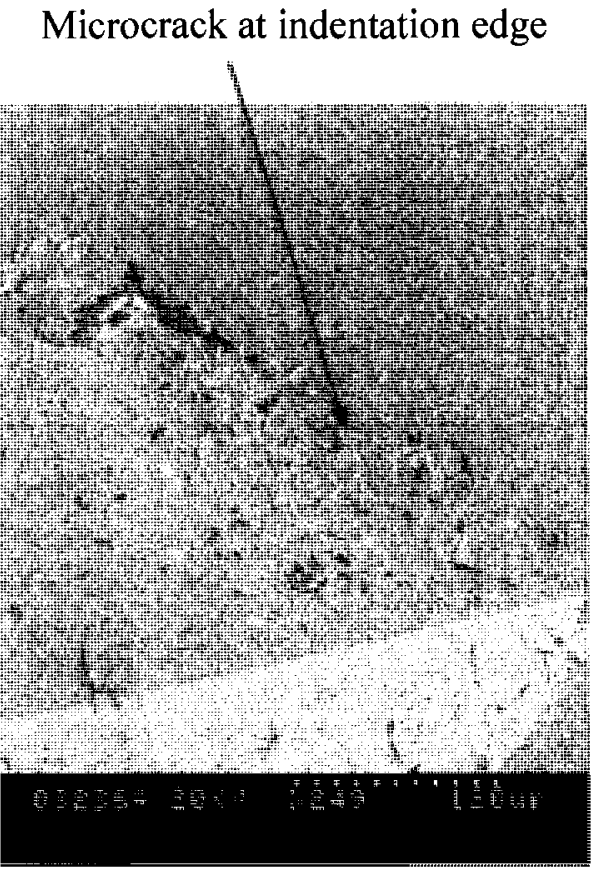

(b)

Figure 3.10 SEM images of indented surface of T-800 under $500 \mathrm{~N}$ : (a) no obvious cracking at indentation edges and (b) microcracks at indentation edge

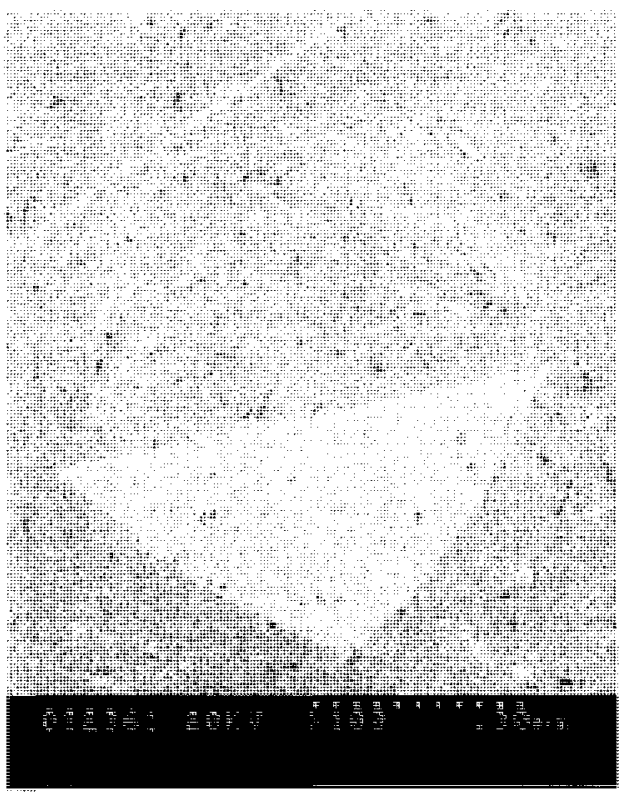

(a)

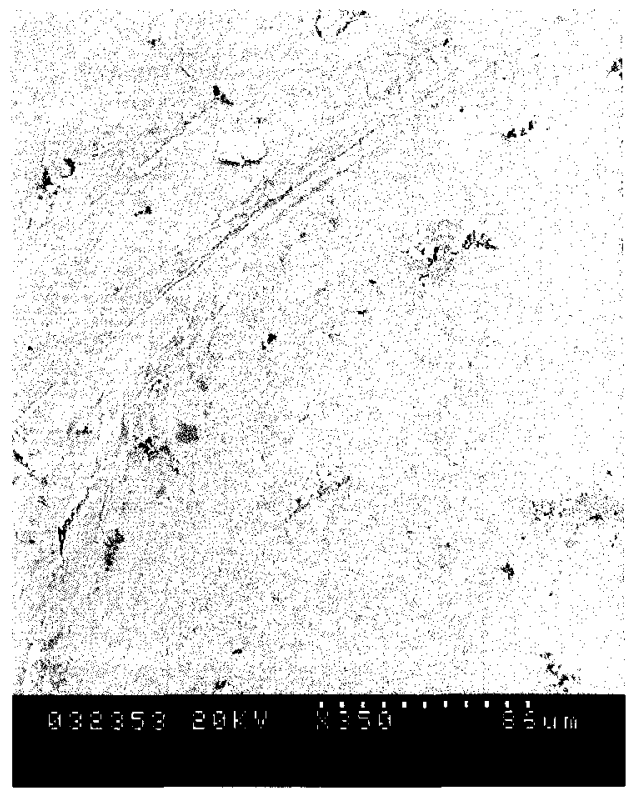

(b)

Figure 3.11 SEM images of indented surface of T-800 under $700 \mathrm{~N}$ : (a) no obvious cracking at indentation edges and (b) microcracks at indentation edge 
Unlike the brittle coatings, the superalloys Nistelle C and Nistelle Super C have better ductility, as reported [124], therefore, specimens Nistelle C-propylene, Nistelle Super C-propylene, Nistelle C-hydrogen and Nistelle Super C-hydrogen did not exhibit the brittle fracture behavior as specimens WC-Co and WC-Co-Cr did. It was observed that the indented surfaces of the four superalloy coatings had similar features and no significant difference between them was found. As seen in Figures $3.12-3.19$, they have the following two common features:

(1) Whether under a low load or under a high load, no significant cracking or fracture was observed, even in the indentation edge region and in the indentation corner region.

(2) Micro or small cracks were found in the regions of indentation edge and indentation corner under high loads.

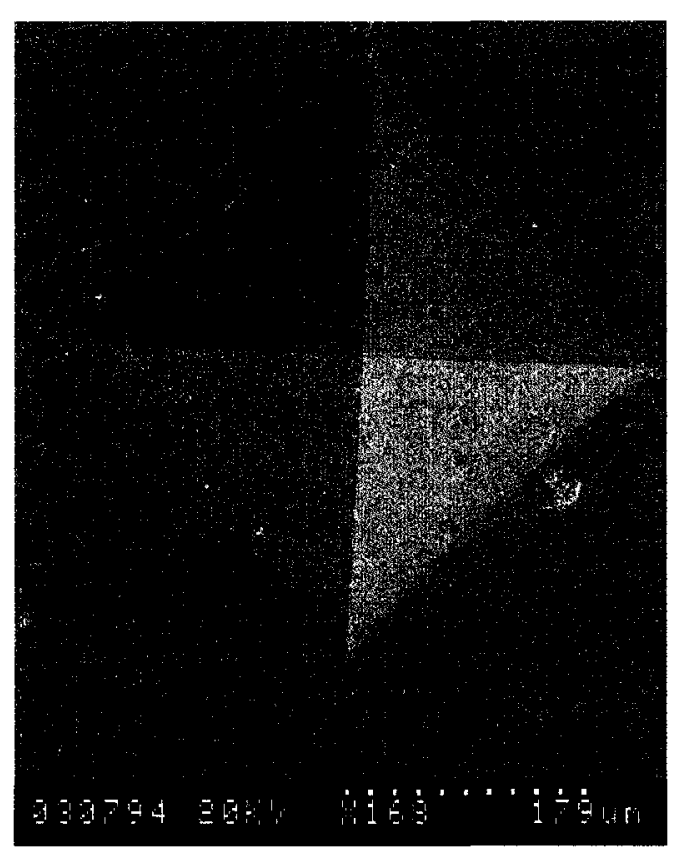

(a)

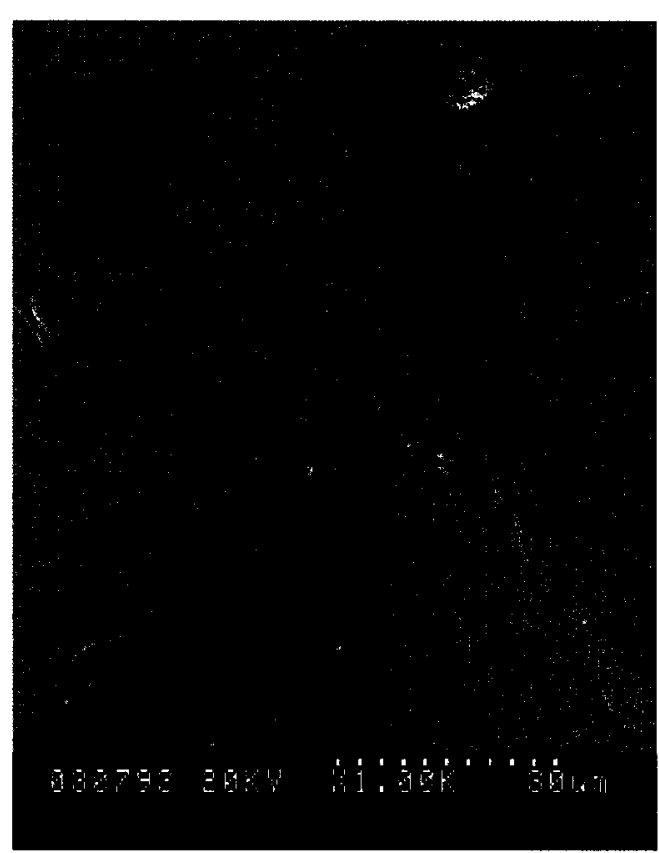

(b)

Figure 3.12 SEM images of indented surface of Nistelle C-propylene under $100 \mathrm{~N}$ :

(a) overall indentation area and (b) indentation edge and corner areas 


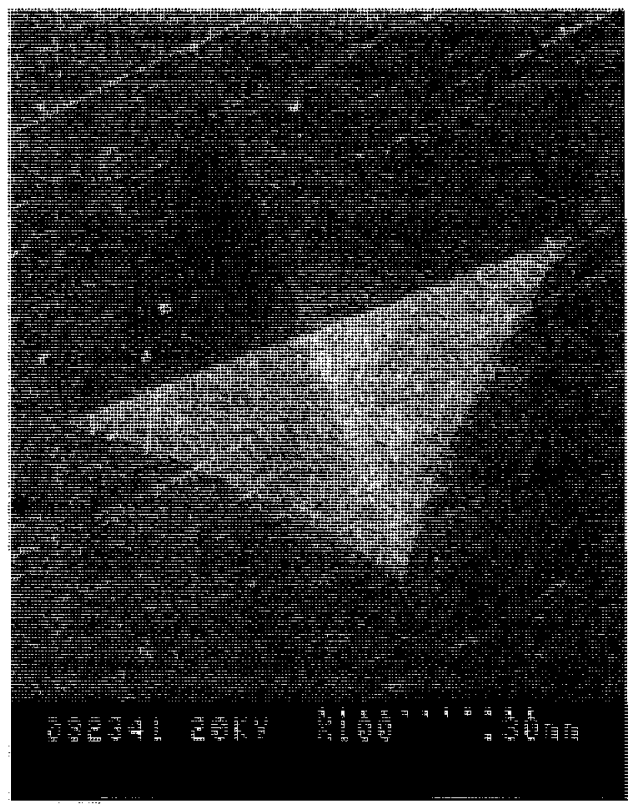

(a)

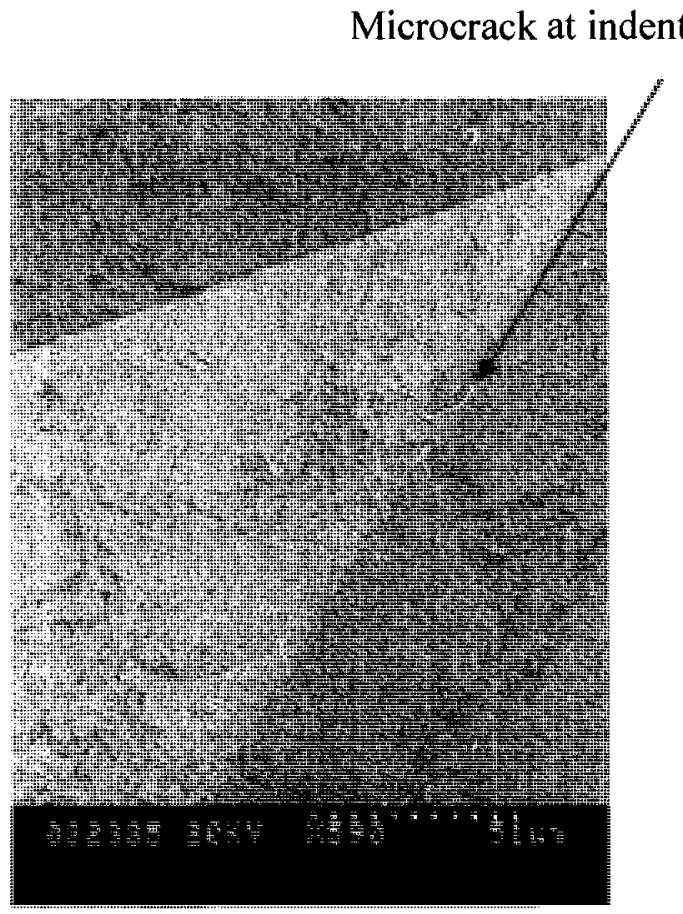

(b)
Microcrack at indent corner

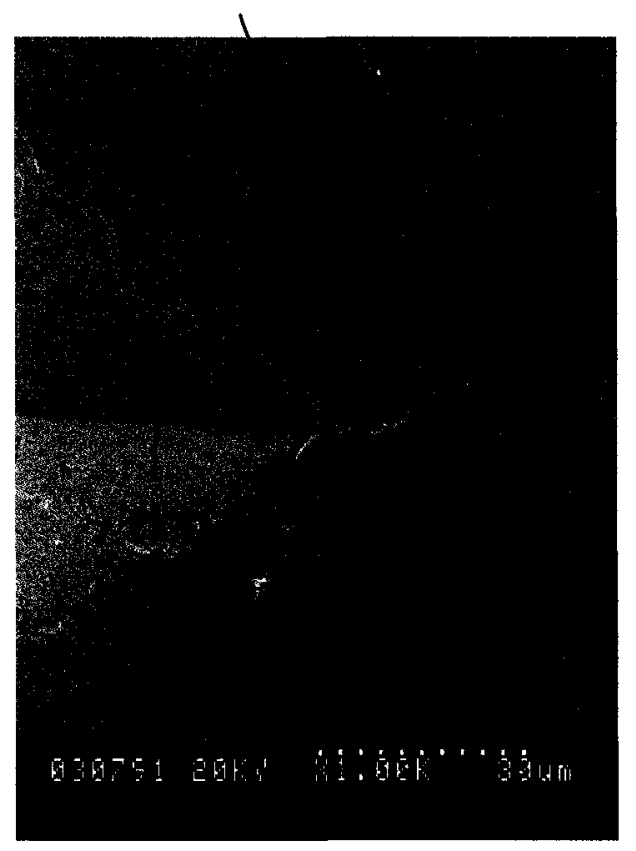

(c)

Figure 3.13 SEM images of indented surface of Nistelle C-propylene under $700 \mathrm{~N}$ :

(a) overall indentation area; (b) indentation edge area and (c) indentation corner area 


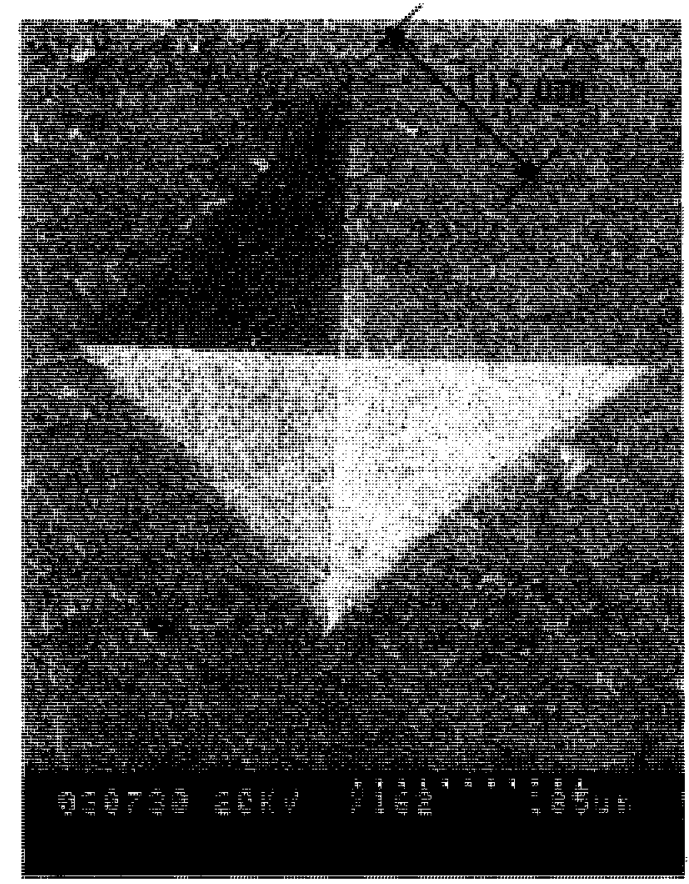

(a)

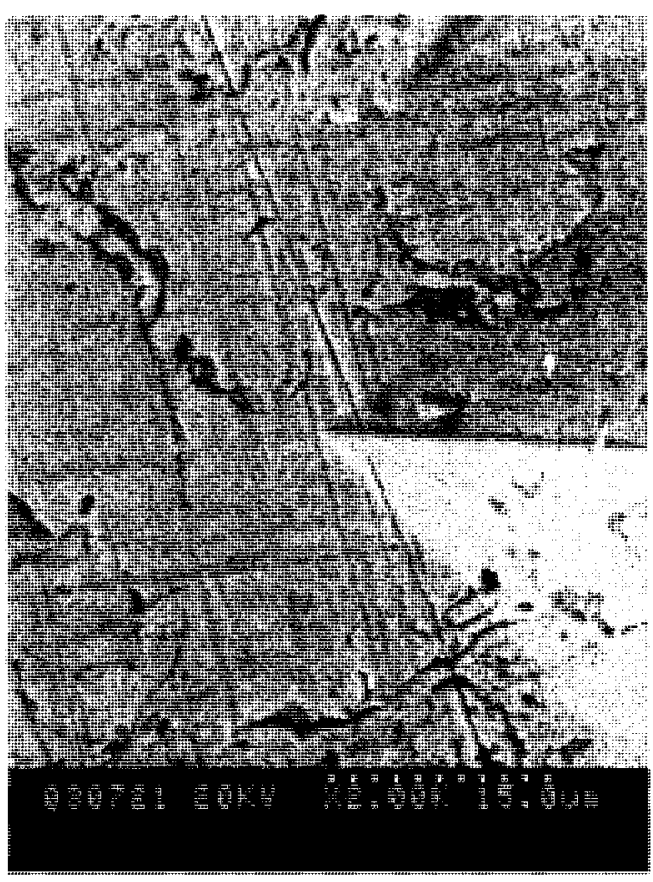

(b)

Figure 3.14 SEM images of indented surface of Nistelle Super C-propylene under $100 \mathrm{~N}$ :

(a) overall indentation area and (b) indentation edge and corner areas

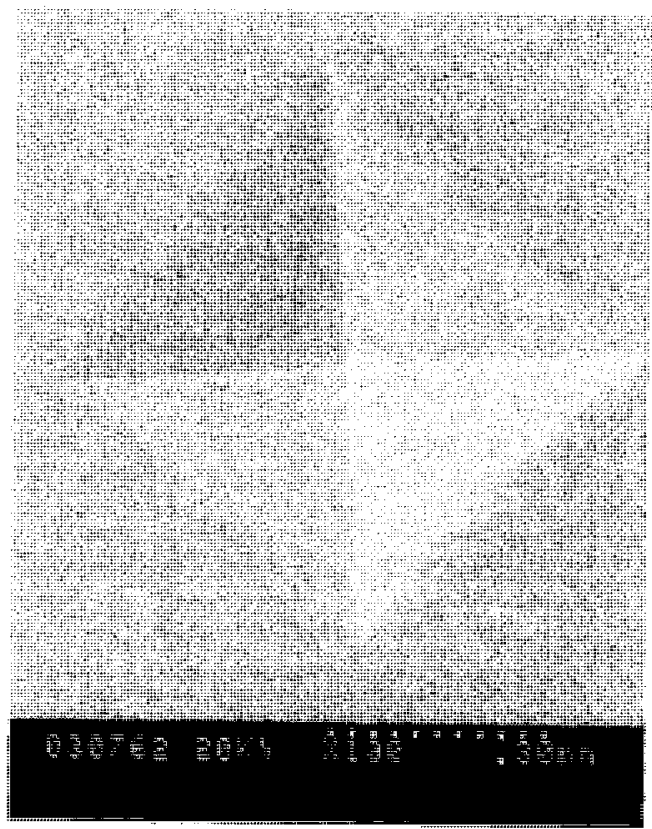

(a) 


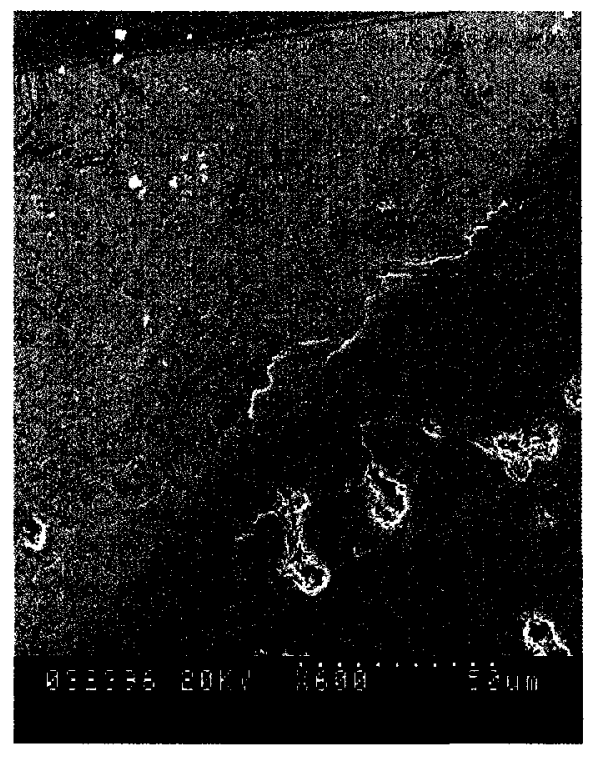

(b)

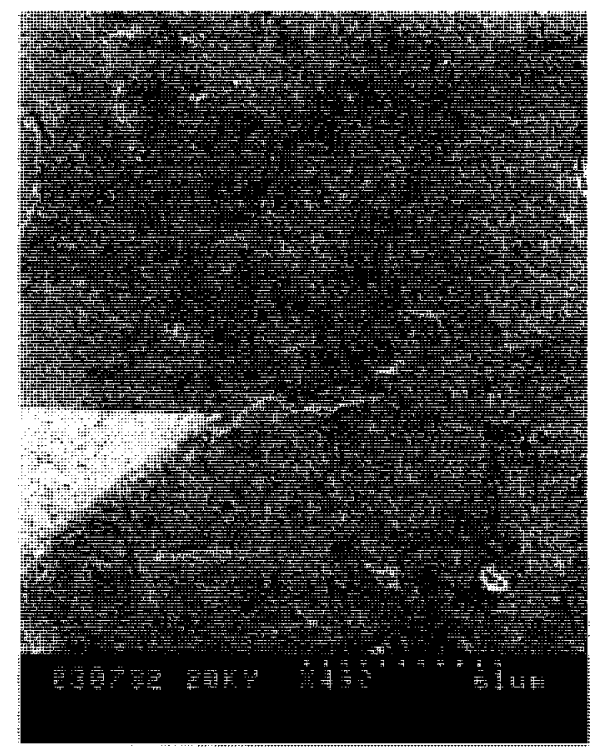

(c)

Figure 3.15 SEM images of indented surface of Nistelle Super C-propylene under $700 \mathrm{~N}$ : (a) overall indentation area; (b) indentation edge area and (c) indentation corner area

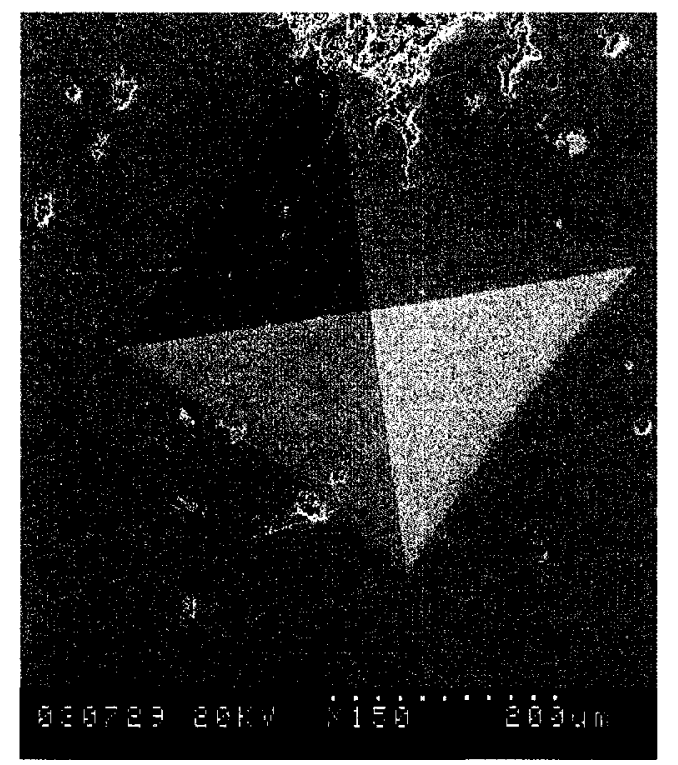

(a)

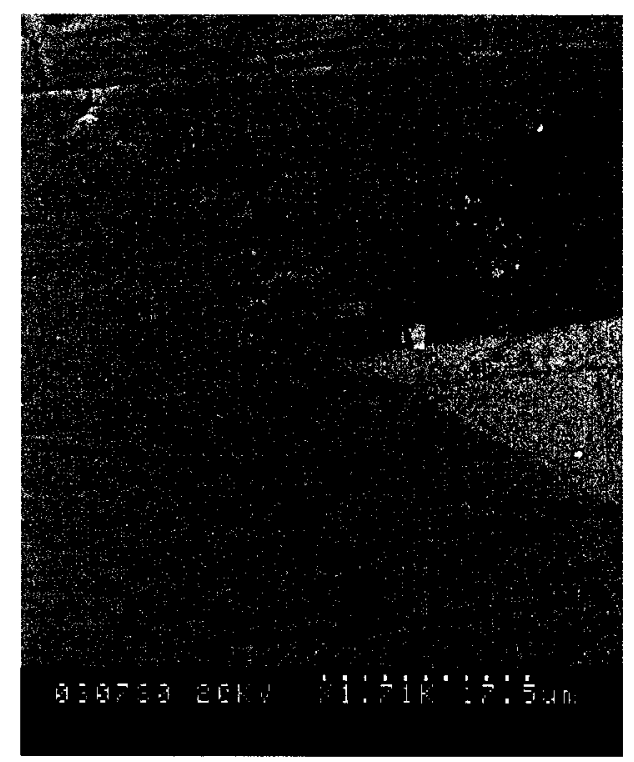

(b)

Figure 3.16 SEM images of indented surface of Nistelle C-hydrogen under $100 \mathrm{~N}$ :

(a) overall indentation area and (b) indentation edge and corner areas 


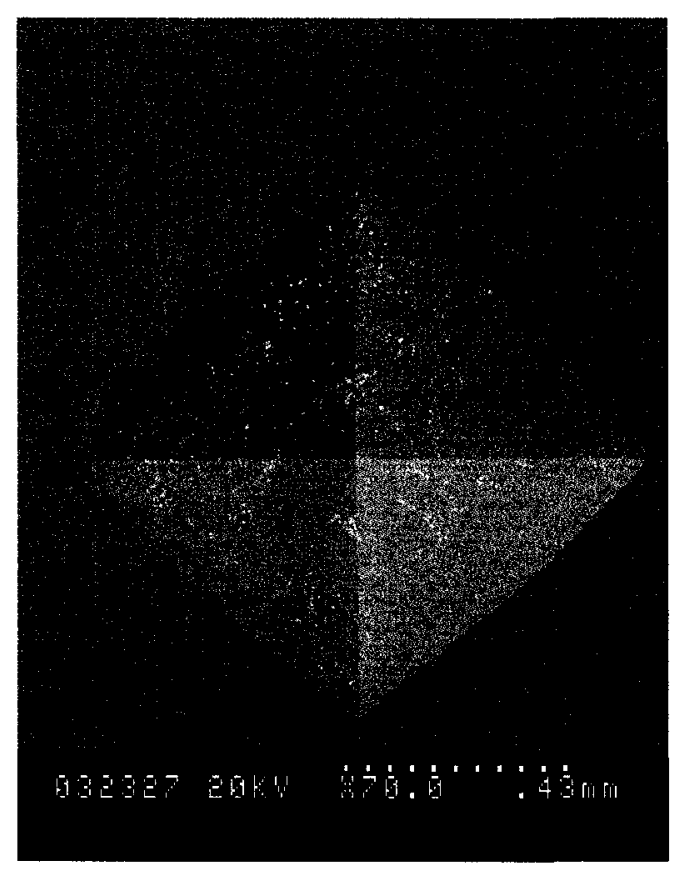

(a)

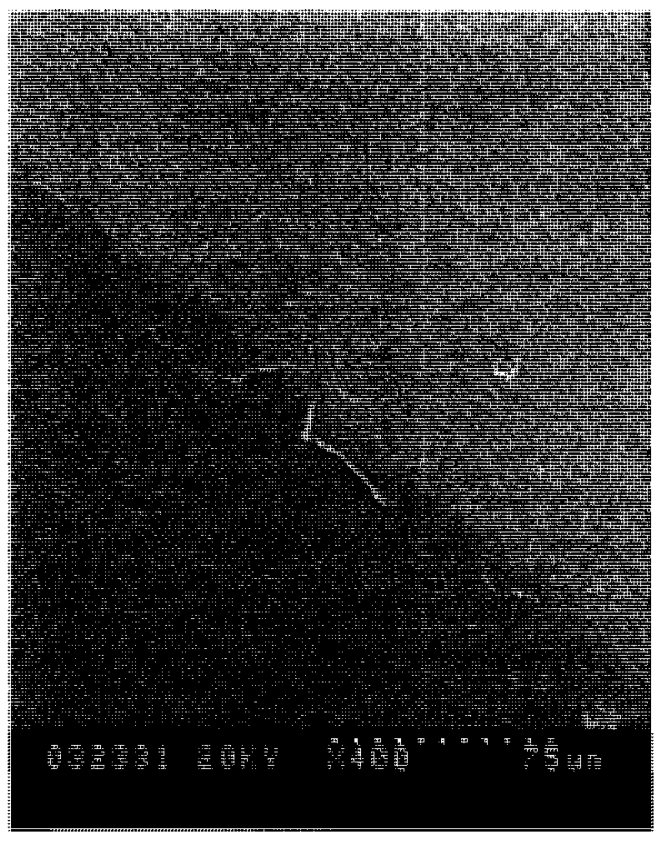

(b)

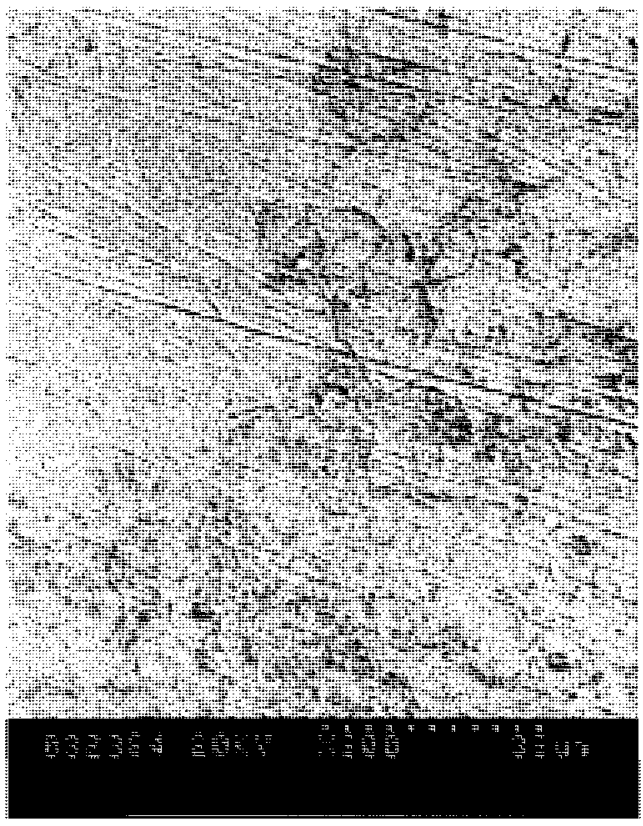

(c)

Figure 3.17 SEM images of indented surface of Nistelle C-hydrogen under $700 \mathrm{~N}$ :

(a) overall indentation area; (b) indentation edge area and (c) indentation corner area 


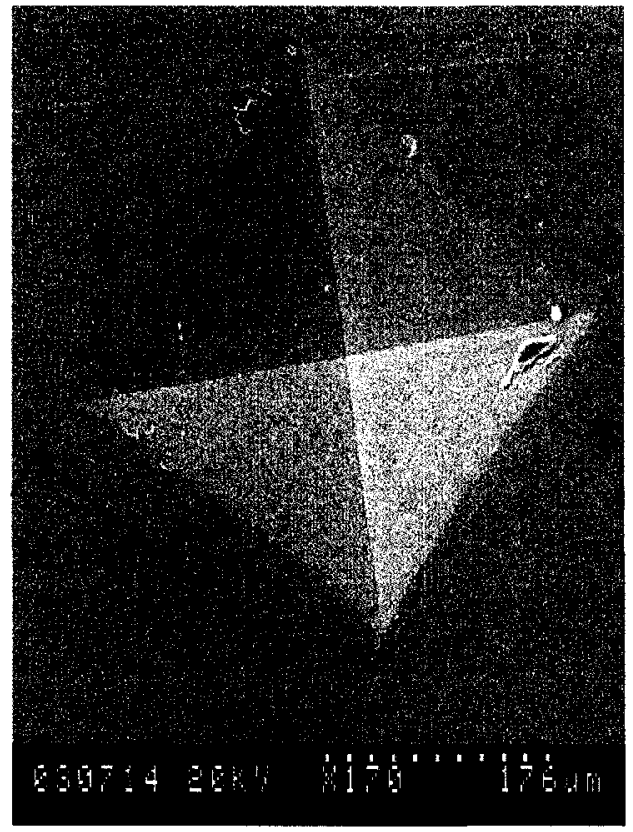

(a)

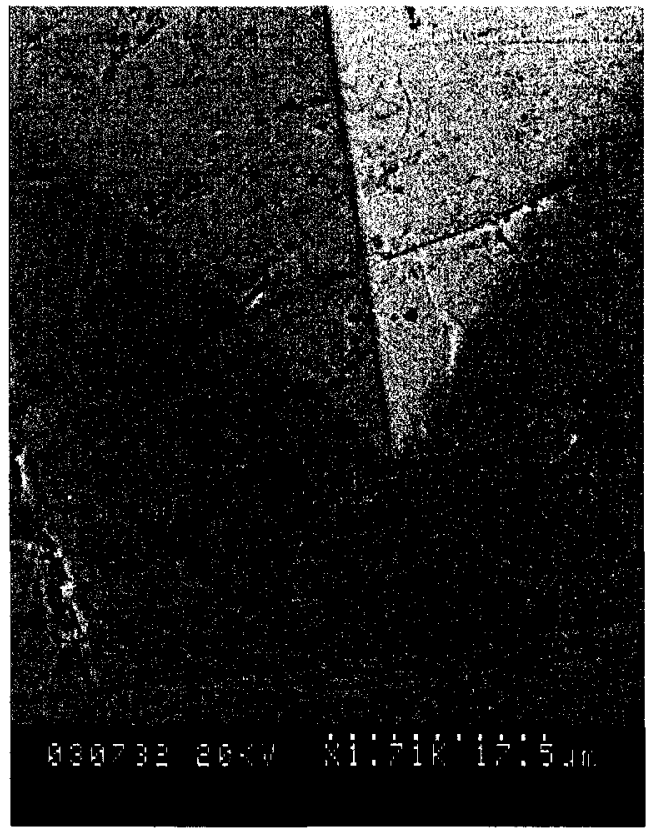

(b)

Figure 3.18 SEM images of indented surface of Nistelle Super C-hydrogen under $100 \mathrm{~N}$ : (a) overall indentation area and (b) indentation edge and corner areas

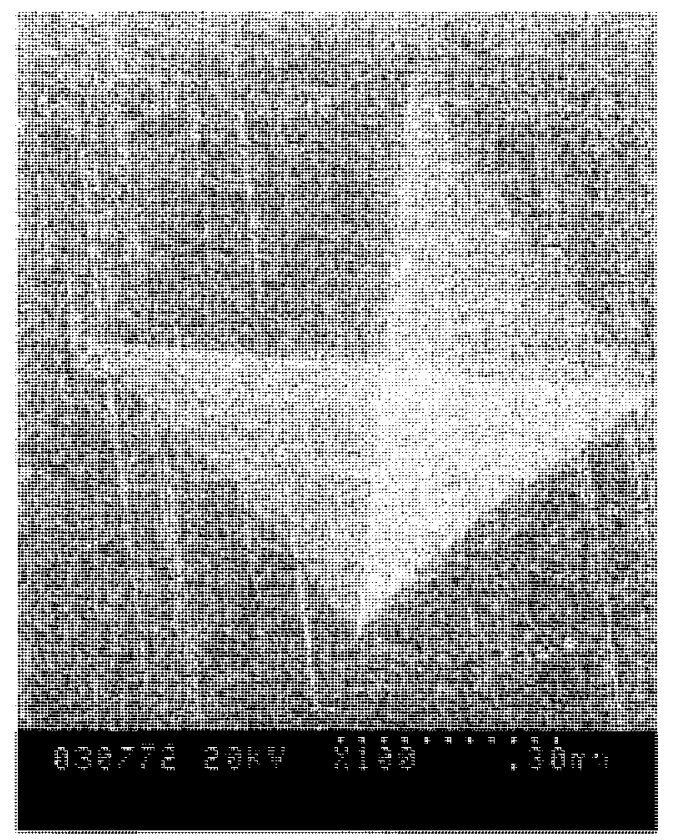

(a) 


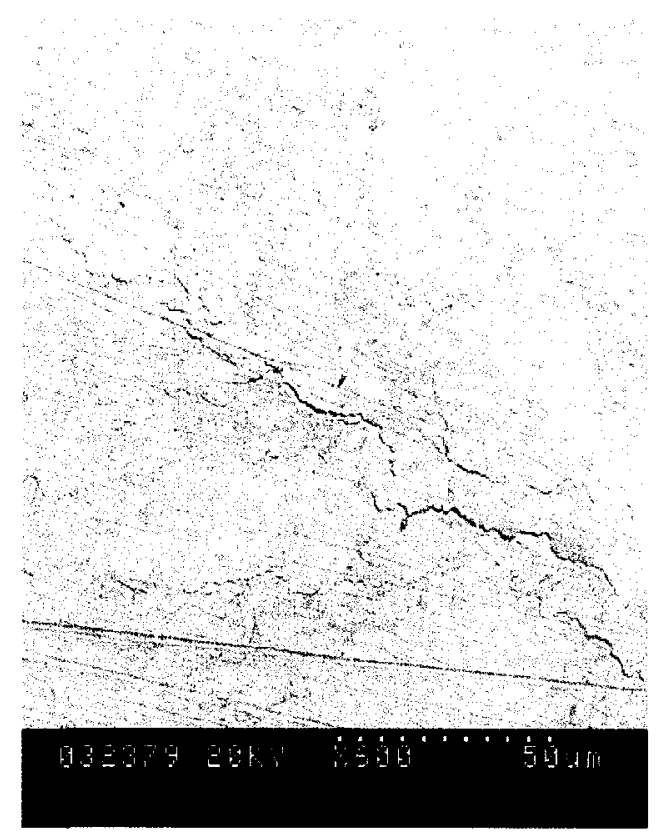

(a)

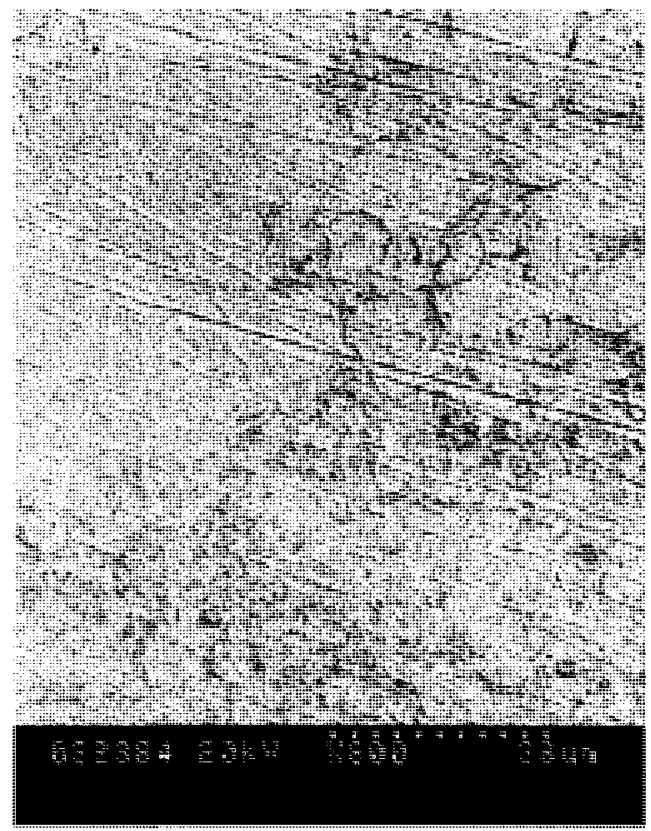

(b)

Figure 3.19 SEM images of indented surface of Nistelle Super C-hydrogen under $700 \mathrm{~N}$ :

(a) overall indentation area; (b) indentation edge area and (c) indentation corner area

Based on the observation of the indented surfaces in the Vickers indentation test, the cracking/fracture behavior of the seven coating specimens can be summarized as below. The seven specimens behaved differently under the indentation loads. The hard metal coatings exhibited lowest fracture strength; even under low loads the coatings totally fractured. Cracking occurred firstly in the indentation edge area; the indentation corner area was cracked with increasing the indentation load. The crack at the indentation edge propagated along the indentation edge and that at the indentation corner grew radially with an increased load. The Tribaloy alloy coating exhibited the highest resistance to cracking/fracture among the seven coating specimens; no obvious cracking was observed in this specimen even under the highest load. Only small or micro cracks were found at the indentation edges and the 
indentation corners in the coating surface under high indentation loads. The superalloy coatings also exhibited high fracture strength, compared to the hard metal coatings. They behaved similarly to the Tribaloy alloy coating; no significant cracking occurred in these coatings, but only micro or small cracks were found in the indentation edge and indentation corner areas when the specimens were highly loaded. 


\section{CHAPTER 4 FINITE ELEMENT ANALYSIS}

\subsection{Simulation of Vickers Indentation Test}

\subsubsection{Problem Description}

In order to investigate the fracture mechanisms of the coating specimens under Vickers indentation test and associate the cracking profiles with the stress fields in the coating systems, three-dimensional FEA modeling was conducted simulating the Vickers indentation process. The model was generated by a square-based pyramid shape indenter loaded on the coated surface, corresponding to the indentation test. The model consists of a rigid indenter and a deformable-coated specimen (coating and substrate). The indenter was loaded on the coated surface under a normal force and an indentation mark was created, corresponding to the magnitude of the applied load in the Vickers indentation test. The stress field in the indentation area was determined, which was related to the cracking profile observed in the indentation test. The FEA results were expected to predict the locations where cracks might occur and also the critical loads for the cracks.

To simplify the FEA models, the following important assumptions were made in the FEA simulation:

(1) The coating surface was flat and smooth; roughness was ignored.

(2) The coating layer and the substrate were solid cohesively joined with a zero-thickness interface, that is, the interface was planar without thickness. This was based on a cross section examination under SEM, see Figure 3.1. 
(3) The interface between the coating and the substrate was a flat plane, although, in reality, the interface was not exactly flat or smooth but rugged, as shown in Figure 3.1.

(4) Based on linear elastic fracture mechanics, the coating materials were considered to deform elastically only; plastic deformation was not considered in the modeling although it may occurs in the materials under indentation. But the substrate material, AISI 1080 low carbon steel, deformed elastically and plastically, because it is more ductile compared with the coating materials.

\subsubsection{Indenter-tip Geometry}

In the Vickers indentation test, the load was applied to the coating surface through an indenter. The contact between the indenter and the coating surface was treated as a non-linear 'contact' problem in the FEA modeling. The geometry of the indenter used in this research is based on the shape of a standard Vickers indenter [124], which has an angle of $136^{\circ}$ between

opposite faces. The precise measure of the indenter geometrical dimension under an optical microscope is shown in Figure 4.1(a), which is a side review. The base side length was measured to be $1.201 \mathrm{~mm}$ with $0.345 \mathrm{~mm}$ of height and $68^{\circ}$ draft angle. The tip of the indenter, however, is not actually sharp; it should be a very small square instead. The side length of the indenter tip can be measured from the top view of the indenter tip, as shown in Figure 4.1(b). It is approximately $12.5 \mu \mathrm{m}$.

It should be mentioned that the geometry of the indenter tip has influence on the stress distribution in the coating/substrate system, because it would determine the size of the contact area between the indenter tip and the coating surface. However, since the indenter tip area is far from the indentation edges and corners where cracks are initiated and the coating 
has a high compressive stress near the indenter tip, the stress field near the indenter tip is not critical to the cracking.

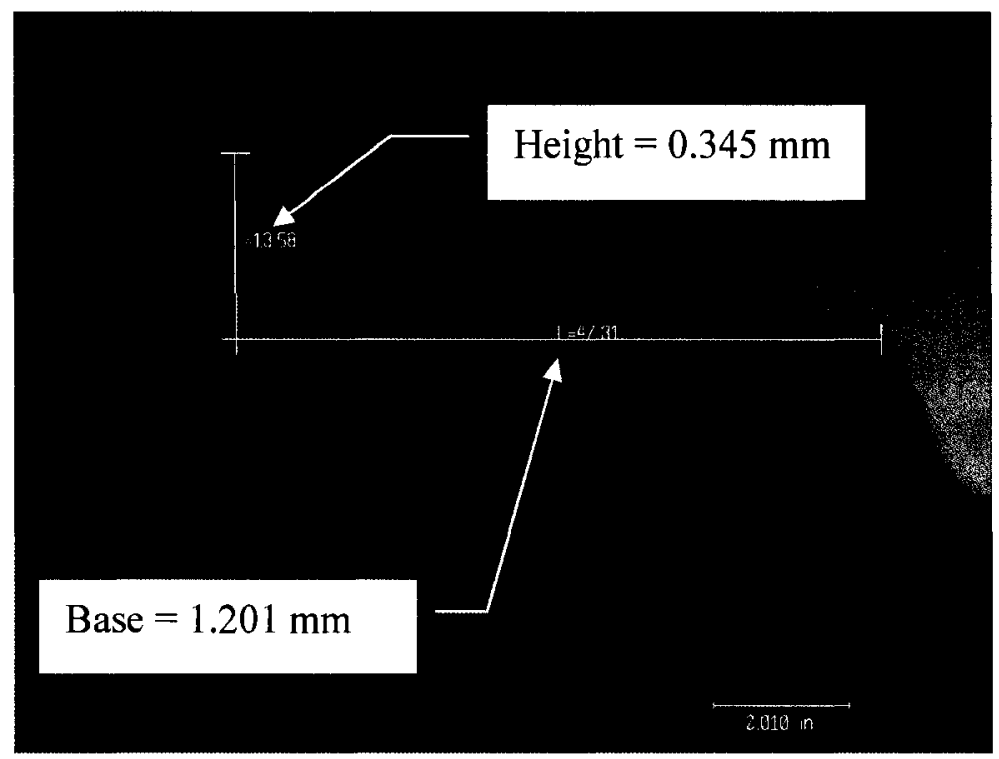

(a)

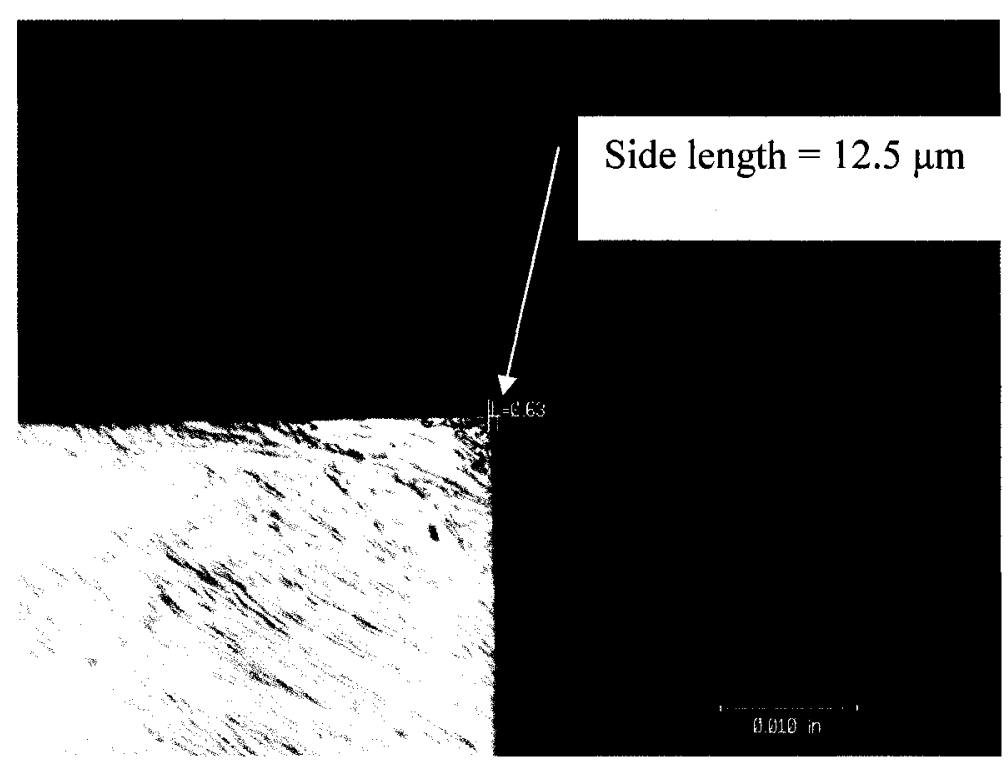

(b)

Figure 4.1 Indenter-tip geometry under an optical microscope:

(a) side view and (b) top view 


\subsection{Construction of FEA Models}

\subsubsection{Geometrical Models}

The Vickers indentation test on the coating specimens was simulated with three-dimensional models using the commercial FEA software package ABAQUS/CAE version 6.5.1. Both the coating and substrate materials were considered solid and homogenous. Due to the geometrical and loading symmetry, the problem was solved by modeling a quarter of the coating/substrate system, as shown in Figure 4.2. The 1-, 2- and 3axes intersect at the indenter tip, which correspond to the $x-, y$ - and $z$ - coordinate axes, respectively. Three planes were also defined, as shown in Figure 4.2.

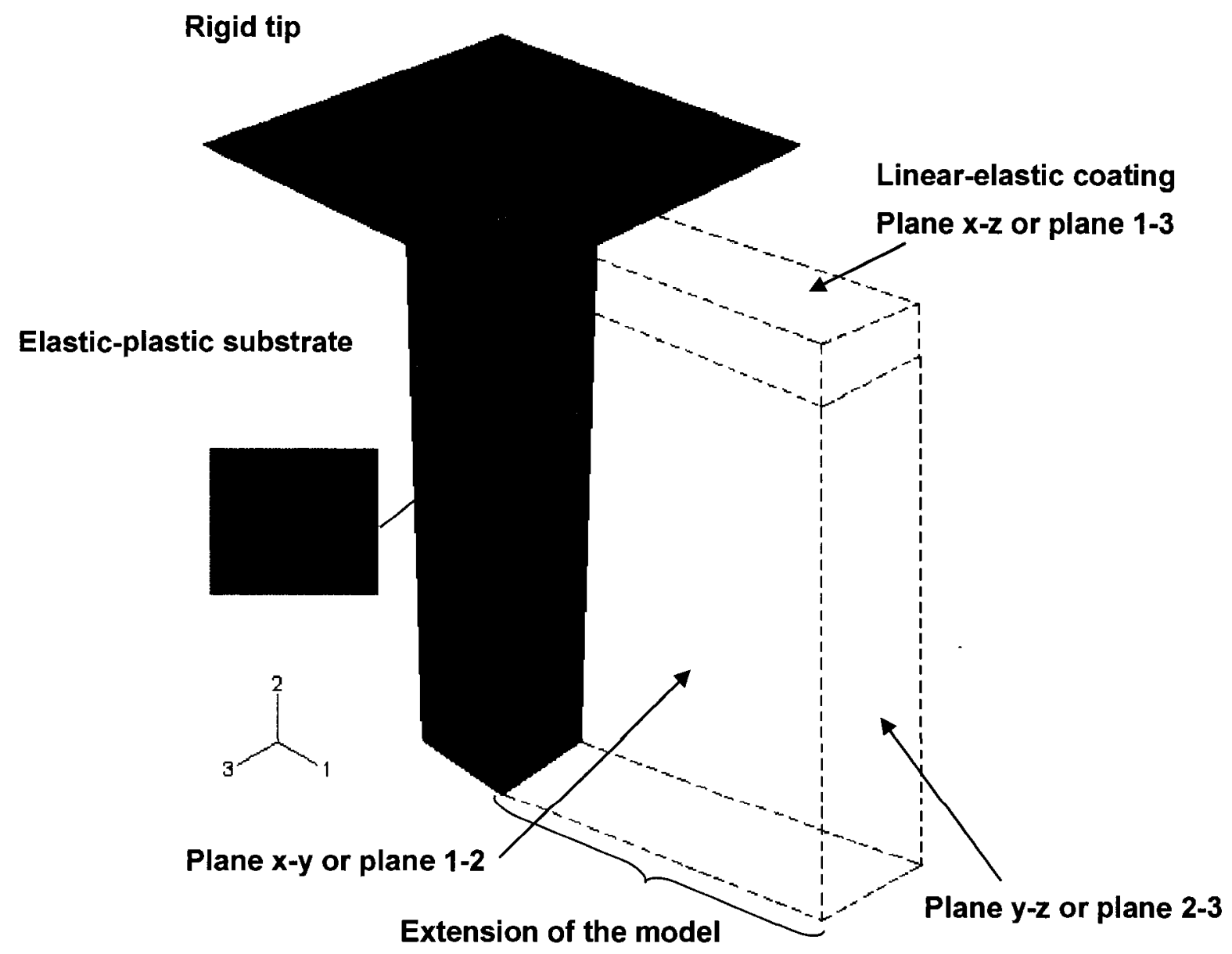

Figure 4.2 FEA model of a coating/substrate system under Vickers indentation test 
The volume of the substrate was fixed by $0.6 \times 0.6 \times 3 \mathrm{~mm}$ (length, width, thickness) for all the coating specimens. This dimension was determined such that compared with the dimension of the indenter the boundary constraint of the volume would not affect the stress results in the region of the indenter. The indenter tip was modeled as a truncated four-sided pyramid. The mesh of the model was constructed using a twenty-node quadratic brick, reduced integration element. The substrate contained 81773 nodes with 18671 hexahedral elements, whereas the coating contained 36102 nodes and 7201 hexahedral elements. The meshing element size at the localized region of the indentation on the coating surface was very small; $0.010 \mathrm{~mm}$, while for the meshing element that crossed the coating thickness, the size was only one to the sixth of the coating thickness, that is, $0.050 \mathrm{~mm}$ for $0.3 \mathrm{~mm}$ coatings and $0.067 \mathrm{~mm}$ for $0.4 \mathrm{~mm}$ coatings. The element size was increased gradually from the indenter region to the coating boundary in 1 - direction and 3- direction, and from the interface to the substrate bottom in 2- direction, see Figure 4.2.

The five coating specimens (fuel gas effect on the Nistelle $\mathrm{C}$ and Nistelle Super $\mathrm{C}$ coatings was not considered in the FEA simulation) used the same volume of the substrate, but the thicknesses of the coatings are not the same. As measured under SEM in Figure 3.1, the coating thickness varied from approximately $0.3 \mathrm{~mm}$ for $\mathrm{WC}-\mathrm{Co}$, WC-Co-Cr, and T-800 specimens, and to approximately $0.4 \mathrm{~mm}$ for the Nistelle $\mathrm{C}$ and Nistelle Super $\mathrm{C}$ specimens. 


\subsubsection{Constraint Treatment}

In this model, there are two surface contacts: (1) between the indenter tip and the coating surface, and (2) the interface between the coating and substrate surface. The special surface treatments were employed to simulate the real contact behavior of the surfaces during the indentation test.

To model the strong bond between the coating and the substrate, both were bonded using a "tie" constraint, where the bottom surface of the coating was selected as a "master surface" and the top surface of the substrate as a "slave surface". By bonding the coating and the substrate in a 'tie' constraint, the coating-substrate could be treated as a whole body. Therefore, symmetric boundary conditions were defined for the cutting section of the coating/substrate system under a normal load. In this case, in plane 2-3, the displacement in 1- direction was under symmetric condition (where displacement, $U$ in 1- and rotational displacement, UR in 2- and 3- directions were zero; $\mathrm{U} 1=\mathrm{UR} 2=\mathrm{UR} 3=0$ ), and in plane 1-2, the symmetric condition was experiencing at the 3- direction (displacement, $\mathrm{U}$ in 3-, rotational displacement, UR in 1 - and 2- directions, were zero, U3 $=\mathrm{URI}=\mathrm{UR2}=0$ ), see Figure 4.2. However, the bottom surface and the outside surfaces of the coating-substrate system were fully constrained.

The indenter tip and the coating surface should be allowed to contact dynamically during an indentation test, that is, relative motions between the indenter and coating was allowed. Thus the augmented Lagrangian contact constraint enforcement was employed. Another control that allows a small sliding between two deformable bodies in three 
dimensions is small-sliding control. However, a kinematic constraint is reinforced to the slave surface nodes to restrict penetration into the master surface [125].

The indenter was modeled as a rigid body and placed at the end-corner of the coating/substrate specimen with only $1 / 4$ of the indenter tip's area contacting the coating surface. It was positioned this way because the specimen was assumed to be cut into four parts, where each section would experience equal load and yield the same stress distribution. Similar to the coating-substrate contacting at the interface, small sliding between rigid and deformable bodies was allowed. In augmented Lagrangian surface behavior, a default value of 1 for the stiffness scale factor and $0.1 \%$ penetration tolerance are allowed. In the present model, a static stress analysis was conducted as no velocity was involved during the displacement. The rigid body modes in the indenter were constrained in all directions and moved in 2- direction only.

\subsubsection{Material Properties}

For linear elastic mechanics analysis, only Young's modulus and Poisson's ratio are required for the material properties. The Poisson's ratio was assumed to be 0.3 and the Young's modulus data for the coating and the substrate materials were obtained from the previous research [90], $300 \mathrm{GPa}$ for WC-Co, $310 \mathrm{GPa}$ for WC-Co-Cr, $240 \mathrm{GPa}$ for T-800, $180 \mathrm{GPa}$ for Nistelle C and $200 \mathrm{GPa}$ for Nistelle Super C, respectively. The substrate material is AISI 1080 low carbon steel, the Young's modulus is $250 \mathrm{GPa}$ and the yield stress is $380 \mathrm{MPa}$ [126]. This datum was used in the FEA modeling as the substrate material was considered to deform elastically and plastically. 


\subsubsection{Indentation Load}

For each specimen model, three load levels were used, consistent with the loads employed in the Vickers indentation test. The non-linear simulation in FEA requires a prescribed displacement or a prescribed force. In the present analysis a uniform displacement of the indenter in negative $y$ - direction (-U2) was used to simulate the applied load in the indentation test. The rigid body rotations (UR1, UR2, and UR3) and other normal displacements (U1 and U3) of the indenter were set to zero. The force in y-direction (TF2) was then obtained by adding up the total reaction force of each unique node at the bottom surface of the substrate, caused by the displacement which corresponded to the force load of the indentation test. The TF2 values were compared in accordance to the applied load of the indenter, and thus the displacement of $\mathrm{U} 2$ was adjusted accordingly.

\subsection{Stress Results}

\subsubsection{Maximum Principal Stress}

For brittle fracture analysis maximum principal stress is the major consideration. According to the indentation test results, the hard metal $\mathrm{WC}-\mathrm{Co}$ and $\mathrm{WC}-\mathrm{Co}-\mathrm{Cr}$ specimens fractured at low loads while the Tribaloy alloy T-800 and the superalloy Nistelle C and Nistelle Super C specimens only cracked but not totally fractured even under high loads, the FEA stress results are presented in two groups - low-load group for the hard metal specimens and high-load group for the other specimens. Figures 4.3 and 4.4 illustrate the isometric view of topographical distributions of the maximum principal stress (in $\mathrm{Pa}$ ) for the low-load group and the high-load group, respectively. The vector contours are shown in Figures 4.5 and 4.6. The half of the indentation edge was measured after the computation for 
each specimen, as denoted in Figures 4.3 and 4.4, which are in accordance with the indentation edge lengths measured of the specimens under the indentation test, as seen in Figures 3.2(a), 3.6(a), 3.9(a), 3.12(a), 3.14(a), 3.16(a) and 3.18(a).

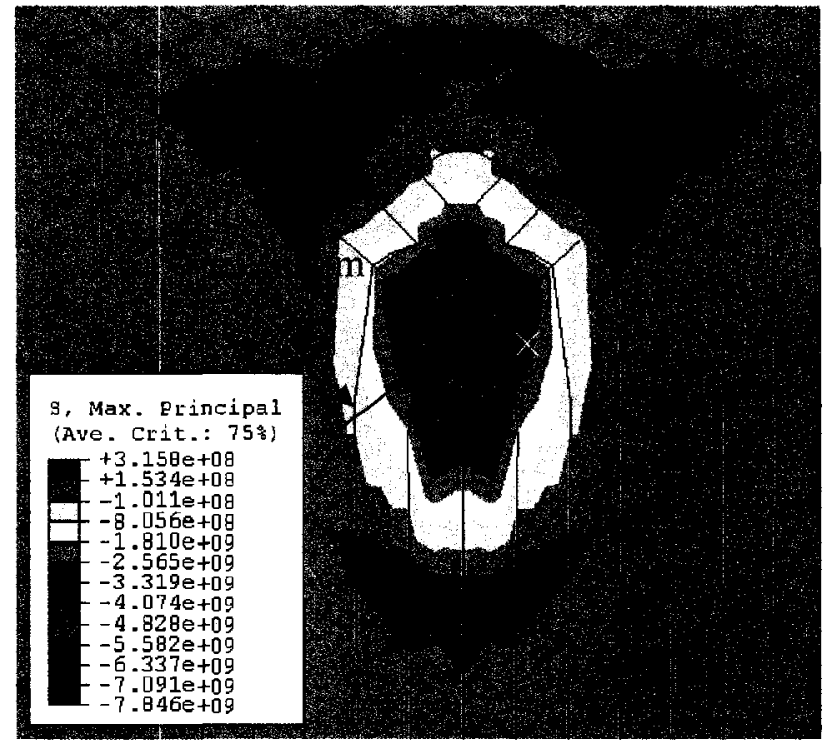

(a)

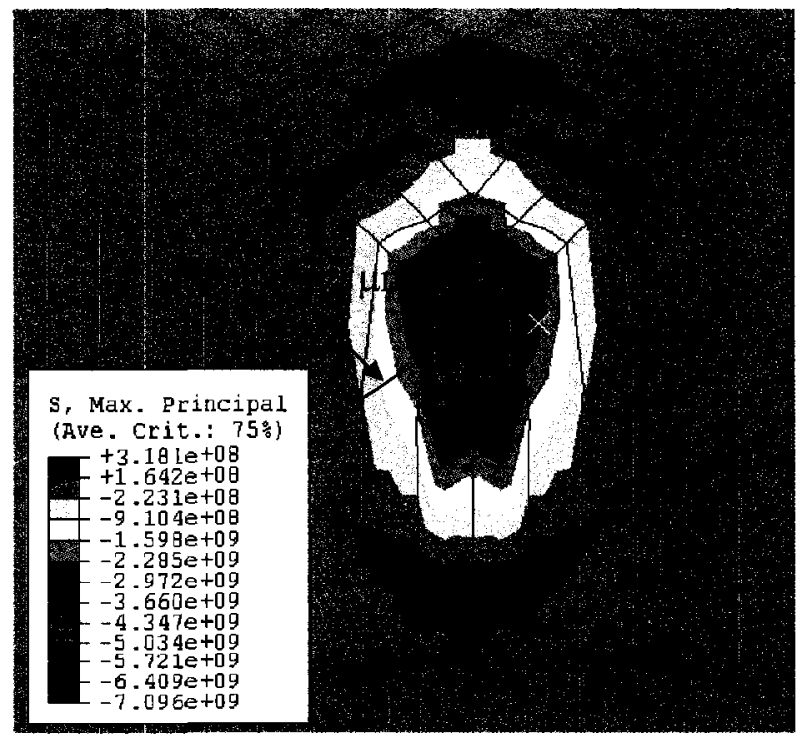

(b)

Figure 4.3 Maximum principal stress under $10 \mathrm{~N}$ : (a) WC-Co and (b) WC-Co-Cr 


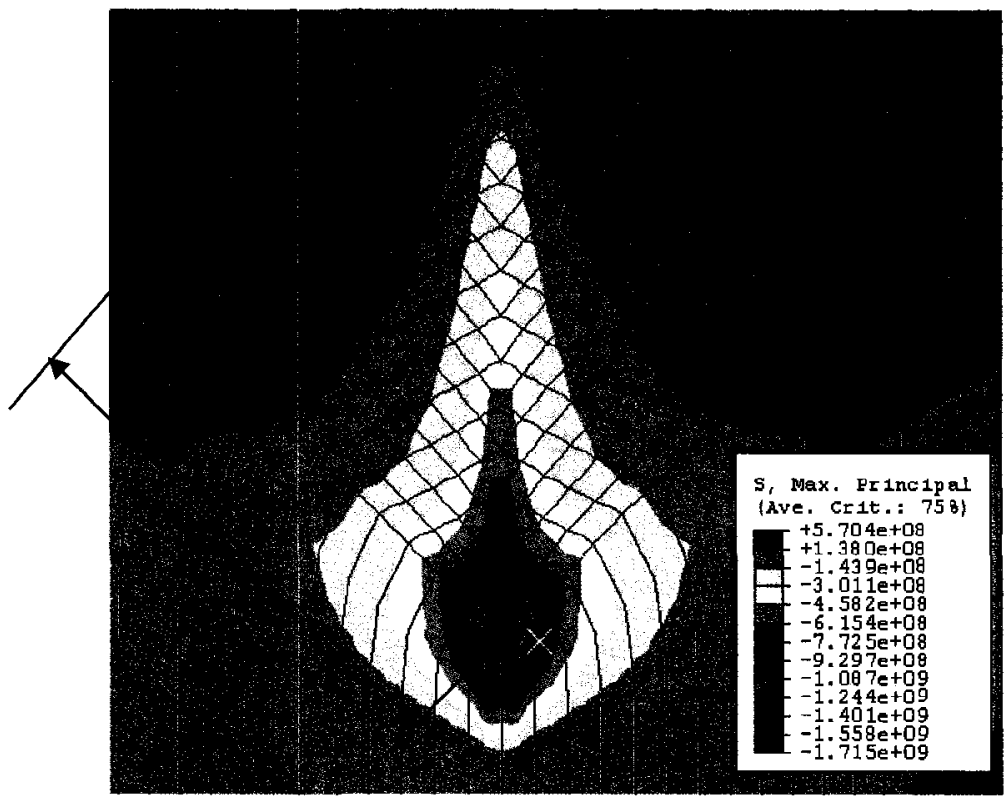

(a)

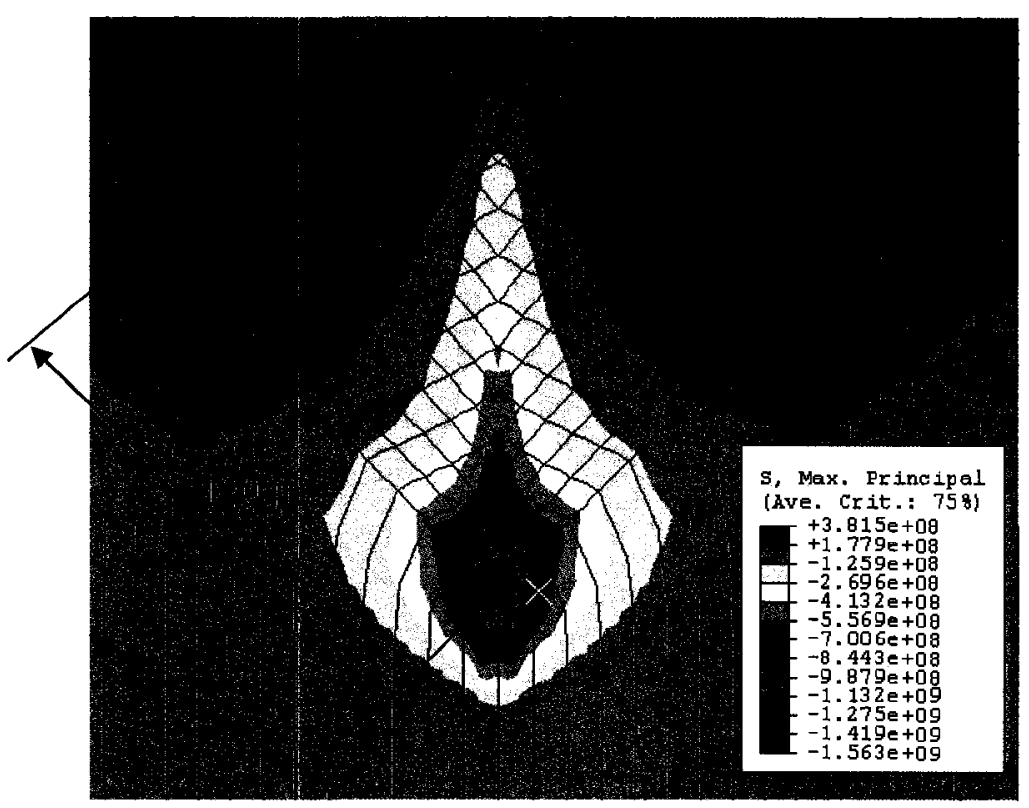

(b) 


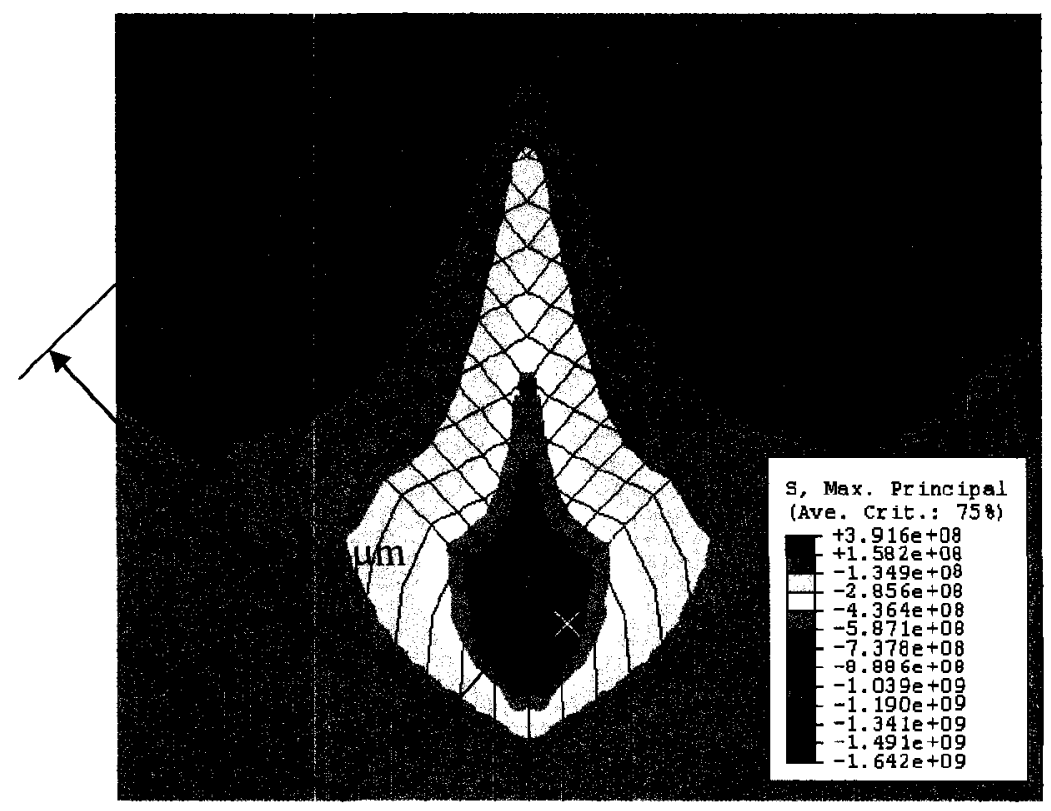

(c)

Figure 4.4 Maximum principal stress under $100 \mathrm{~N}$ : (a) T-800; (b) Nistelle C and (c) Nistelle Super C

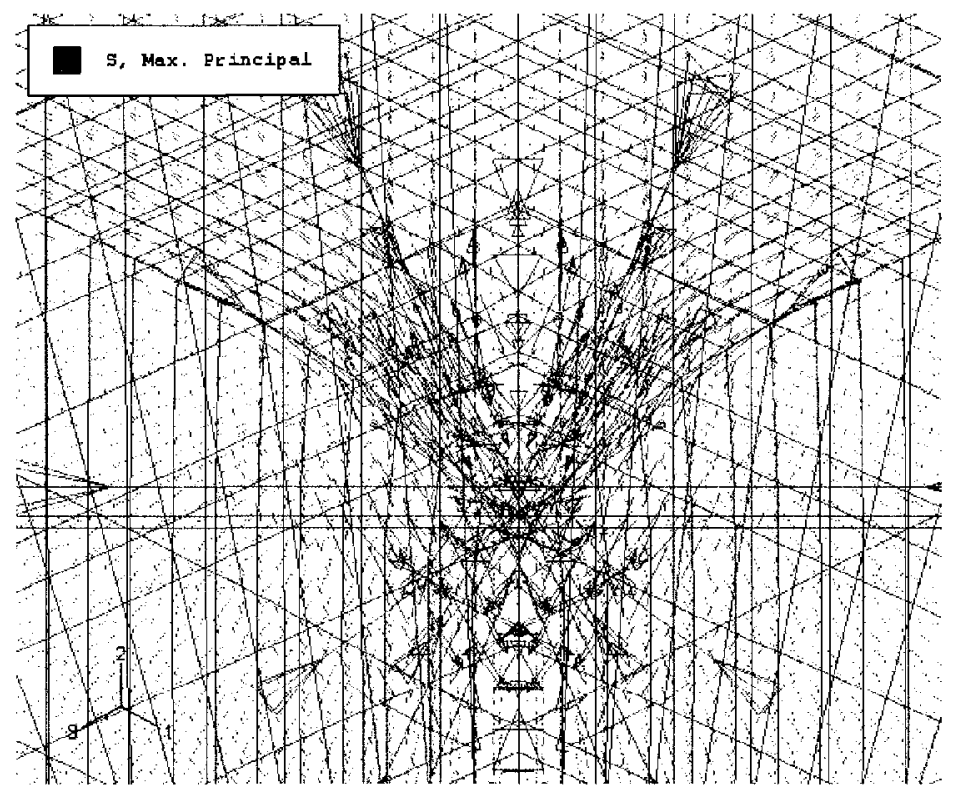

(a) 


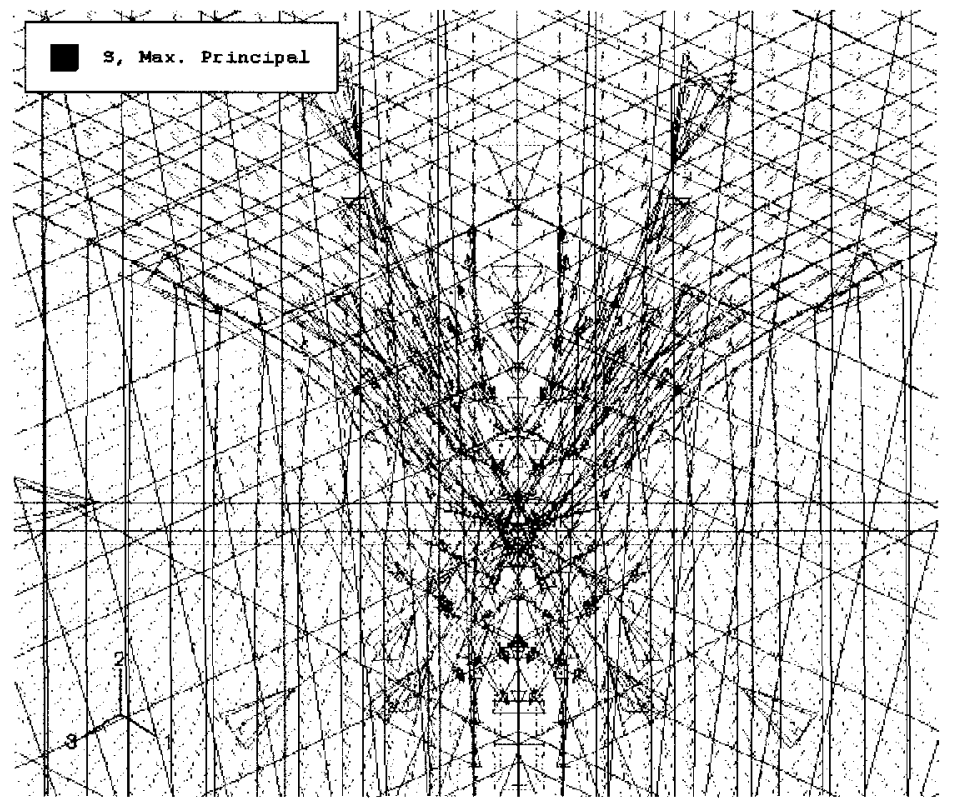

(b)

Figure 4.5 Maximum principal stress vector: (a) WC-Co and (b) WC-Co-Cr

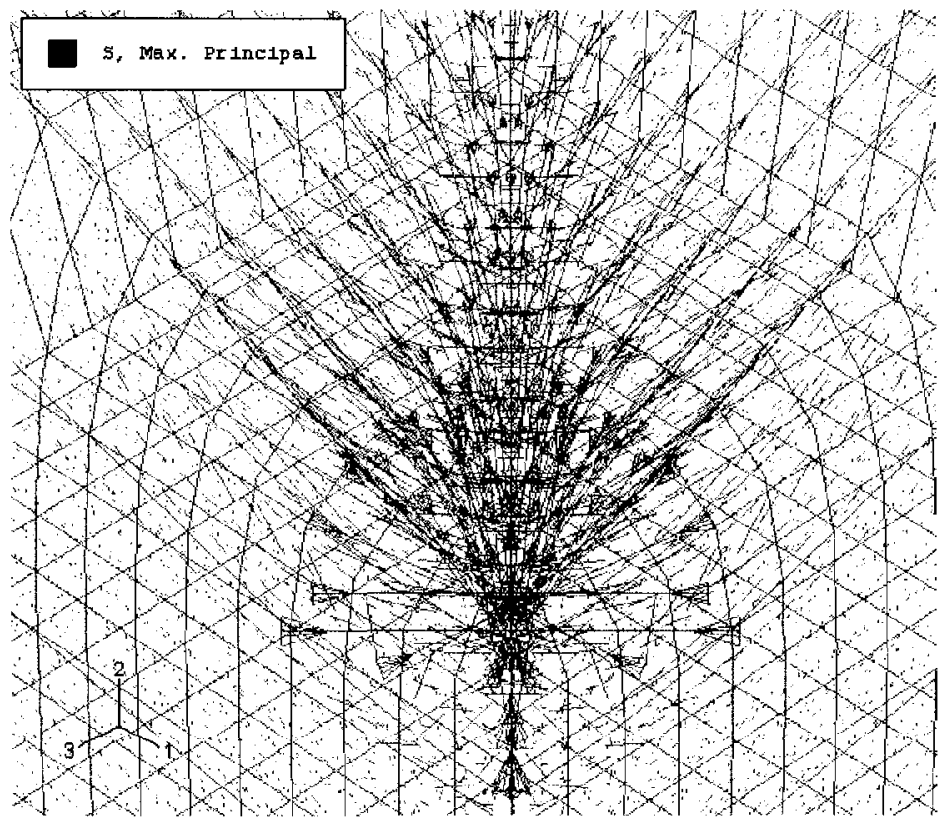

(a) 


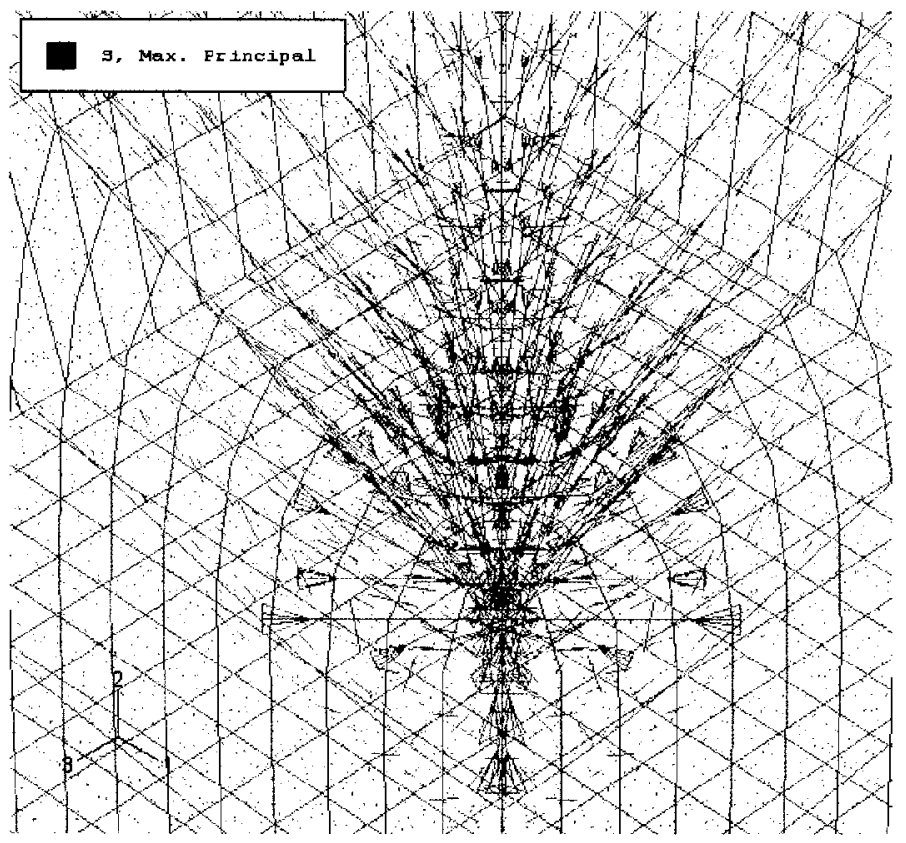

(b)

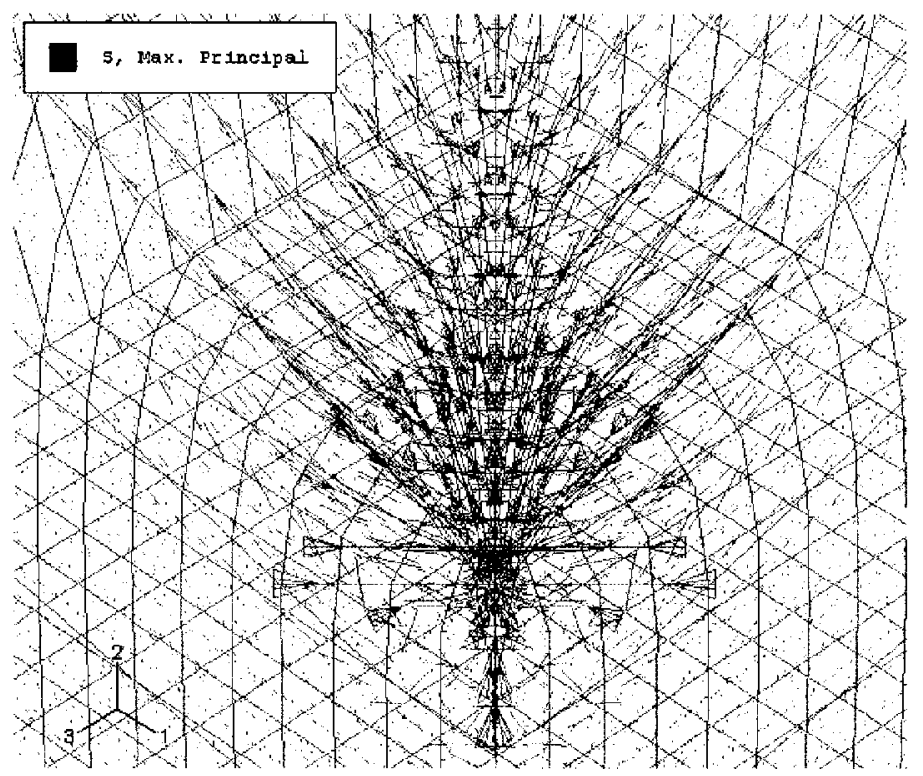

(c)

Figure 4.6 Maximum principal stress vector: (a) T-800; (b) Nistelle C and (c) Nistelle Super C 
It is clear that in the coating surface the highest compressive stress occurs in the area right beneath the indenter tip and the highest tensile stress occurs in the area of the indentation edges and in the area of the indentation vertices or corners. The vector contours show that the maximum principal stresses in the indentation edge area are in the direction normal to the indentation edge and the stresses in the indentation corner area are in the direction normal to the diagonal of the indentation. This is in good agreement with the experimental observation of the Vickers indentation that, cracks were initiated in the indentation edge area and the indentation corner area, and the edge crack was extended along the indentation edge and the corner crack grew radially along the diagonal of the indentation.

To better understand the fracture mechanisms of the coating specimens under the Vickers indentation test, the variation of the maximum principal stress along the indentation edge and the variation of the maximum principal stress along the diagonal of the indentation in the indentation corner area, as illustrated in Figure 4.7, are plotted for each specimen, because it was observed in the Vickers indentation test that cracks were generated at the indentation edges and at the indentation corners under the indentation load and the crack at the indentation edge grew along the indentation edge and the crack at the indentation corner propagated radially along the diagonal of the indentation when the load was increased. The plotted curves are shown in Figures 4.8 and 4.9. It is demonstrated that the highest tensile stress occurs in the center of the indent edge, point $\mathrm{A}$ in Figure 4.7 and the maximum principal stress decreases along the indentation edge towards its vertex, point B in Figure 4.7. This also agrees with the observation in the indentation test that the edge crack was initiated 
in the central region of the indentation edge first and propagated along the edge with further loading.

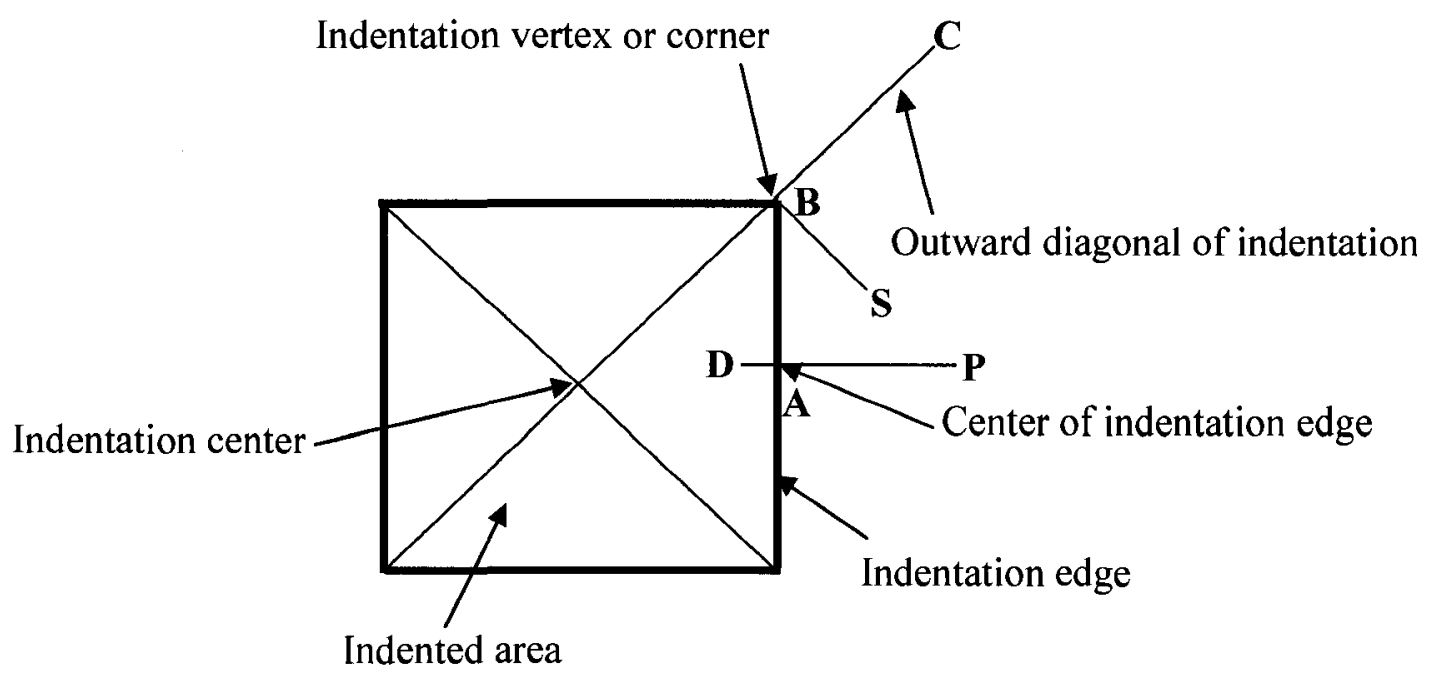

Figure 4.7 Schematic drawing of the indentation components

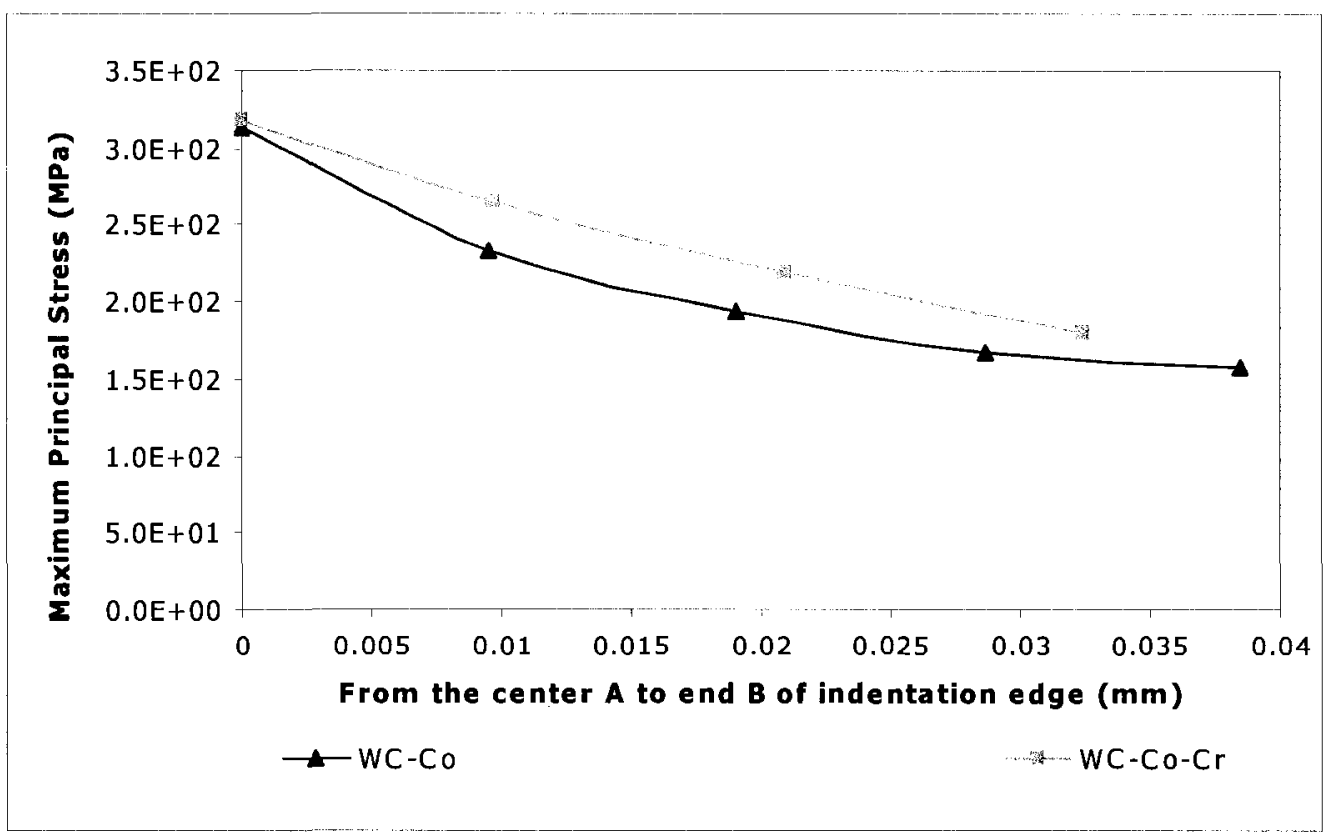

(a) 


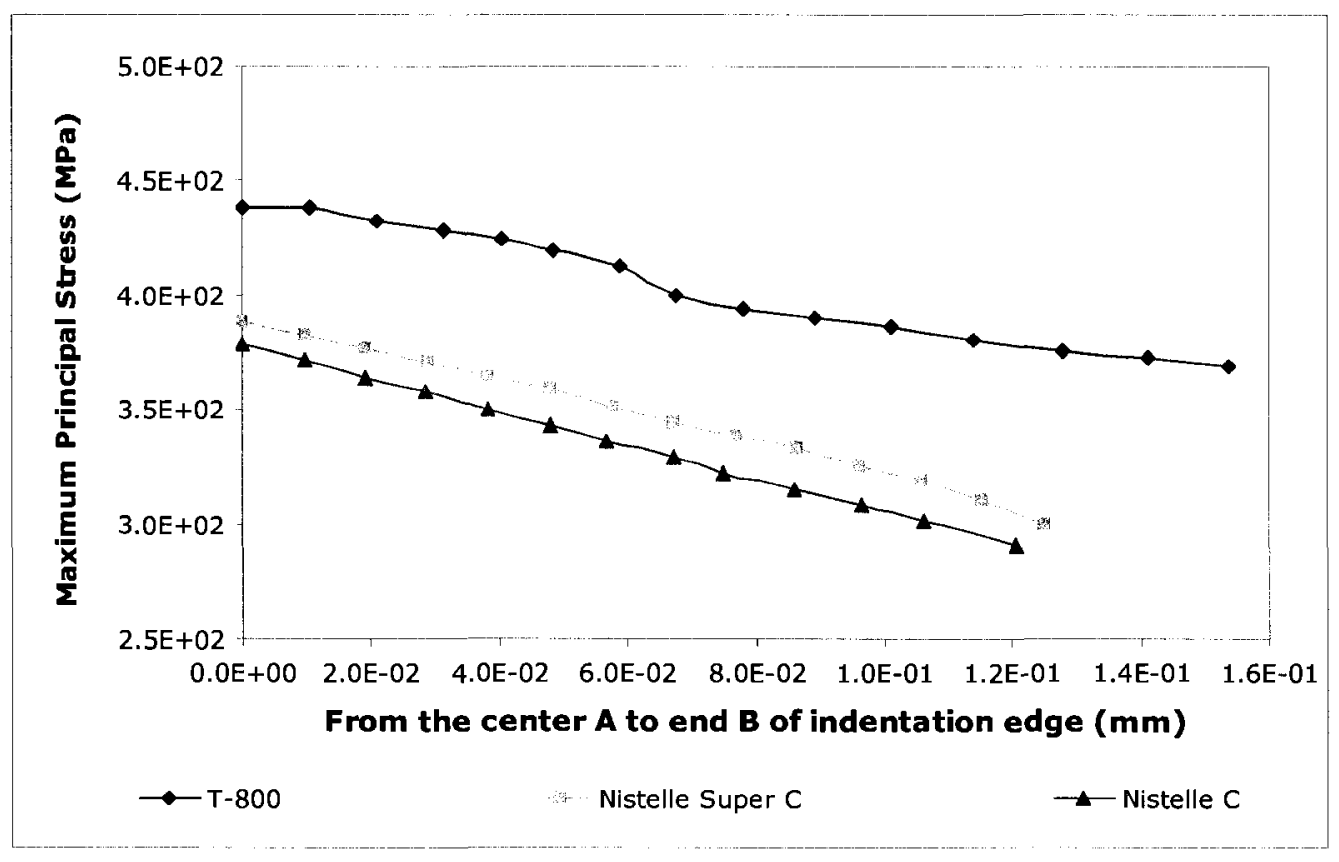

(b)

Figure 4.8 Variations of the maximum principal stress along the indentation edge:

(a) low-load group under $10 \mathrm{~N}$ and (b) high-load group under $100 \mathrm{~N}$

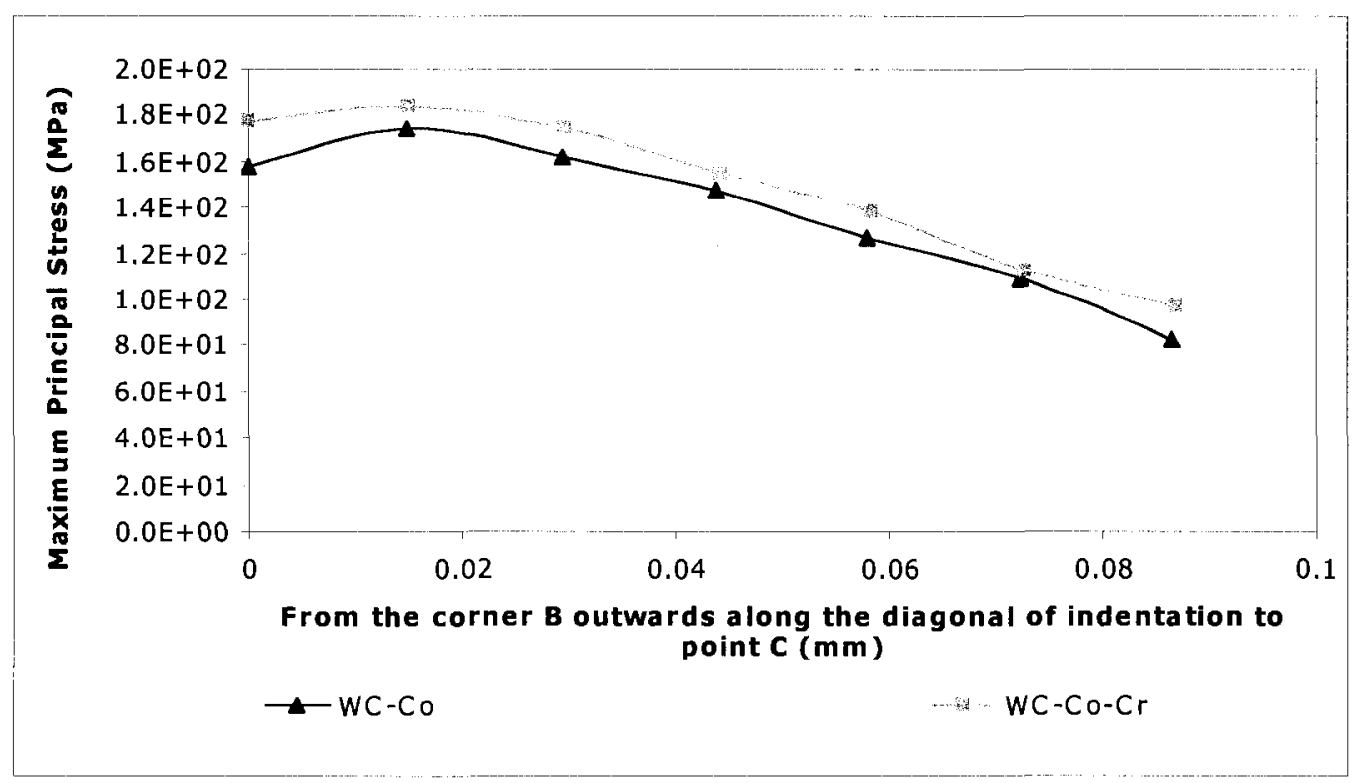

(a) 


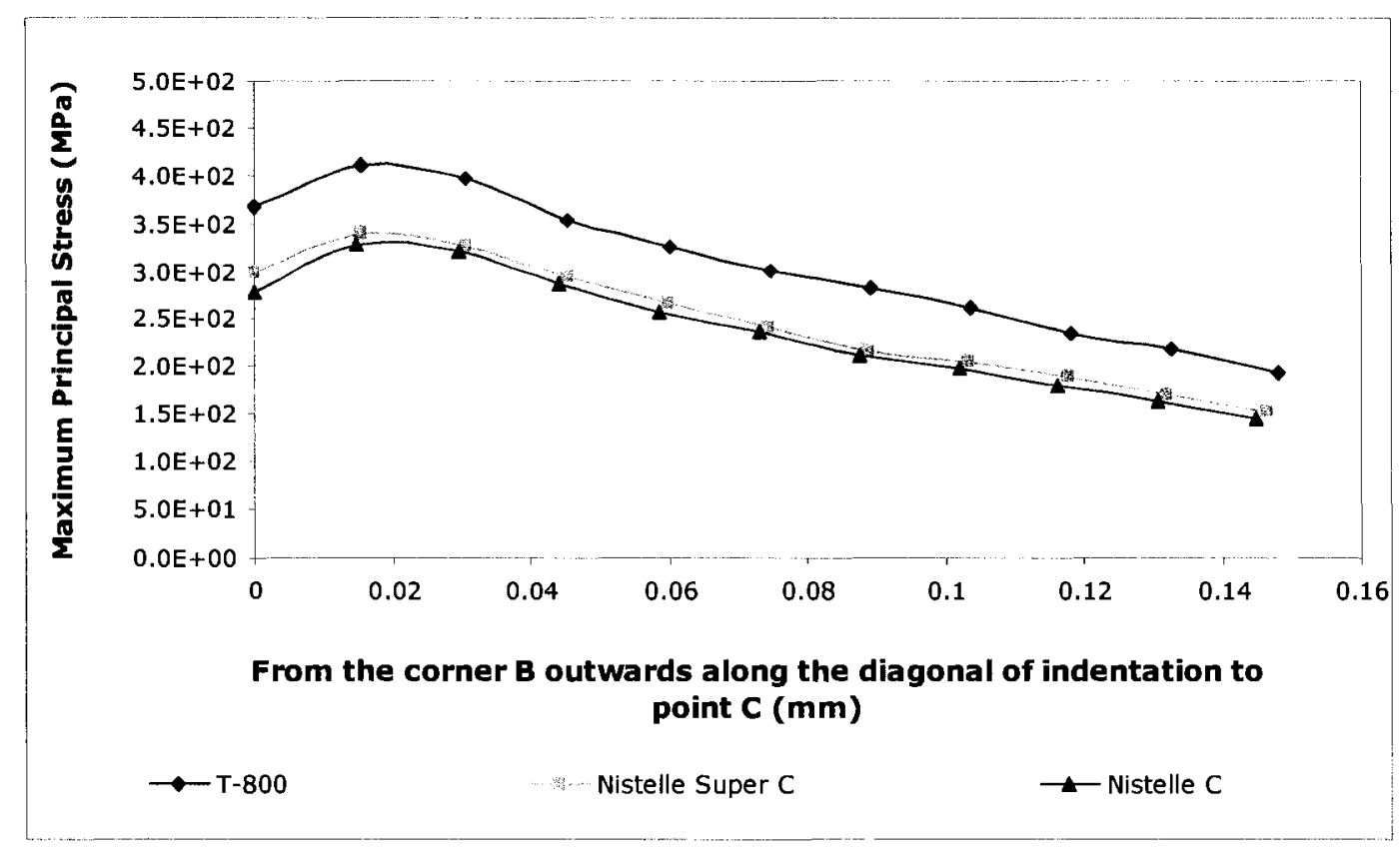

(b)

Figure 4.9 Variations of the maximum principal stress along the diagonal of the indentation edge: (a) low-load group under $10 \mathrm{~N}$ and (b) high-load group under $100 \mathrm{~N}$

As seen in Figure 4.8(a), at the center of the indentation edge the maximum principal stress is about $310 \sim 320 \mathrm{MPa}$ for the WC-Co and WC-Co-Cr specimens. According to the tensile strength of the WC hard metals, about $200 \mathrm{MPa}$ [90], the maximum principal stress in the center of the indentation edge under the load of $10 \mathrm{~N}$ is greater than the tensile strength of the coating material for the WC-Co specimen and the WC-Co-Cr specimen, therefore, the coating materials should fail under this load. As observed in the indentation test, cracks were initiated in the central region of the indentation edge. Under the same indentation load the stress in the WC-Co-Cr specimen is slightly higher than in the WC-Co specimen, as shown in Figure 4.8(a). However, the latter exhibited higher strength against cracking/fracture in the 
indentation test, as demonstrated in Chapter 3. This implies that the WC-Co-Cr material has higher tensile strength than the WC-Co material.

Previous research has reported that the tensile strength of Tribaloy T-800 is about 700 MPa [77]. From Figure 4.8(b), the maximum principal stress in the T-800 specimen under the load of $100 \mathrm{~N}$, which is about $440 \mathrm{MPa}$, is lower than the tensile strength of the T-800 material. In accordance with the experimental observation, no cracks were found in the T800 specimen under the $100 \mathrm{~N}$ load.

For the Nistelle $\mathrm{C}$ and Nistelle Super $\mathrm{C}$ specimens, the stress values under the same indentation load are very close, as seen in Figure 4.8(b), the highest stresses at the center of indentation edge are between $370 \sim 380 \mathrm{MPa}$. The tensile strength of Nistelle $\mathrm{C}$ and Nistelle Super $\mathrm{C}$ is about $530 \mathrm{MPa}$ [48]. Since the maximum principal stress is lower than the tensile strength of the coating material for the Nistelle $\mathrm{C}$ and Nistelle Super $\mathrm{C}$ specimens under the 100 indentation load, cracking would not occur in the specimens at this load level, as observed in the indentation test.

Figure 4.9 illustrates the variation of the maximum principal stress along the outward diagonal of the indentation in the indent corner region. It is shown that the highest stress occurs around the corner, but not right at the corner, point $\mathrm{B}$ in Figure 4.7, the stress decreases along the outward diagonal of the indentation to point $\mathrm{C}$ in Figure 4.7. Comparing the stress at the indentation edge with that at the indentation corner for each specimen, it is found that the former is larger. That is why the edge crack was found first in the coating 
surface under the indentation and the corner crack was generated with a higher load which induced the maximum principal stress greater than the tensile strength of the coating material at the indentation corner. The corner crack propagated radially along the outward diagonal of the indentation and stopped at a distance where the maximum principal stress decreased below the tensile strength of the coating material.

For the hard metal coatings, the maximum principal stresses at the indentation corner are lower than the tensile strengths of the coating materials under the $10 \mathrm{~N}$ load, as seen in Figure 4.9(a); therefore, corner crack would not occur in these specimens at this load level, which accords with the experimental observation. For the Tribaloy specimen and the superalloy specimens the maximum principal stresses induced in the coating surfaces under the $100 \mathrm{~N}$ load are all below the tensile strengths of their coating materials so that both edge crack and corner crack would not occur under this load.

It is also interesting to investigate the variation of the maximum principal stress from the indented area, point $\mathrm{D}$ in Figure 4.7, to the indentation-free area, point $\mathrm{P}$ in Figure 4.7, across the center $\mathrm{A}$ of the indentation edge, and the variation of the maximum principal stress from the indentation corner $\mathrm{B}$ along the normal of the indentation diagonal to point $\mathrm{S}$ in Figure 4.7. The plotted curves are shown in Figures 4.10 and 11.

It is seen that the indented area experiences very high compressive stresses and the maximum principal stress becomes tensile at the indentation edge with the largest magnitude, 
it then decreases gradually from the indentation edge in the indentation-free area, see Figure 4.10. This further explains why cracks were generated at the indentation edges in the Vickers indentation test. From the curves in Figure 4.11, along the normal of the indentation diagonal the highest stress occurs at the indentation corner and the maximum principal stress decreases away from the indentation corner. Since the stress distribution is symmetrical about the diagonal of the indentation because of the symmetry of the model geometry and loading, the highest stresses must occur along the diagonal of the indentation, which results in the corner crack propagating along the diagonal.

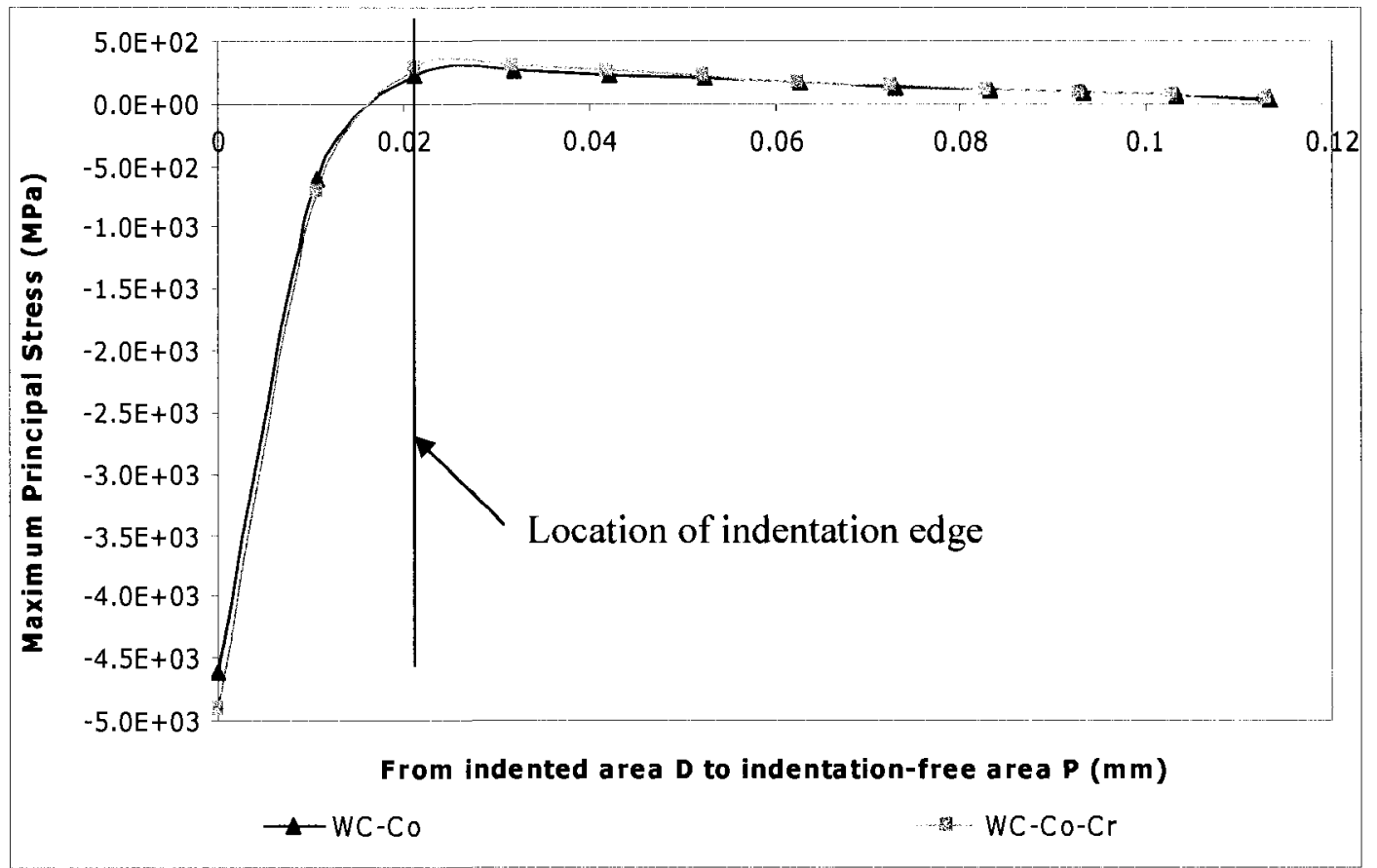

(a) 


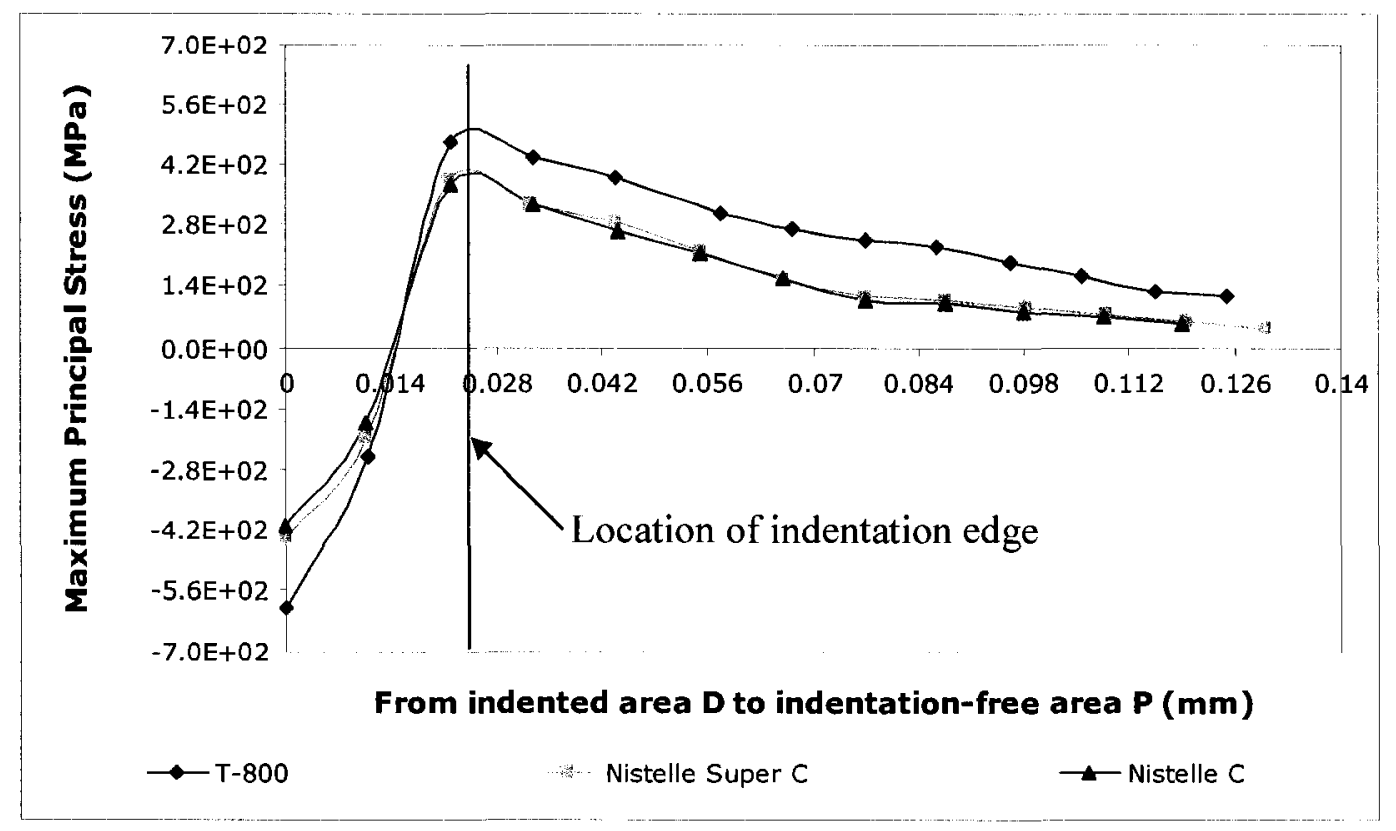

(b)

Figure 4.10 Variations of the maximum principal stress from the indented area to the indentation-free area across the center of the indentation edge: (a) low-load group under $10 \mathrm{~N}$ and (b) high-load group under $100 \mathrm{~N}$

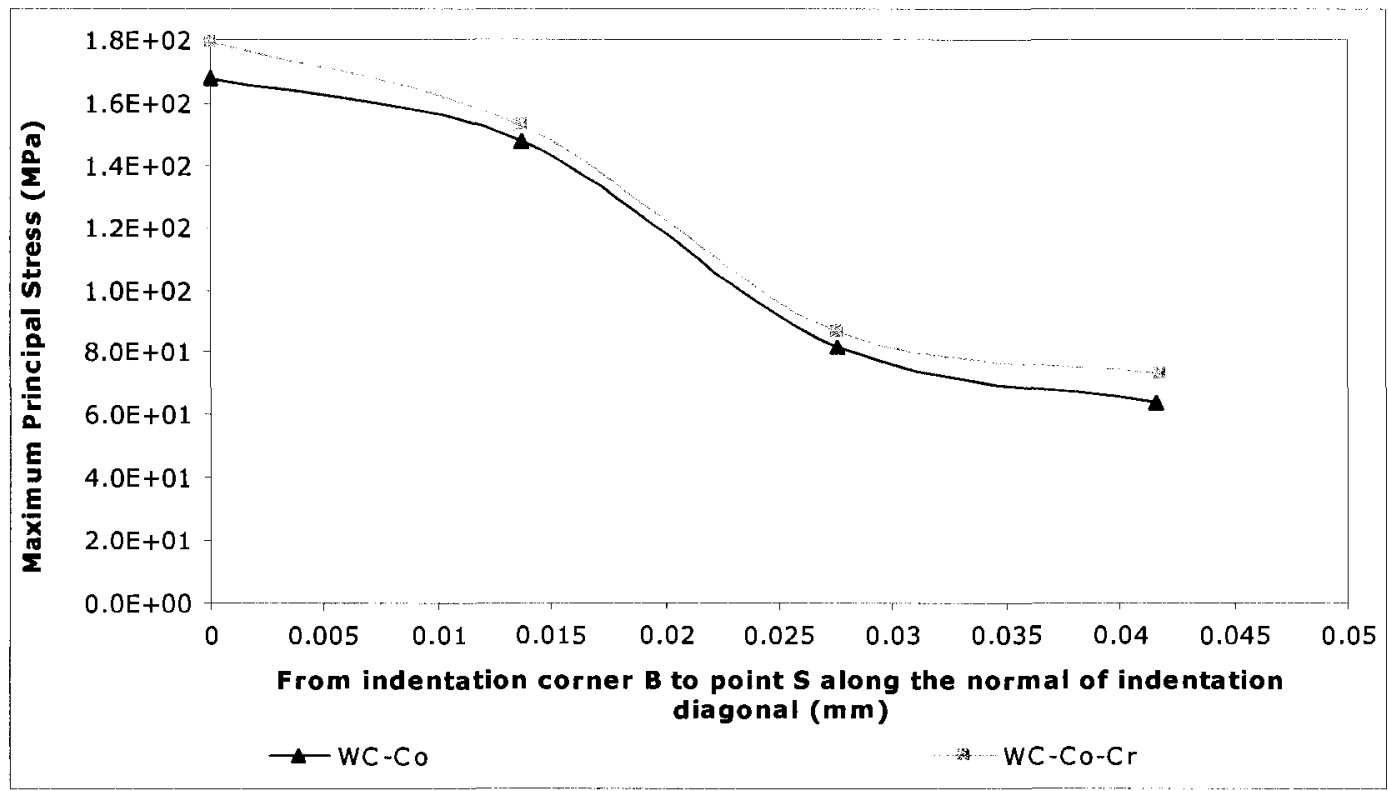




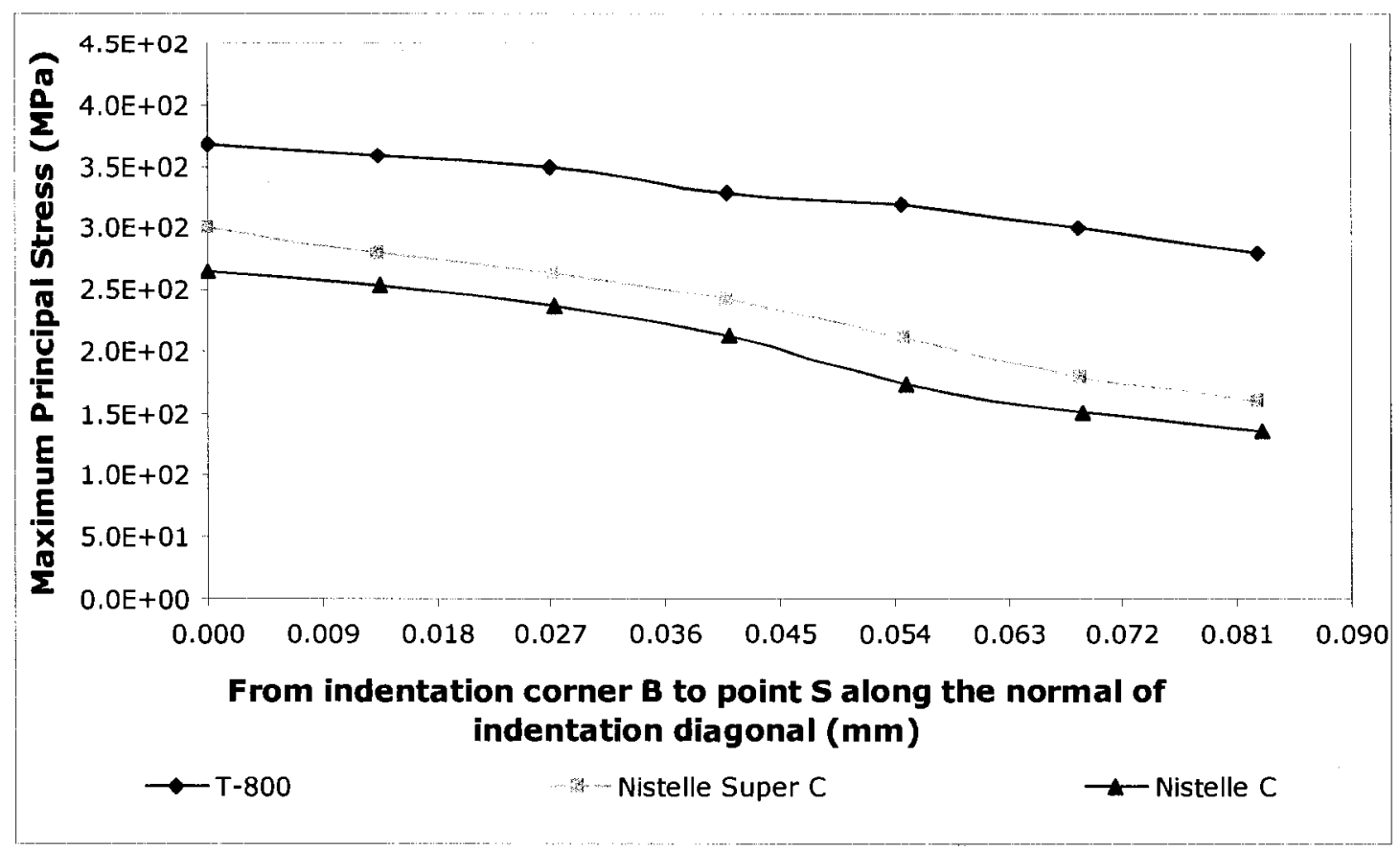

(b)

Figure 4.11 Variations of the maximum principal stress from the indentation corner along the normal of the indentation diagonal: (a) low-load group under $10 \mathrm{~N}$ and (b) high-load group under $100 \mathrm{~N}$

It has been noticed from the stress results that whether under the low indentation loads or under the high indentation loads, the stress at the coating/substrate interface is nearly uniform for all the specimens, that is, the stress concentration in the loading area does not affect the stress distribution of the interface region. This is because the coating specimens being studied are thick coatings. However, since the maximum principal stress at the interface is tensile, if the interface bonding is not strong enough, cracking may occur at the interface, a condition that will cause delamination of the coating from the substrate. 
For the low-load group specimens, three load levels, $10 \mathrm{~N}, 35 \mathrm{~N}$ and $100 \mathrm{~N}$, were used in the stress computation, which correspond to the loads applied in the Vickers indentation test. Figures 4.12 and 4.13 present the results of the maximum principal stress for low-load group under $35 \mathrm{~N}$ and under $100 \mathrm{~N}$.

As seen in Figure 4.12(a), under the higher indentation load of $35 \mathrm{~N}$, the maximum principal stress along the indentation edge is all larger than the tensile strength of the coating material for both the hard metal specimens; therefore, the edge crack would be developed over the entire indentation edge in specimens WC-Co and WC-Co-Cr. In the meanwhile, the maximum principal stress at the indentation corner also reaches the tensile strength of the coating material, see Figure 4.13(a), which would lead to the corner crack. However, as the stress decreases rapidly along the outward diagonal of the indentation, the corner crack would not grow at this load level. This has been confirmed by the indentation test.

Under the higher indentation load of $100 \mathrm{~N}$, however, the maximum principal stresses over the entire indentation edge and in a certain region of the indentation corner are greater than the tensile strength of the coating material for both of the hard metal specimens; see Figures 4.12(b) and 4.13(b). As a result, the edge crack would grow over the entire indentation edge; at the same time, the corner crack would propagate along the outward diagonal of the indentation to a distance, as observed in the indentation test. 


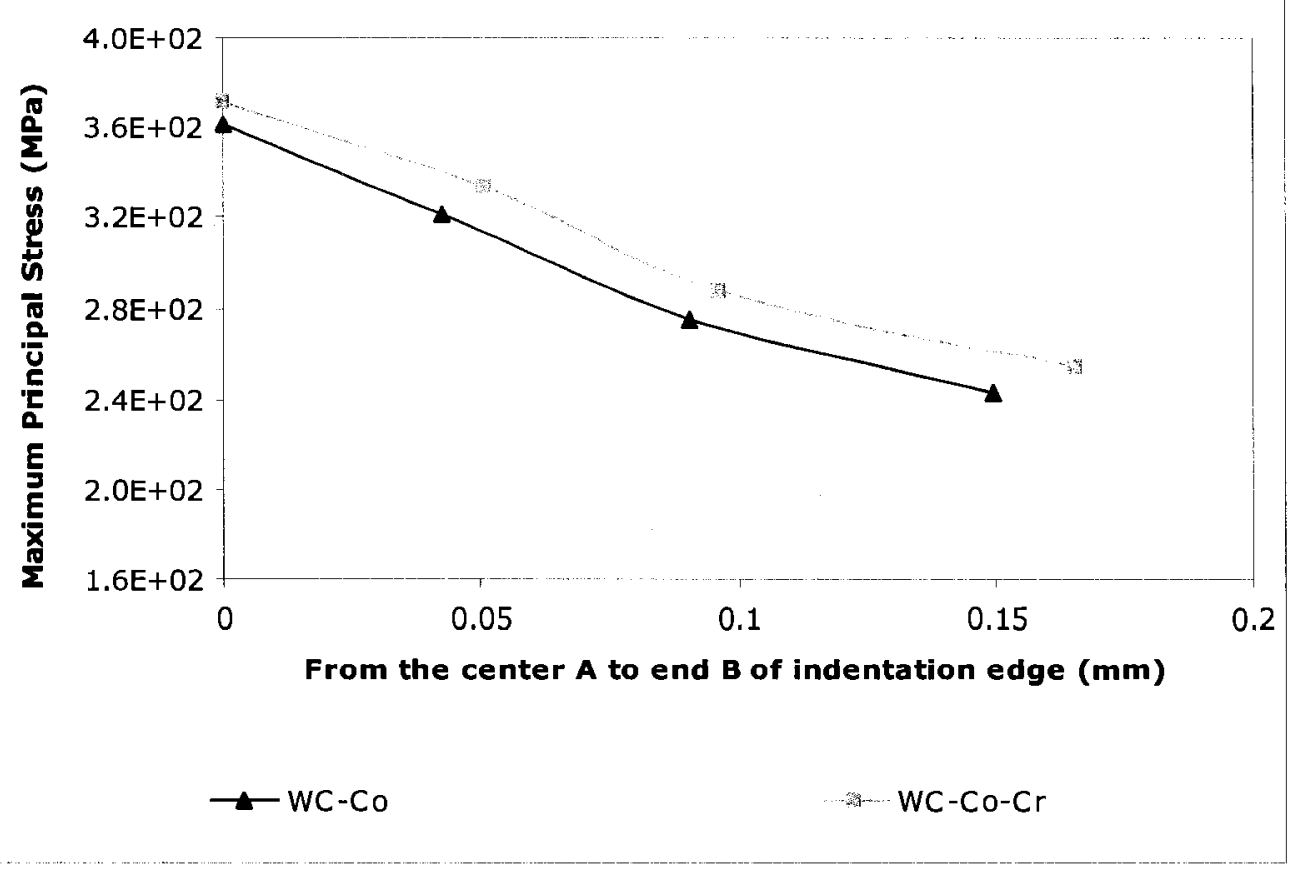

(a)

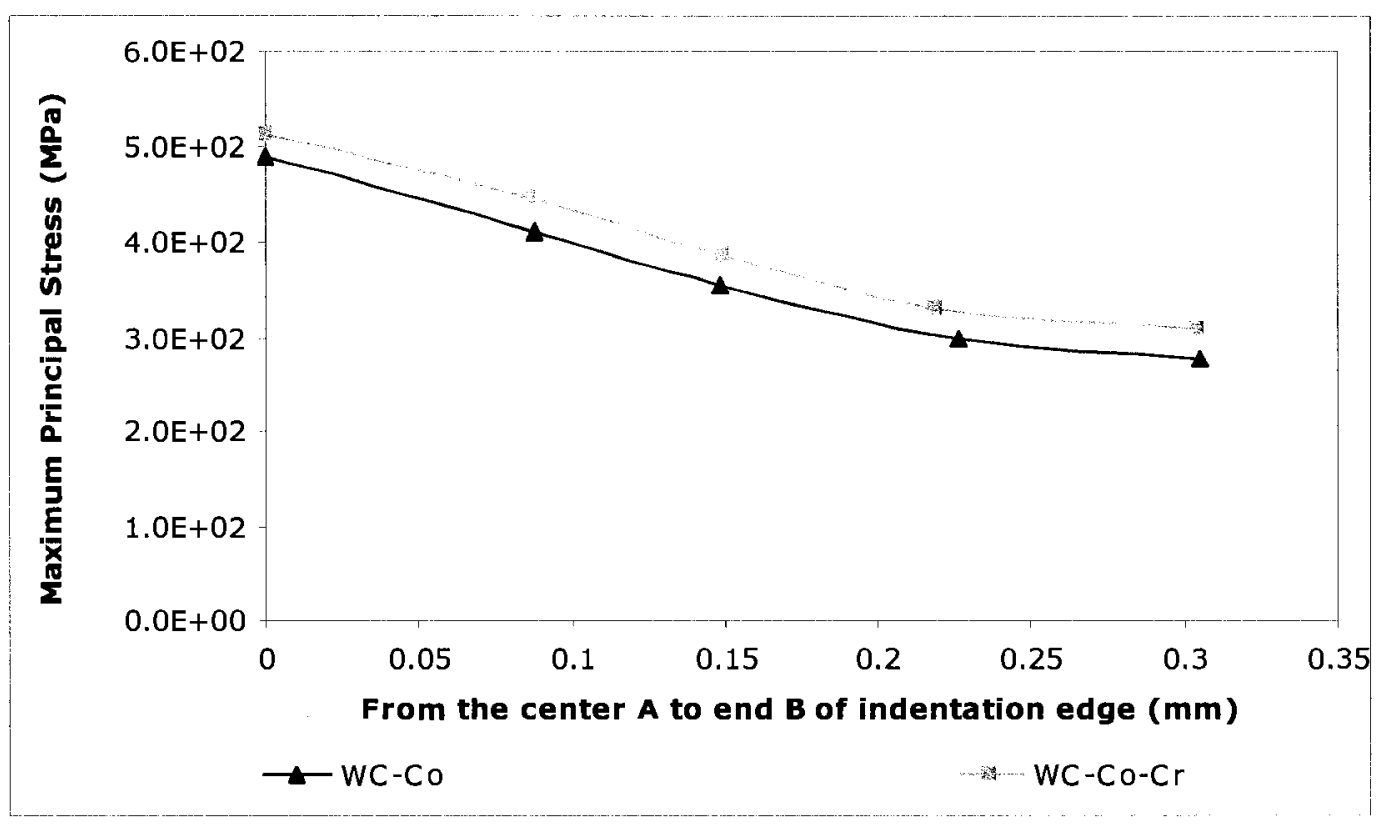

(b)

Figure 4.12 Variations of the maximum principal stress along the indentation edge for low-load group: (a) under $35 \mathrm{~N}$ and (b) under $100 \mathrm{~N}$ 


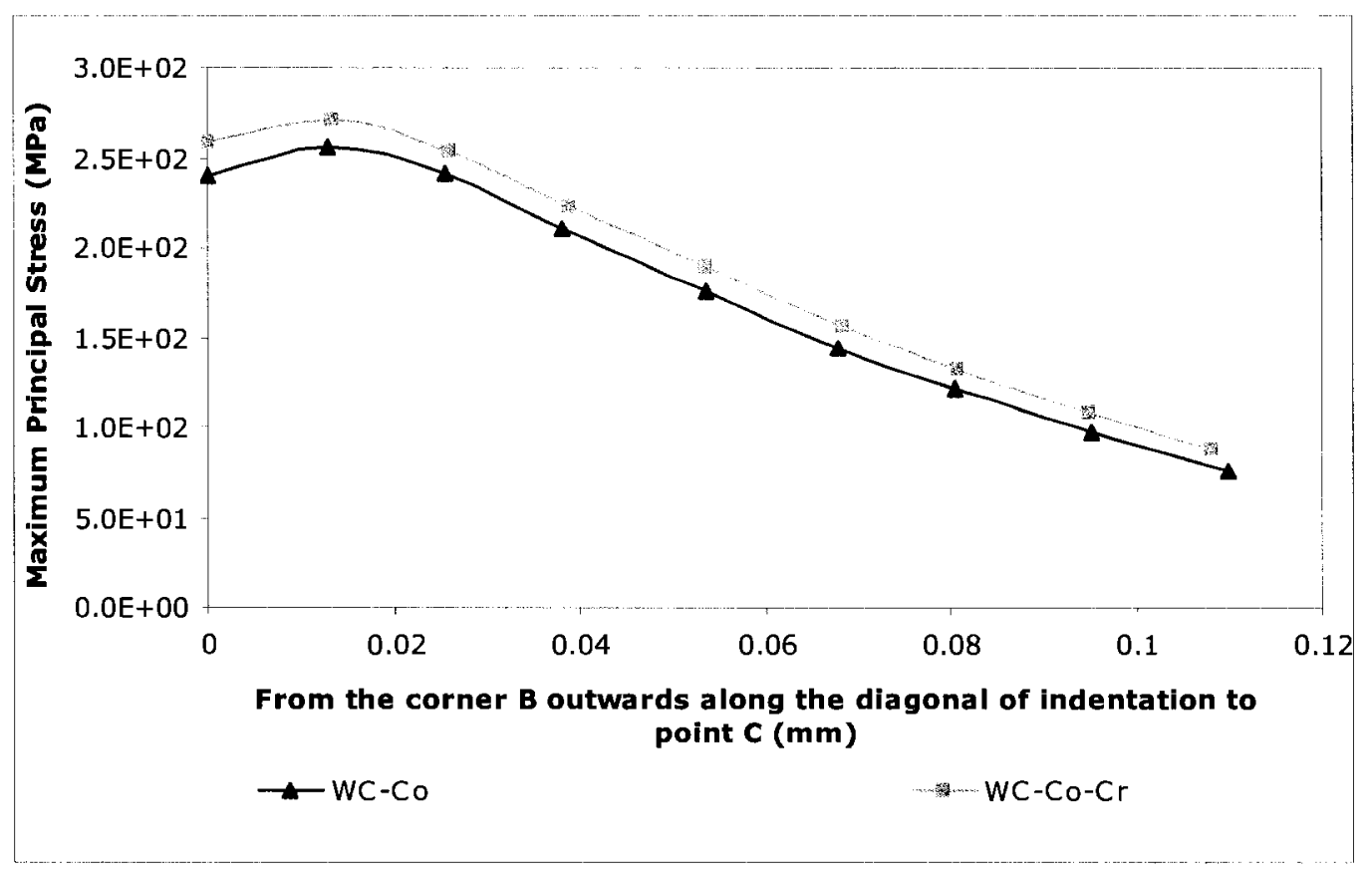

(a)

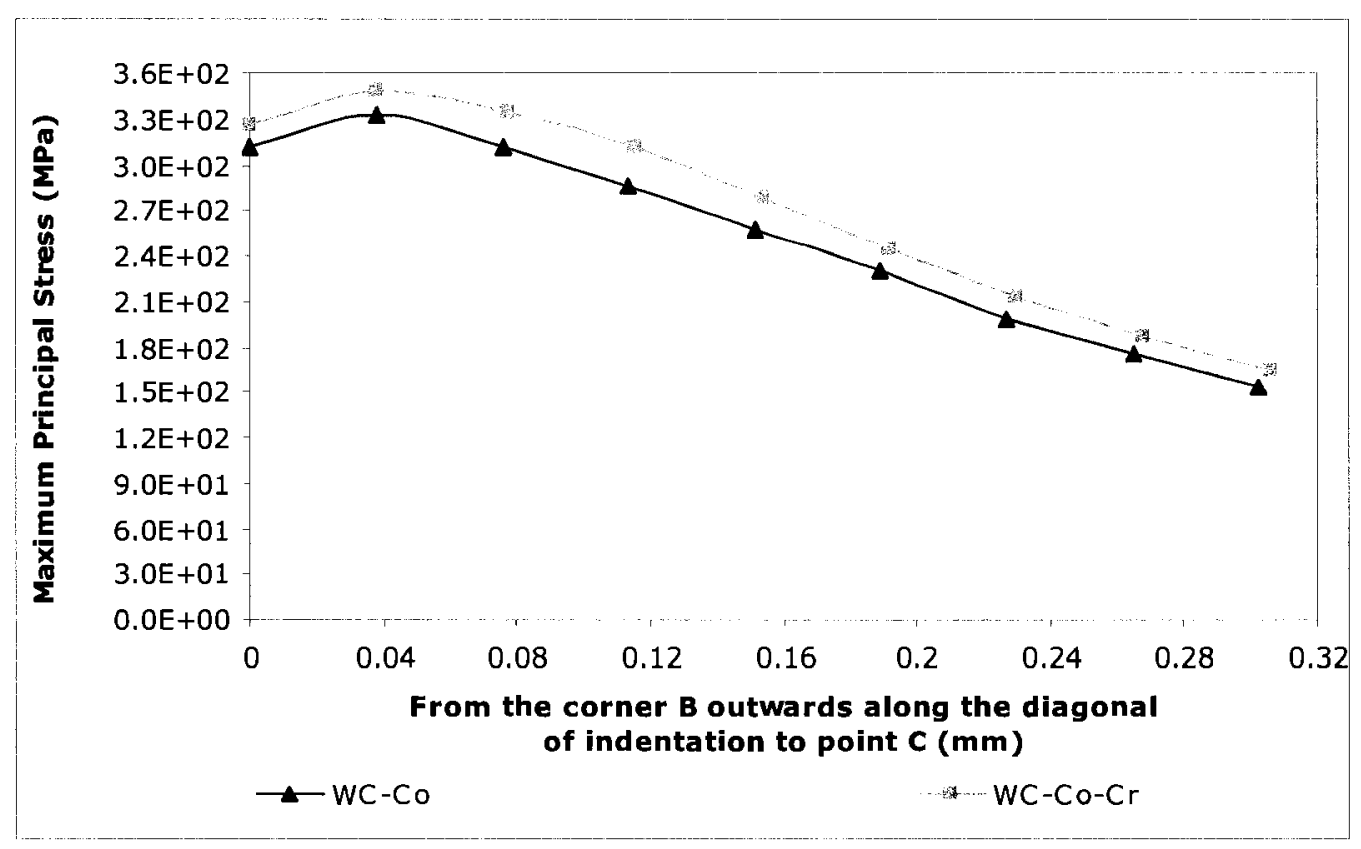

(b)

Figure 4.13 Variations of the maximum principal stress along the diagonal of the indentation for low-load group: (a) under $35 \mathrm{~N}$ and (b) under $100 \mathrm{~N}$ 
For the high-load group specimens, also three load levels were used in the stress computation; they are $100 \mathrm{~N}, 300 \mathrm{~N}$ and $500 \mathrm{~N}$, corresponding to the loads employed in the Vickers indentation test. As presented in Figures 4.14 and 4.15, the maximum principal stress in all the specimens under the load of $300 \mathrm{~N}$ is below the tensile strength of their coating materials, therefore, no cracking would occur in the specimens at this load level, as observed in the Vickers indentation test. With increasing the load to $500 \mathrm{~N}$, the maximum principal stress in the T-800 specimen is still lower than the tensile strength of the coating materials so that cracking would not occur in this specimen under this load either, but further load may induce cracks in this specimen, as demonstrated in the Vickers indentation test, micro or small cracks were found in the T-800 specimen under the $700 \mathrm{~N}$ load.

For the Nistelle C and Nistelle Super C specimens under the $500 \mathrm{~N}$ indentation load, the maximum principal stresses at the indentation edge reach the tensile strengths of their coating materials. This means that edge cracks would be induced in these specimens at this load level. However, since the maximum principal stresses in the indentation corner area are lower than the tensile strengths of the coating materials for these specimens, no cracking would occur at the indentation corner in these specimens under this load, but further loading may induce corner cracks in these specimens. 


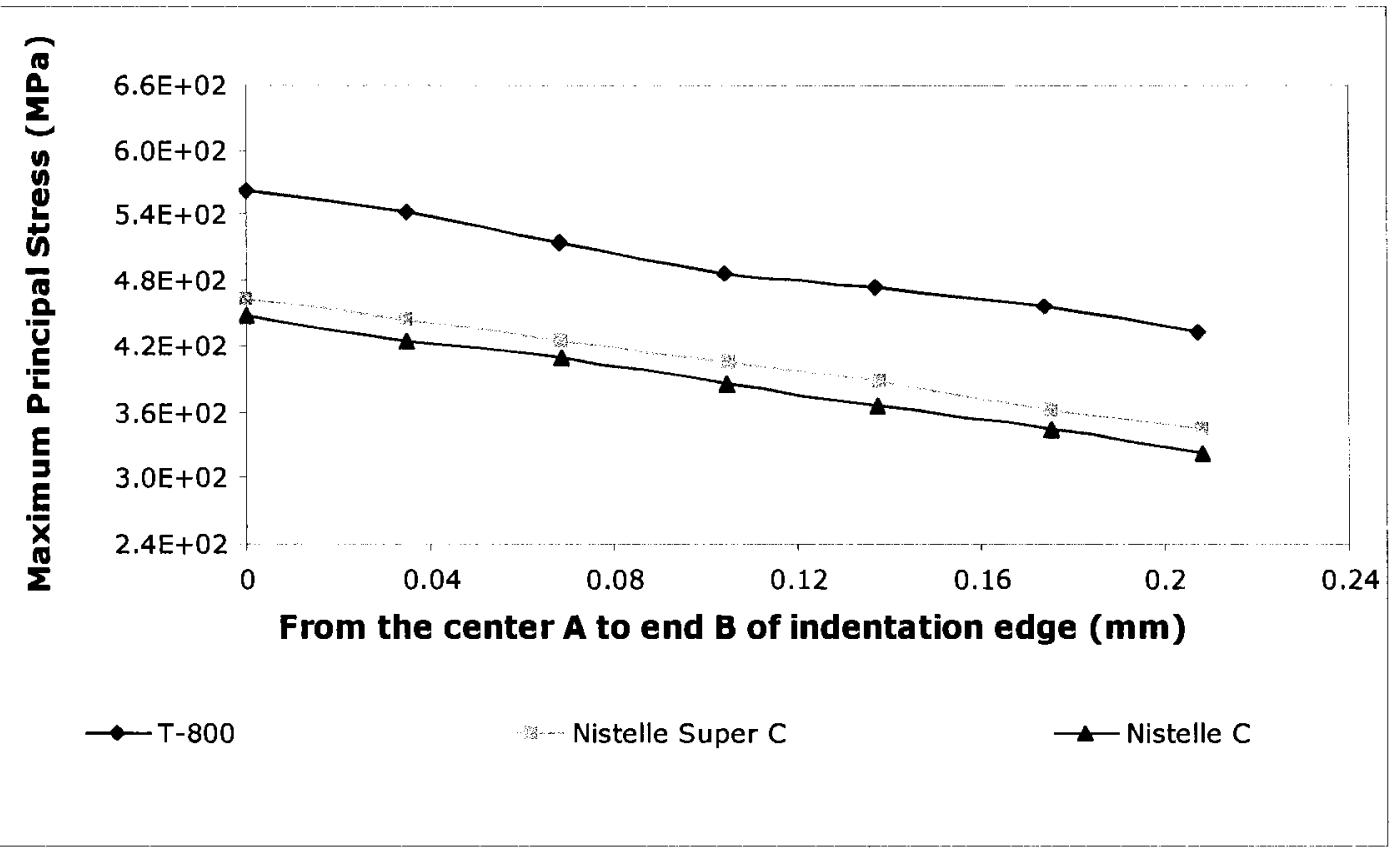

(a)

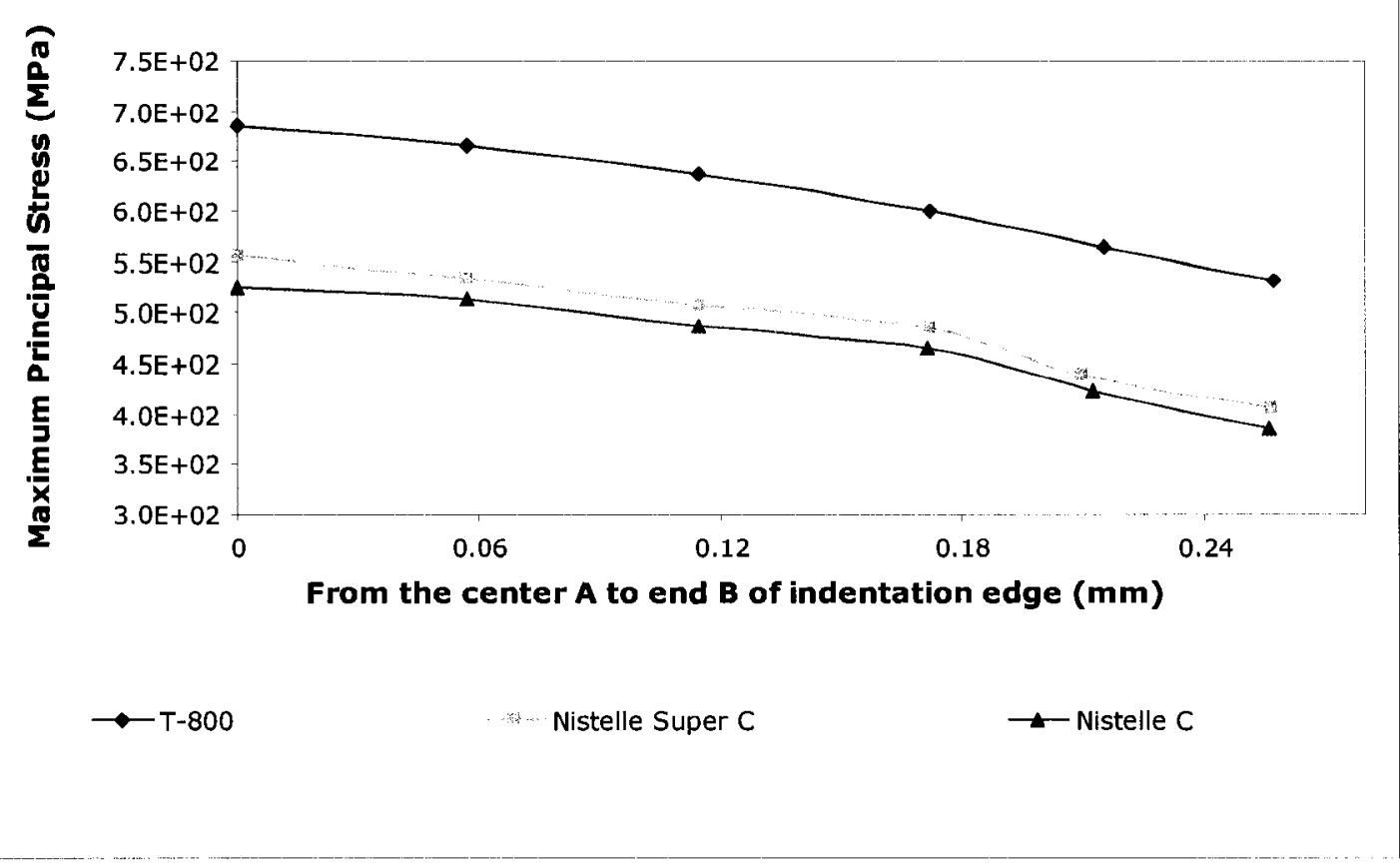

(b)

Figure 4.14 Variations of the maximum principal stress along the indentation edge for high-load group: (a) under $300 \mathrm{~N}$ and (b) under $500 \mathrm{~N}$ 


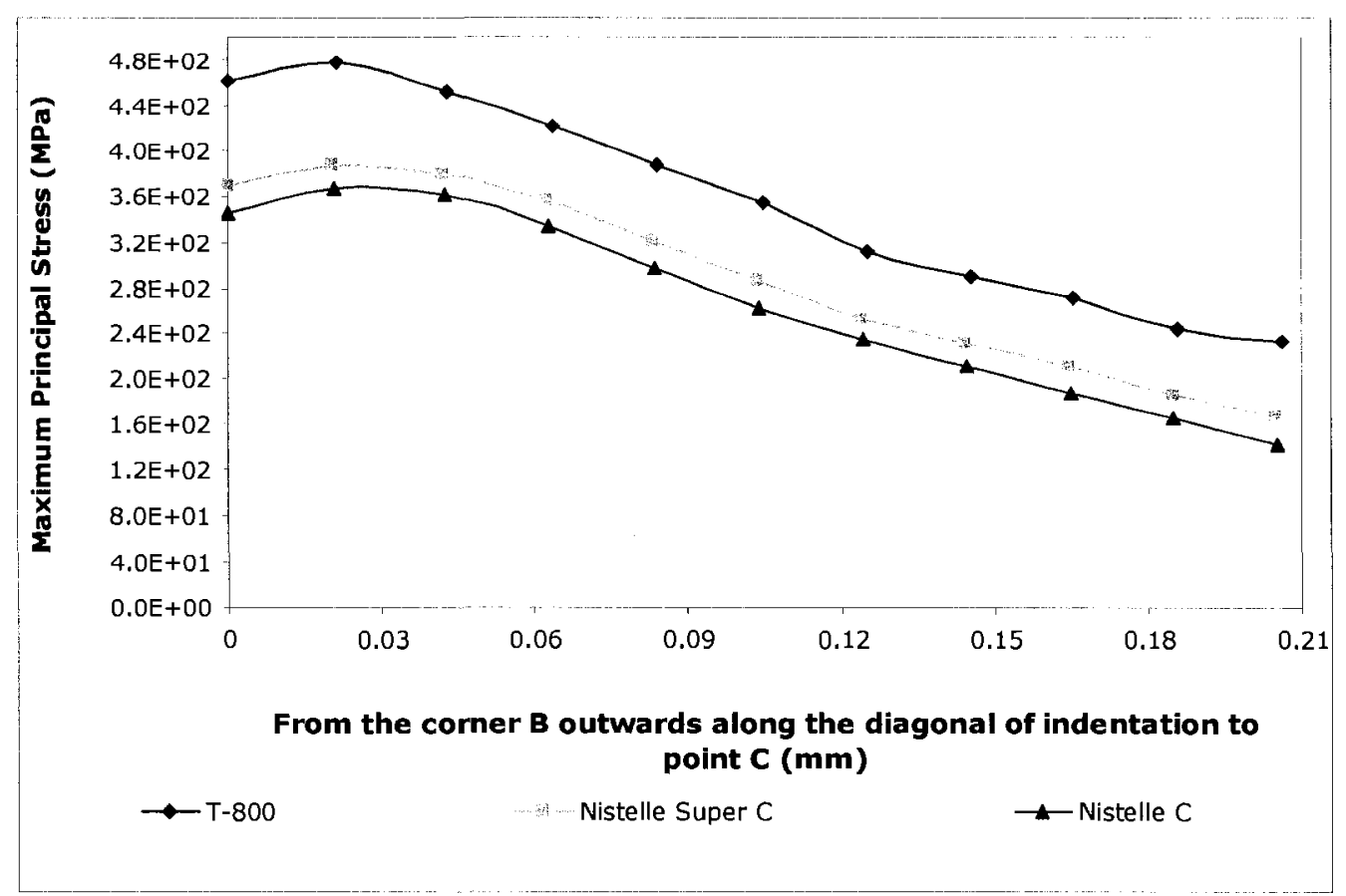

(a)

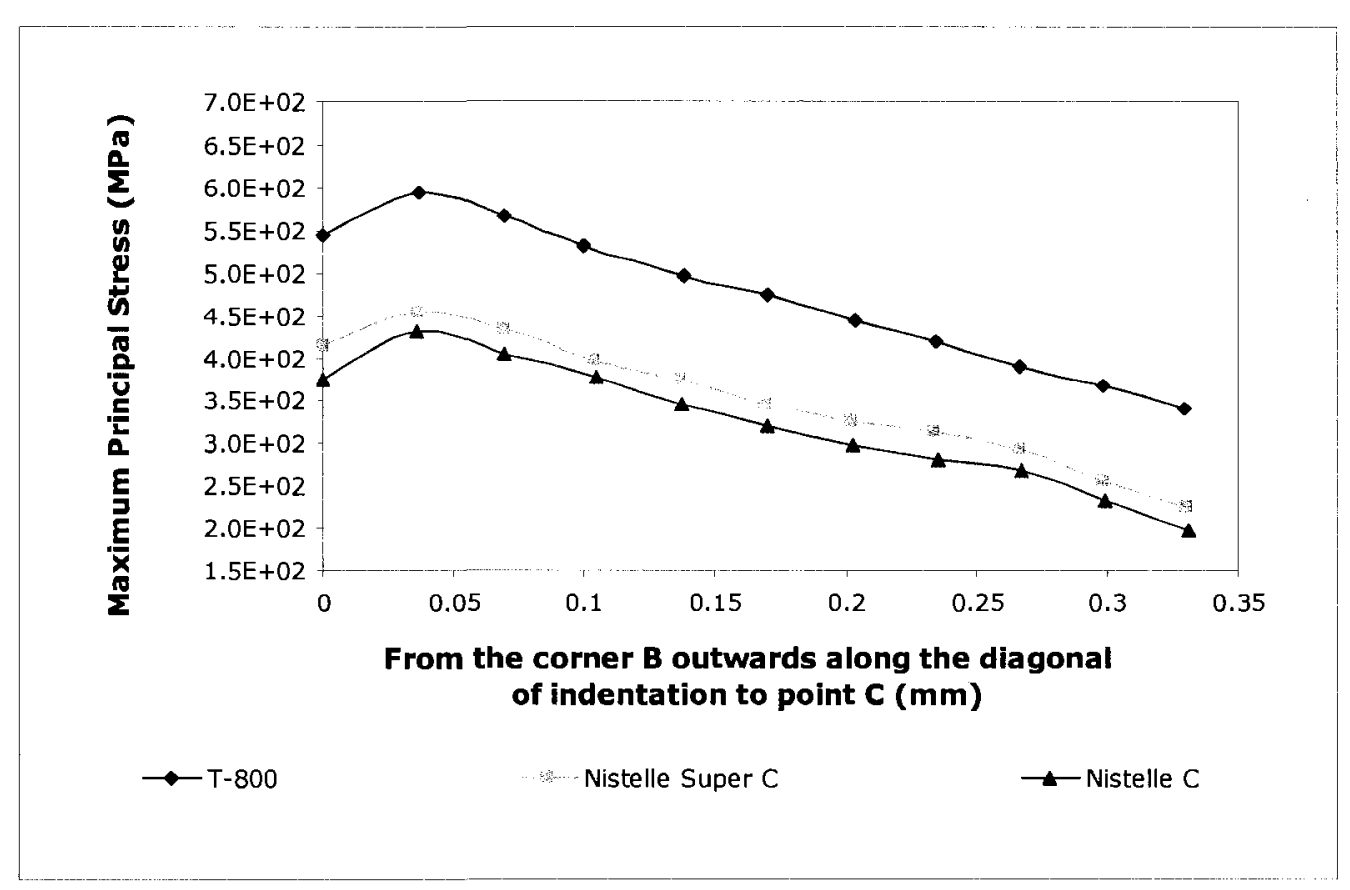

(b)

Figure 4.15 Variations of the maximum principal stress along the diagonal of the indentation for high-load group: (a) under $300 \mathrm{~N}$ and (b) under $500 \mathrm{~N}$ 
It should be mentioned that in linear elastic mechanics the external load and the induced stress should be in linear relation. However, in the present analysis, since a 'contact' problem between the indenter and the coating surface, which is non-linear, was involved, the linear relation is not expected. This is because under different load levels the surface contact area changes, which definitely affect the stress distribution in the coating surface. The higher the load, the larger the contact area is. The higher load would produce higher stress, but the larger contact area would reduce the stress. Therefore, the combined effect would make the stress variation with the load more complex. 


\section{CHAPTER 5 DISCUSSION AND CONCLUSIONS}

\subsection{Discussion on the Results}

\subsubsection{Coating Material versus Fracture Strength}

Five coating materials were studied through seven coating specimens in this thesis. From the previous studies, as reported in Chapter 2, WC-Co, WC-Co-Cr hard metals, which are brittle; T-800 is a Tribaloy alloy containing 55 vol.\% brittle Laves phase; and Nistelle C and Nistelle Super C are Ni-based superalloys with good ductility.

Comparing the cracking profiles of these coatings under the Vickers indentation test, the hard metals WC-Co and WC-Co-Cr exhibited typical brittle fracture behavior. However, T-800 did not behaved as WC-Co and WC-Co-Cr did, although it exhibited brittle features in tensile testing [94]. The significant difference between the hard metals and the Tribaloy alloy is that the hard phase WC in the hard metal powders used for the HVOF process exists as separate particles while the brittle Laves phase in the Tribaloy alloy powder is alloyed with the cobalt solid solution. In the HVOF coating fabrication process, although the fuel temperature was very high (about $3000^{\circ} \mathrm{C}$ ), due to the high velocity $(1350 \mathrm{~m} / \mathrm{s}$ ), the powder was deposited on the substrate surface forming the coating in a very short time. In this case, the WC particles had no time melting or dissolving into the cobalt matrix; they were just embedded in the matrix as separate particles. Therefore, the bond between the WC particle and the cobalt matrix in the coatings was not very strong. Unlike in the hard metal coatings, for the Tribaloy alloy T-800 coating, the interface between the Laves phase and the Co solution matrix in T-800 was already formed in the powder form, leading to stronger 
interface bonding in the coating after the HVOF process, compared with the WC-Co and WC-Co-Cr hard metal coatings. As a result, T-800 coating exhibited much higher resistance to cracking and fracture than WC-Co and WC-Co-Cr coatings in the Vickers indentation test.

Between the $\mathrm{WC} / 17 \mathrm{Co}$ and $\mathrm{WC} / 10 \mathrm{Co} / 4 \mathrm{Cr}$ coatings, the latter contains a higher level of WC and the cobalt matrix is strengthened by Cr dissolution. By comparing the cracking profiles, WC-Co-Cr coating exhibited slightly higher fracture strength than WC-Co coating in the Vickers indentation test. As for most composite materials, the failure of the hard metal coatings was controlled mainly by the interface bonding strength. Since the interface bonding strength between the WC particles and the Co matrix may be close or only a little different in WC-Co and WC-Co-Cr coatings, these two coatings fractured in a similar manner under the Vickers indentation. However, as discussed above, the presence of $\mathrm{Cr}$ in WC-Co-Cr modified the mechanical properties of the matrix and may also have altered the interface bonding strength thus changing the overall performance of the coating in resisting fracture.

For the superalloy specimens both Nistelle $\mathrm{C}$ and Nistelle Super $\mathrm{C}$ possess high ductility, as reported previously [127]. Therefore they did not behave as the brittle WC-Co and WC-Co-Cr did in the Vickers indentation test. According to the microstructures of Nistelle C and Nistelle Super C, they consist of a Ni solid solution matrix with an eutectic of intermetallic compounds, $\mathrm{Ni}_{3}(\mathrm{Mo}, \mathrm{Cr})$ and $\mathrm{Ni}_{4}(\mathrm{Mo}, \mathrm{Cr})$, embedded. Although the intermetallic compounds are brittle, their volume fraction in these alloys is very small (less than $20 \%$ ), so that Nistelle $\mathrm{C}$ and Nistelle Super $\mathrm{C}$ exhibit ductile features. In the indented surfaces of these two alloys no severe fracture was observed even under the maximum 
indentation load while only microcracks were found at the indentation edges and in the area of the indentation corners where stress concentration occurred. Owing to the good ductility, the microcracks in these alloys may not propagate unless a fatigue load is applied.

As demonstrated by previous research [128], comparing Nistelle C $(\mathrm{Ni} / 16 \mathrm{Cr} / 16 \mathrm{Mo} / 4 \mathrm{Fe} / 4 \mathrm{~W})$ with Nistelle Super $\mathrm{C}(\mathrm{Ni} / 23 \mathrm{Cr} / 18 \mathrm{Mo})$, it is found that these two alloys contain almost the same amount of $\mathrm{Ni}$, but the latter has better ductility owing to the reduced volume fraction of the brittle intermetallic compounds $\mathrm{Ni}_{3}(\mathrm{Mo}, \mathrm{Cr})$ and $\mathrm{Ni}_{4}(\mathrm{Mo}, \mathrm{Cr})$. However, this difference was not exhibited obviously by the indentation tests in the present research. This is because the Vickers indentation was performed on macro scale, but as the volume fraction of the intermetallic compounds in the alloys is small, the $\mathrm{Ni}$ solid solutions dominate the overall performance of the alloys, which are ductile. Also, the brittle intermetallic compounds were alloyed with the Ni solid solution, similar to the Laves phase in Tribaloy alloys, but unlike the WC in hard metals present as separate particles. Thus the bond between the intermetallic compounds and the solid solution in Nistelle C and Nistelle Super $\mathrm{C}$ would be much stronger than in hard metals. Therefore, the damage of Nistelle $\mathrm{C}$ and Nistelle Super $\mathrm{C}$ in the indentation test might not be caused mainly by the interface debonding, but the cracking or failure of the solid solution matrices. As a result, one may hardly see the difference in the cracking profiles between the Nistelle C and Nistelle Super C coatings.

\subsubsection{Indentation Test versus FEA Stress Results}

The FEA simulation determined the stress fields of the coating/substrate systems under the Vickers indentation, which provided the fundamentals of the fracture analysis of 
the coatings under the indentation load. The FEA results are in good agreement with the experimental observation, and thus help understand the fracture mechanisms of the seven coating specimens under the Vickers indentation.

Firstly, the distributions of the maximum tensile principal stress demonstrate the highest stress occurs in the center of the indentation edge for all the specimens, in accordance with the observation on in the Vickers indentation test, cracks were induced initially in the central region of the indentation edges. Since the stress is tensile over the entire indentation edge, the edge crack would propagate along the indentation edge towards the vertex or corner of the indentation, as observed in the indentation test.

Secondly, the FEA results show that the maximum principal stress at the indentation corner is also tensile and high. This explains why cracks were also generated at the indentation corners. However, since the stress at the indentation corner is lower than that at the indentation edge, the corner crack requires an increased load. As demonstrated by the indentation test, edge crack was initiated first and corner crack was induced with further loading.

Thirdly, based on the experimental observation that the corner crack was extended radially along the outward diagonal of the indentation, the variation of the maximum principal stress from the indentation corner along the outward diagonal of the indentation and the variation of the maximum principal stress from the indentation corner along the normal of the indentation diagonal were plotted. As seen in Figure 4.9, the stress is tensile over the 
outward diagonal but it decreases from the indentation corner to zero at a distance. This is why the corner crack propagated to a certain length and then stopped under a given indentation load. From Figure 4.11, the largest magnitude of the maximum tensile principal stress occurs at the indentation corner along the normal of the indentation diagonal. Due to the symmetry of the model geometry and loading, the highest stresses must occur over the diagonal of the indentation, which leads to the corner crack growing radially along the indentation diagonal.

\subsubsection{Indentation Load versus Coating Fracture}

By testing the coating strength and computing the stress field under different indentation loads, one may obtain the response of the coating fracture to the applied load, in terms of the tensile strength of the coating material. Again, the indentation test results agree well with the FEA stress results.

For the brittle hard metal coatings, it was observed in specimen WC-Co that edge cracks were generated under the indentation load of $10 \mathrm{~N}$ and corner crack were induced by the higher load of $35 \mathrm{~N}$. Consistent with the experimental observation, the FEA results show that the maximum principal stress occurring in the central area of the indentation edge in this specimen is $310 \mathrm{MPa}$ in Figure $4.8(\mathrm{a})$, which is larger than the tensile strength of the coating material (reported about $200 \mathrm{MPa}$ ), but the maximum principal stress at the indentation corner is $170 \mathrm{MPa}$ under this load in Figure 4.9(a), which is lower than the tensile strength of the coating material. When the load of $35 \mathrm{~N}$ was applied, the maximum principal stress at the indentation corner reaches $240 \mathrm{MPa}$ in Figure 4.13(a), which is high enough for the corner 
crack. With further loading to $100 \mathrm{~N}$, the maximum principal stresses over the indentation edge and over the indentation diagonal in a certain length are all greater than the tensile strength of the WC-Co material, see Figures 4.12(b) and 4.13(b), thus both the edge cracks and corner cracks grow, leading to the fracture of the coating surface, which has been confirmed by the indentation test. For the WC-Co-Cr coating, the indentation test demonstrated that it has higher fracture strength than the WC-Co coating, as no corner cracks occurred under the load of $35 \mathrm{~N}$, while the FEA results show that at this load level the maximum principal stress at the indentation corner is $260 \mathrm{MPa}$ in Figure 4.13(a). This discrepancy may be due to the coating material property. Since there is no available data for the tensile strength of the $\mathrm{WC} / 10 \mathrm{Co} / 4 \mathrm{Cr}$ hard metal, $200 \mathrm{MPa}$ is only generally or approximately for WC hard metals. Therefore it can be a case that the real tensile strength of $\mathrm{WC} / 10 \mathrm{Co} / 4 \mathrm{C}$ is greater than $200 \mathrm{MPa}$ or $260 \mathrm{MPa}$.

As concerns the $\mathrm{T}-800$ coating, in the indentation test no obvious cracking was observed in this specimen, even under the highest indentation load of $700 \mathrm{~N}$, but microcracks were found at the indentation edges under the load of $500 \mathrm{~N}$ and the load of $700 \mathrm{~N}$. From the FEA results, see Figure 4.14(b), the maximum principal stress at the indentation edges in the specimen under the load of $500 \mathrm{~N}$ is $680 \mathrm{MPa}$, which is below, but close to, the tensile strength of the coating material, $700 \mathrm{MPa}$. Also defects or flaws were possibly introduced during the coating fabrication process, which may result in microcracks occurring under the lower load. 
Finally, considering the Nistelle C and Nistelle Super C coatings, under a same indentation load the stress levels in the two specimens are very close and they are lower than the stress in the T-800 coating. This is because T-800 has higher Young's modulus. Also the coating thickness of the Nistelle C and Nistelle Super C specimens is larger than that of the T-800 specimen. As reported by previous research, Nistelle $C$ and Nistelle Super $C$ have almost same tensile strength, which is about $530 \mathrm{MPa}$. When the indentation load is below $500 \mathrm{~N}$, the maximum principal stresses in these coating specimens are all less than $530 \mathrm{MPa}$, as seen in Figures 4.8(b), 4.9(b), 4.14 and 4.15, which implies that cracking would not occur in this loading case. This is consistent with the indentation test, but a higher load would increase the stress level in the specimens, leading to cracking, as demonstrated by the indentation test. Since Nistelle C and Nistelle Super C have good ductility, the cracks in these coating specimens are small and stable, unlike the cracks in the hard metal coating specimens. These small cracks may not grow unless a fatigue load is applied.

\subsubsection{Fuel gas effect}

In the entire study of these coating specimens, there is no significant difference found in the performance and properties of the Nistelle $C$ and Nistelle Super C coatings fabricated by using either propylene fuel gas or using hydrogen fuel gas in the HVOF process. The slight variations of the testing data and the FEA stress values can be considered as the experimental errors and the cause of the numerical approximation. This is consistent with previous research showing that the type of the fuel gas does not influence the quality of the coating but that the flow rate has an effect [129]. 


\subsection{Conclusions}

Based on the experimental and FEA results as well as the above analysis and discussion, the following conclusions can de drawn from this research:

1. Seven HVOF coatings, which were made of different materials or with different fuel gases in the HVOF process but deposited on the same substrate, were studied under Vickers indentation test, associated with the FEA simulation. The experimental observation of the coating fracture is in good agreement with the FEA stress results.

2. Among the seven coatings WC-Co and WC-Co-Cr hard metals have the lowest fracture strength, characterized by significant cracking under a low indentation load. This is due to their low tensile strength and brittleness.

3. T-800 Tribaloy alloy has the highest resistance to fracture. It was not seriously cracked even under high indentation loads. This is because it possesses high tensile strength.

4. Nistelle $\mathrm{C}$ and Nistelle Super $\mathrm{C}$ have good ductility so that they did not exhibit significant cracking even under high indentation loads. Only micro or small cracks were observed in the indented surfaces under high loads.

5. Under the Vickers indentation cracking occurred initially in the central area of the indentation edge in the coating surfaces. Further loading induced cracks at the indentation corners. The edge crack grew along the indentation edge and the corner crack propagated radially along the outward diagonal of the indentation.

6 In consideration of the maximum principal stress in the coating/substrate systems under the Vickers indentation, the highest tensile stress occurs in the center of the indentation edge and the stress decreases along the indentation edge towards the indentation corner, which induced the edge crack first in the coating surface and promoted the edge crack 
growing along the indentation edge. The area of the indentation corner also has high tensile stress, which induced the corner crack and caused the crack to propagate radially along the outward diagonal of the indentation.

7 Vickers indentation was demonstrated to be an effective method in studying the fracture strength of coatings. The FEA stress solutions provided the basis of the fracture analysis corresponding to the indentation test.

8 The fuel gases, propylene and hydrogen, used in the HVOF process for the fabrication of the coating specimens Nistelle C-propylene, Nistelle Super C-propylene, Nistelle C-hydrogen and Nistelle Super C-hydrogen did not make a significant difference in the performance and the properties of the coatings. 


\section{References:}

[1] A.A. Boudi, M.S.J. Hashmi, B.S. Yilbas, HVOF coating of Inconel 625 onto stainless and carbon steel surfaces: corrosion and bond testing, J. Mater. Process. Technol.155-156 (2004) 2051.

[2] Handbook of thermal spray technology, Ed. by J.R. Davis, Davis \& Associates; prepared under the direction of the Thermal Spray Society Training Committee, Materials Park, OH, ASM International, 2004.

[3] R.C. Tucker, A.A. Asharay, Advanced thermal spray coatings for corrosion and wear resistance, A.R. Srivatsa, C.R. Clayton, J.Hirvonen (Eds.), Advances in Coatings Technologies for Corrosion and Wear Resistant Coatings, The Minerals, Metals \& Materials Society, 1995.

[4] L. Zhao, E. Lugscheider, High velocity oxy-fuel of a NiCoCrAlY and intermetallic NiAl-TaCr alloy, Surf. Coat. Technol. 149 (2002) 231.

[5] D.A. Stewart, P.H. Shipway, D.G. McCartney, Influence of heat treatment on the abrasive wear behaviour of HVOF sprayed WC-Co coatings, Surf. Coat. Technol. 105 (1998) 13.

[6] A.J. Sturgeon, High velocity oxy-fuel spraying, Trans. Inst. Met. Finish. 72 (1994) 139.

[7] R. Hofman, M.P.W. Vreijing, G.M. Ferrari, J.H.W. de Wit, Electrochemical methods for characterization of thermal spray corrosion resistant stainless steel coatings, Mater. Sci. Forum 289-292 (1998) 641. 
[8] L.M. Lau, E.J. Lavernia, Microstructural evolution and oxidation behavior of nanocrystalline 316-stainless steel coatings produced by high-velocity oxygen fuel spraying, Mater. Sci. Eng. A: Struct. Mater.: Prop. Microstruct. Process, A272 (1999) 222.

[9] K. Dobler, H. Kreye, R. Schwetzke, Oxidation of stainless steel in the high velocity oxy-fuel process, J. Therm. Spray Technol. 9 (2000) 407.

[10] V.V. Sobolev, J.M. Guilemany, J.A. Calero, Development of coating structure and adhesion during high velocity oxygen-fuel spraying of $\mathrm{WC}-\mathrm{Co}$ powder on a copper substrate, J. Therm. Spray Technol. 9 (2000) 100.

[11] L. Pawlowski, The Science and Engineering of Thermal Spray Coating, John Wiley Sons, UK, 1995.

[12] Y. Hu, M. Aindow, I.P. Jones, I.R. Harris, Effects of $\mathrm{Zn}$ coating on the microstructure and magnetic properties of Nd-Fe-B magnets, J. Alloys Compd. 351 (2003) 299.

[13] K. Tokunaga, N. Yoshida, N. Noda, T. Sogabe, T. Kato, High heat load properties of tungsten coated carbon materials, J. Nucl. Mater. 258-263 (1998) 998.

[14] S. Sampath, G.A. Bancke, H. Herman, S. Rangaswamy, Plasma sprayed Ni-Al coatings, Surf. Eng. 5 (1989) 293.

[15] ASTM Standard Committee, D 4541-02, Standard Test Method for Pull-Off Strength of Coatings Using Portable Adhesion Tester, ASTM International, USA, 2002.

[16] ASTM Standard Committee, C633-79, Standard Test Method for Adhesion or Cohesive Strength of Flame-Sprayed Coatings, ASTM International, USA, 1999. 
[17] K. Kuwahara, H. Hirota, N. Umemeto, In adhesion Measurement of Thin Films, Thick Films and Bulk Coatings, Ed. by K.L. Mittal, STP 640, ASTM, Philadelphia, PA, 1978.

[18] G. Rosa, R. Oltra, Evaluation of the coating-substrate adhesion by laser-ultrasonics: modeling and experiments, J. Appl. Phys. 91 (10) (2002) 6744.

[19] N. Aravas, K.S. Kim, M.J. Loukis, On the mechanics of adhesion testing of flexible films, Mater. Sci. Eng. A107 (1989) 159.

[20] T. Arai, H. Fujita, M. Watanabe, Evaluation of adhesion strength of thin hard coatings, Thin Solid Films 154 (1987) 387.

[21] L.L. Shaw, Measurement of the fracture energy of interfaces in composites through sandwich-type chevron-notched specimens, J. Test. Eval. 25 (4) (1997) 391.

[22] L.L. Shaw, B. Barber, E.H. Jordan, M. Gell, Measurements of the interfacial fracture energy of thermal coatings, Scr. Mater. 39 (10) (1998) 1427.

[23] P.G. Charalambides, J. Lund, A.G. Evans, R.M. McMeeking, A test specimen for determining the fracture resistance of bimaterial interfaces, J. Appl. Mech. 56 (1989) 77.

[24] L.L. Shaw, R. Ren, D. Goberman, Measurements of the fracture energy of the coating/substrate interfacial region through radial-notched cylindrical specimens, Surf. Coat. Technol. 130 (2000) 74.

[25] B.R. Lawn and M.V. Swain, Microfracture beneath point indentations in brittle solids, J. Mater. Sci. 10 (1975) 113. 
[26] R.F. Cook and G.M. Pharr, Direct observation and analysis of indentation cracking in glasses and ceramics, J. Am. Ceram. Soc. 73 (4) (1990) 787.

[27] T. Fett, A.B. Kounga Njiwa, J. Rödel, Crack opening displacements of Vickers indentation cracks, Eng. Frac. Mech., 72 (2005) 647.

[28] B. Rother, D.A. Dietrich, Evaluation of coating-substrate interface strength by differential load feed analysis of load-indentation measurements, Thin Solid Films $250(1-2)(1994) 181$.

[29] M.M. Lima, C. Godoy, P.J. Modenesi, J.C. Avelar-Batista, A. Davison, A. Matthews, Coating fracture toughness determined by Vickers indentation: an important parameter in cavitation erosion resistance of WC-Co thermally sprayed coatings, Surf. Coat. Technol. 177-178 (2004) 489.

[30] J. Malzbender, Comparison of surface and cross-sectional indentation in a coating, Surf. Coat. Technol. 201 (6) (2006) 3797.

[31] P.A. Steinmann, Y. Tardy, H.E. Hintermann, Adhesion testing by the scratch test method: the influence of intrinsic and extrinsic parameters on the critical load, Thin Solid Films 154 (1-2) (1987) 333.

[32] D.B. Marshall, A.G. Evans, Measurement of adherence of residually stressed thin films by indentation, I. Mechanics of interface delamination, J. Appl. Phys. 56 (10) (1984) 2632

[33] C. Rossington, A.G. Evans, D.B. Marshall, B.T. Khuri-Yakub, Measurements of adherence of residually stressed thin films by indentation, II. Experiments with $\mathrm{ZnO} / \mathrm{Si}$, J. Appl. Phys. 56 (10) (1984) 2639. 
[34] H. Zhang, Q. Chen, D.Y. Li, Development of a novel lateral force-sensing microindentation technique for determination of interfacial bond strength, Acta Mater. 52 (2004) 2037.

[35] V.N. Zhitomirsky, T. David, R.L. Boxman, S. Goldsmith, A. Verdyan, Ya.M. Soifer, L. Rapoport, Properties of $\mathrm{SnO}_{2}$ coatings fabricated on polymer substrates using filtered vacuum arc deposition, Thin Solid Films 492 (1-2) (2005) 187.

[36] H. Freller, Vapour-phase coating processes for hard coatings, Vacuum 45 (10-11) (1994) 997.

[37] L. Pejryd, J. Wigren, D.J. Greving, J.R Shadley, E.F. Rybicki, Residual stresses as a factor in the selection of tungsten carbide coatings for a jet engine application, $\mathrm{J}$. Therm. Spray Technol. 4 (3) (1995) 268.

[38] S.J. Harris, A.W. Weiner, S.C. Tung, S.J. Simko, M.C. Militello, Diamond-like films for wear protection of steel, Surf. Coat. Technol. 62 (1993) 550.

[39] H.T. Kim, J.S. Kim, Y.S. Kwon, Mechanical properties of binderless tungsten carbide by spark plasma sintering, Science and Technology, 2005. KORUS 2005. Proceedings. The 9th Russian-Korean International Symposium, 458.

[40] M.P. Nascimento, R.C. Souza, I.M. Miguel, W.L. Pigatin, H.J.C. Voorwald, Effects of tungsten carbide thermal spray coating by HP/HVOF and hard chromium electroplating on AISI 4340 high strength steel, Surf. Coat. Technol. 138 (2-3) (2001) 113.

[41] U. Beck, G. Reiners, I. Urban, H.A. Jehn, U. Kopacz, H. Schack, Decorative hard coatings: new layer systems without allergy risk, Surf. Coat. Technol. 61 (1-3) (1993) 215. 
[42] G. Keller, R. Erz, I. Barzen, M. Weiler, K. Jung, H. Ehrhardt, Mechanical properties, structure and composition of ion-plated tungsten carbide films, Vacuum $41(4-6)(1990) 1294$.

[43] H.C. Tsai, D.B. Bogy, Critical review: characterization of diamond like carbon films and their application as overcoats on thin-film media for magnetic recording, J. Vac. Sci. Technol. A5 (6) (1987) 3287.

[44] N.A. Morrison, S.E. Rodil, A.C. Ferrari, J. Robertson, W.I. Milne, High rate deposition of ta-C:H using an electron cyclotron wave resonance plasma source, Thin Solid Films 337 (1-2) (1999) 71.

[45] R. Hauert, U. Muller, An overview on tailored tribological and biological behavior of diamond-like carbon, Diam. Relat. Mater. 12 (2003) 171.

[46] J.R. Gomes, S.S. Camargo Jr., R.A. Simão, J.M. Carrapichano, C.A. Achete, R.F. Silva, Tribological properties of silicon nitride ceramics coated with DLC and DLC-Si against 316L stainless steel, Vacuum 81 (11-12) (2007) 1448.

[47] B. Podgornik, S. Jacobson, S. Hogmark, DLC coating of boundary lubricated components-advantages of coating one of the contact surfaces rather than both or none, Tribol. Int. 36 (11) (2003) 843.

[48] P. Huang, R. Liu, X.J. Wu, M.X. Yao, Mechanical properties and corrosion resistance of a novel Ni-Cr-Mo alloy, Adv. Eng. Mater. 9 (1-2) (2007) 60.

[49] Spinoff, "Industrial Productivity and Manufacturing Technology," NASA Scientific and Technical Information (STI), 1996. [Online].Available: http://www.sti.nasa.gov/tto/spinoff1996/67.html [Accessed: Aug. 10, 2007]. 
[50] Spinoff, "Paper-Thin Coating Offers Maximum Protection," NASA Scientific and Technical Information (STI), 2001. [Online].Available: http://www.sti.nasa.gov/tto/spinoff2001/ip4.html [Accessed: Aug. 10, 2007].

[51] Spinoff, "Fighting Corrosion Public Safety," NASA Scientific and Technical Information (STI), $2001 . \quad$ [Online].Available: http://www.sti.nasa.gov/tto/spinoff2001/ip4.html [Accessed: Aug. 10, 2007].

[52] Cameron Chai, "Chemical Vapour Deposition (CVD) - An Introduction," azom.com. [Online]. Available: http://www.azom.com/details.asp?ArticleID=1552. [Accessed Nov. 20, 2007]

[53] R. Sreenivasan, R. A. Adomaitis, G. W. Rubloff, A comparative study of reactor designs for the production of graded films with applications to combinatorial CVD, J. Cryst. Growth 310 (2) (2008) 270

[54] K. Kamachi, T. Ito, T. Yamamoto, An X-Ray study of residual stress generated in cemented carbide, coated with TiN by CVD process and PVD process, J. Jpn. Inst. Met. 50 (3) (1986) 320.

[55] H. Freller, H.P. Lorenz, TiN plasma CVD coatings deposited by different excitation methods for the gas discharge, Mater. Sci. Eng. A140 (7) (1991) 534.

[56] J. Patscheider, Nanocomposite hard coatings for wear protection, MRS B. 28 (3) (2003) 180.

[57] F. Quli, D. E. Wolfe, J. T. Schriempf, J. Singh, An overview: electron beamphysical vapor deposition technology-present and future applications, Surf. Eng.: Science and Technology I. Proceedings of Symposium, TMS Annual Meeting, (1999) 59 
[58] Q. Yang, C. He, L.R. Zhao, J-P. Immarigeon, Preferred orientation and hardness enhancement of $\mathrm{TiN} / \mathrm{CrN}$ superlattice coatings deposited by reactive magnetron sputtering, Scr. Mater. 46 (4) (2002) 293.

[59] H. Holleck, Material selection for hard coatings, J. Vac. Sci. Technol. 4 (6) (1986) 2661.

[60] S. Vepřek, M.G.J. Vepřek-Heijman, P. Karvánková, J. Procházka, Different approaches to superhard coatings and nanocomposites, Thin Solid Films 476 (1) (2005) 1.

[61] J. Musil, Hard and superhard nanocomposite coatings, Surf. Coat. Technol.125 (13) (2000) 322 .

[62] J. Hugosson, H. Eriksson, O. Nordstrom, L. Jansson, Chemical vapour deposition of molybdenum carbides: aspects of phase stability, Thin Solid Films 370 (1-2) (2000) 203.

[63] W.D. Sproul, New routes in the preparation of mechanically hard films, Science 273 (5277) (1996) 889.

[64] A.H. Dent, A.J. Horlock, D.G. McCartney, S.J. Harris, Microstructure formation in high velocity oxy-fuel thermally sprayed Ni-Cr-Mo-B alloys, Mater. Sci. Eng. A: Struct. Mater.: Prop. Microstruct. Process. A283 (1-2) (2000) 242.

[65] I. Ozdemir, I. Hamanaka, M. Hirose, Y. Tsunekawa, M. Okumiya, In situ formation of Al-Si-Mg based composite coating by different reactive thermal spray processes, Surf. Coat. Technol. 200 (1-4) (2005) 1155.

[66] BryCoat Inc., "PVD Coating," brycoat.com. [Online]. Available: http://www.brycoat.com/pvd-coating.html [Accessed Feb. 14, 2008]. 
[67] J. R. Davis, Handbook of Thermal Spray Technology, Ed., Davis \& Associates, Materials Park, Ohio, USA, 2004

[68] C. Marsden, "Coatings," [Online]. Available:http://www.dynacer.com/coatings.htm [Accessed Feb. 14, 2008]

[69] M. Li, P.D. Christofides, Computational study of particle in-flight behavior in the HVOF thermal spray process, Chem. Eng. Sci. 61 (19) (2006) 6540

[70] BryCoat Inc., "Thermal Spray Coating," brycoat.com. [Online]. Available: http://www.brycoat.com/thermal-spray-coating.html [Accessed Nov. 20, 2007].

[71] G. England, "Thermal Spray Coatings," gordonengland.co.uk. [Online]. Available: http://www.gordonengland.co.uk/tsc.htm [Accessed Nov. 5, 2007].

[72] L. Valim, High Temperature Strain of Metals and Alloys: Physical Fundamentals, WILEY-VCH, Weinheim, USA, 2006.

[73] C.T. Sims, N.S. Stolloff, W.C. Hagel, Superalloys II: High Temperature Materials for Aerospace and Industrial Power, John Wiley \& Sons, New York, USA, 1987.

[74] J.R. Davis, ASM Specialty Handbook: Nickel, Cobalt and Their Alloys, ASM International Materials Park, Ohio, USA, 2000.

[75] W. Betteridge, Cobalt and Its Alloys, Halsted Press, Chichester, U.K., 1982.

[76] A. Halstead, R.D. Rawlings, Structure and hardness of Co-Mo-Cr-Si wear resistant alloys (Tribaloys), Met. Sci. 18 (10) (1984) 491.

[77] C.B. Cameron, D.P. Ferriss, Tribaloy intermetallic materials: new wear- and corrosion-resistant alloys, Anti-Corro. Meth. Mater. 22 (4) (1975) 5. 
[78] G.J. Gibbons, R.G. Hansell, Down-selection and optimization of thermal-sprayed coatings for Aluminum mould tool protection and upgrade, J. Therm. Spray Technol. 15 (3) (2006) 340.

[79] G. England, "High Velocity Oxygen Fuel Thermal Spray Process," gordonengland.co.uk. [Online]. Available: http://www.gordonengland.co.uk/hvof.htm [Accessed Nov. 5, 2007].

[80] C.J. Li, Y.Y. Wang, Effect of particle state on the adhesive strength of HVOF sprayed metallic coating, J. Therm. Spray Technol. 11 (4) (2002) 309.

[81] V.V. Sobolev, J.M. Guilemany, J. Nutting, High Velocity Oxy-Fuel Spraying, Maney Publishing, UK, 2004.

[82] M.H. Li, P.D. Christofides, D. Shi, Modeling and control of HVOF thermal spray processing of WC-Co coatings, Powder Technol. 156 (2-3) (2005) 177.

[83] H. Suzuki, Cemented Carbides and Sintered Hard Materials, Maruzen, Tokyo, Japan, 1986.

[84] 84 S. Imasato, K. Tokumoto, T. Kitada, S. Sakaguchi, Properties of ultra-fine binderless cemented carbide 'RCCFN', Int. J Refr. Metals Hard Mater. 13 (1995) 305.

[85] P. Chivavibul, M. Watanabe, S. Kuroda, K. Shinoda, Effects of carbide size and Co content on the microstructure and mechanical properties of HVOF-sprayed WC-Co coatings, Surf. Coat. Technol. 202 (3) 2007509. 
[86] J. Bergeta, T. Rogne, E. Bardal, Erosion-corrosion properties of different WC-Co$\mathrm{Cr}$ coatings deposited by the HVOF process-influence of metallic matrix composition and spray powder size distribution, Surf. Coat. Technol. 201 (18) (2007) 7619.

[87] A. Halstead, R.D. Rawlings, The fracture behaviour of two Co-Mo-Cr-Si wear resistant alloys (“Tribaloys"), J. Mater. Sci. 20 (4) (1985) 1248.

[88] K. Ramachandran, N. Kikukawa, Plasma in-flight treatment of electroplating sludge, Vacuum, 59 (1) (2000) 244.

[89] S. Okamoto, K. Otsuka, Y. Nakazono, Y. Shimoitani, J. Takada, Mechanical properties of WC/Co cemented carbide with largerWC grain size, Mater. Charact. 55 (2005) 281

[90] S-P. Lu, O-Y. Kwon, Microstructure and bonding strength of WC reinforced Ni-ase alloy brazed composite coating, Surf. Coat. Technol. 153 (2002) 40.

[91] Ul-Hamid, H.M. Tawancy, A.I. Mohammed, S.S. Al-Faroudi, N.M. Abbas, Cyclic oxidation behavior of a Ni-Mo-Cr alloy at $800^{\circ} \mathrm{C}$, Anti-Corro. Meth. Mater. 51 (5) (2004) 339.

[92] S. Dymek, M. Wrobel, M. Dollar, Optimization of mechanical properties of a Ni-Mo-Cr alloy by structural modifications induced by changes in heat treatment, Scr. Mater. 43 (2000) 343.

[93] P. Crook, Corrosion characteristics of the wrought Ni-Cr-Mo alloys, Mater. Corro. $56(9)(2005) 606$.

[94] J.X. Dong, M.C. Zhang, Y.P. Zeng, X.S. Xie, Freckle formation and characterization of a Ni-Cr-Mo-Fe-W alloy, Acta Metal. Sinica. 17 (4) (2004) 414. 
[95] S.E. Mason, R.D. Rawlings, Fracture behavior of two Co-Mo-Cr-Si wear resistant alloys, J. Mater. Sci. 20 (4) (1985) 1248.

[96] R.D. Schmidt, D.P. Ferriss, New materials resistant to wear and corrosion to $1000^{\circ} \mathrm{C}$, Wear $32(3)(1975) 279$.

[97] H.E. Hintermann, Adhesion, friction and wear of thin hard coatings, Wear 100 (1984) 381.

[98] E. Bergnann, J. Vogel, L. Simmen, Failure mode analysis of coated tools, Thin Solid Films 153 (1987) 219.

[99] P.A. Steinmann, H.E. Hintermann, Adhesion of $\mathrm{TiC}$ and $\mathrm{Ti}(\mathrm{C}, \mathrm{N})$ coatings on steel, J. Vac. Sci. Technol. 3 (6) (1985) 2394.

[100] E. Posti, I. Nieminen, Influence of coating thickness on the life of TiN-coated high speed steel cutting tools, Wear 129 (1989) 273.

[101] J. Valli, A review of adhesion test methods for thin hard coatings, J. Vac. Sci. Technol. A4 (6) (1986) 3007.

[102] A.J. Perry, Scratch adhesion testing: a critique, Surf. Eng. 2 (3) (1986) 183.

[103] A.J. Perry, Scratch adhesion testing of hard coatings, Thin Solid Films 107 (1983) 167.

[104] W.C. Wake, Adhesion and the Formulation of Adhesives, Second Edition, Applied Science Publishers, New York, USA, 1982. 
[105] H. Kagawa, M. Ichikawa, T. Takamatu, H. Kuwano, Elasto-plastic finite analysis of stress distribution on a film-substrate system indented by a spherical indenter in relation to evaluation of fracture strength of films, Trans. Jpn Soc. Mech. Eng. A60 (570) (1994a) 409.

[106] H. Kagawa, M. Ichikawa, T. Takamatu, H. Kuwano, Approximate expression for stress distribution in film subjected to indentation by spherical indenter, Trans. Jpn Soc. Mech. Eng. A60 (570) (1994b) 416.

[107] U. Wiklund, J. Gunnars, S. Hogmark, Influence of residual stresses on fracture and delamination of thin hard coatings, Wear 232 (2) (1999) 262.

[108] M. Shima, J. Sato, H. Koguchi, Contact stresses of an elastic surface layer bonded to a half-space elastic body, Trans. Jpn Soc. Mech. Eng. A51 (468) (1985) 1983.

[109] J-Q. Xu, M. Yoshiharu, Analytical solution for interface stresses due to concentrated surface force, Int. J Mech. Sci. 45 (11) (2003) 1877.

[110] N. Schwarzer, F. Richter, Adhesion and elastic contact stresses of coating/substrate systems under normal and tangential loads, Surf. Coat. Technol. 74-75 (1) (1995) 97.

[111] D. Nolan, V. Leskovsek, M. Jenko, Estimation of fracture toughness of nitride compound layers on tool steel by application of the Vickers indentation method, Surf. Coat. Technol. 201(1-2) (2006) 182.

[112] Y.F. Gao, S.M. Xia, A.F. Bower, L.C. Lev, Y.T. Cheng, Delamination mechanism maps for a strong elastic coating on an elastic-plastic substrate subjected to contact loading, Int. J Solids Struct. 44 (11-12) (2007) 3685. 
[113] K.-D. Bouzakis, N. Vidakis, Superficial plastic response determination of hard isotropic materials using ball indentations and a FEM optimization technique, Mater. Charact. 42 (1) (1999) 12.

[114] V. Linss, T. Chudoba, M. Karniychuk, F. Richter, Combination of normal and lateral force-displacement measurements as a new technique for the mechanical characterization of surfaces and coatings, Thin Solid Films 494 (1-2) (2006) 179.

[115] J.L. Bucaille, E. Felder, G. Hochstetter, Mechanical analysis of the scratch test on elastic and perfectly plastic materials with the three-dimensional finite element modeling, Wear 249 (2001) 422.

[116] X.Y. Jiang, B. Lauke, T. Schuller, Numerical simulation of micro-scratch tests for coating/susbstrate composites, Compos. Interfaces 8 (2001) 19.

[117] X.Y. Jiang, B. Lauke, T. Schuller, Frictional contact analysis of scratch test for elastic and elastic-plastic thing-coating/substrate materiasl, Thin Solid Films 414 (2002) 63.

[118] E.R. Kral, K. Komvopoulos, Three-dimensional finite element analysis of subsurface stress and strain fields due to sliding contact on an elastic-plastic layered medium, Trans. ASME J. Tribol. 119 (1997) 332.

[119] E.R. Kral, K. Komvopoulos, Three-dimensional finite element analysis of surface deformation and stresses in an elastic-plastic layered medium subjected to indentation and sliding contact loading, ASME J. Appl. Mech. 63 (1996) 365.

[120] E.R. Kral, K. Komvopoulos, Three-dimensional finite element analysis of subsurface stresses and shakedown due to repeated sliding on a layered medium, ASME J. Appl. Mech. 63 (1996) 967. 
[121] J. Li, W. Beres, Three-dimesional finite element modeling of the scratch test for a TiN coated titanium alloy substrate, Tribol. Int. 38 (2005) 1035.

[122] K.Holmberg, A. Laukkanen, H. Ronkainen, K. Wallin, S. Varjus, A model for stresses, crack generation and fracture toughness calculation in scratched TiNcoated steel surfaces, Wear 254 (2003) 278.

[123] K. Holmberg, A. Laukkanen, H. Ronkainen, K. Wallin, Tribological analysis of fracture conditions in thin surface coatings by $3 \mathrm{D}$ FEM modelling and stress simulations, Tribol. Int. 38 (11-12) (2005) 1035.

[124] D. Mclean, Mechanical Properties of Metals, John Wiley \& Sons, Inc, New York, USA, 1962.

[125] ABAQUS, Analysis User's Manual, Version 6.5, Hibbit, Karlsson \& Sorensen, Inc., Pawtucket, Rhode Island, USA, 2004.

[126] K. Holmberg, A. Laukkanen, H. Ronkainen, K. Wallin, Tribological analysis of fracture conditions in thin surface coatings by $3 \mathrm{D}$ FEM modeling and stress simulations, Tribo. Intl. 38 (2005) 1035.

[127] D. Cheng, Q. Xu, G. Trapaga, E.J. Lavernia, A numerical study of high-velocity oxygen fuel thermal spraying process. Part I: gas phase dynamics, Metall. Mater. Trans A 32A (2001) 1609.

[128] W.C. Oliver, G.M. Pharr, An improved technique for determining hardness and elastic modulus using load and displacement sensing indentation experiments, J. Mater. Res. 7 (1992) 1564.

[129] J. Musil, F. Kunc, H. Zeman, H. Polakova, Relationships between hardness, Young's modulus and elastic recovery in hard nanocomposite coatings, Surf. Coat. Technol. 154 (2002) 304. 